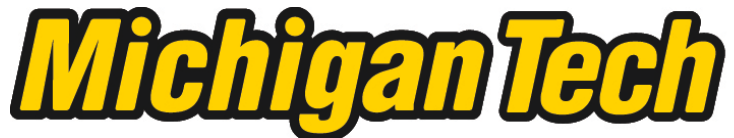 \\ Michigan Technological University Create the Future Digital Commons @ Michigan Tech
}

Preliminary Investigation of Ultra-High Performance Concrete Behavior at High Strain Rates using the Split-Hopkinson Pressure Bar

Jacob Clark

Michigan Technological University

Follow this and additional works at: https://digitalcommons.mtu.edu/etds

Part of the Civil Engineering Commons

Copyright 2013 Jacob Clark

\section{Recommended Citation}

Clark, Jacob, "Preliminary Investigation of Ultra-High Performance Concrete Behavior at High Strain Rates using the Split-Hopkinson Pressure Bar", Master's Thesis, Michigan Technological University, 2013.

https://doi.org/10.37099/mtu.dc.etds/1023

Follow this and additional works at: https://digitalcommons.mtu.edu/etds

Part of the Civil Engineering Commons 


\title{
PRELIMINARY INVESTIGATION OF ULTRA-HIGH PERFORMANCE CONCRETE BEHAVIOR AT HIGH STRAIN RATES USING THE SPLIT- HOPKINSON PRESSURE BAR
}

\author{
By \\ Jacob F. Clark
}

\begin{abstract}
A THESIS
Submitted in partial fulfillment of the requirements for the degree of MASTER OF SCIENCE

In Civil Engineering
\end{abstract}

MICHIGAN TECHNOLOGICAL UNIVERSITY

2013

(C) 2013 Jacob F. Clark 
This thesis has been approved in partial fulfillment of the requirements for the Degree of MASTER OF SCIENCE in Civil Engineering.

\section{Department of Civil and Environmental Engineering}

Thesis Advisor: $\quad$ Theresa M. Ablborn, Ph.D., P.E.

Committee Member: Stanley J. Vitton, Ph.D., P.E.

Committee Member: $\quad$ Paul G. Sanders, Ph.D.

Department Chair: $\quad$ David W. Hand, Ph.D., P.E. 


\section{Disclaimer}

The views, opinions, and findings expressed in this paper are those of the author and do not represent the official policy or viewpoints of Michigan Technological University, any state, industry member, or other entity. 


\section{Table of Contents}

List of Figures ………………………………………………………………………....vii

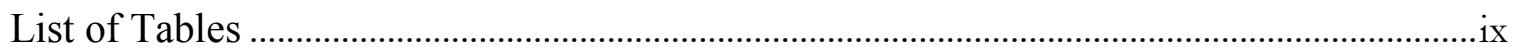

Acknowledgements.........................................................................................................

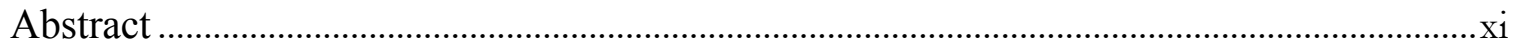

Chapter 1 Introduction................................................................................................

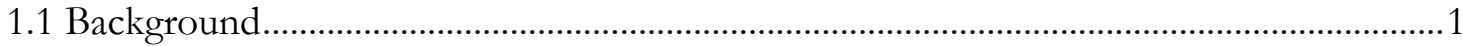

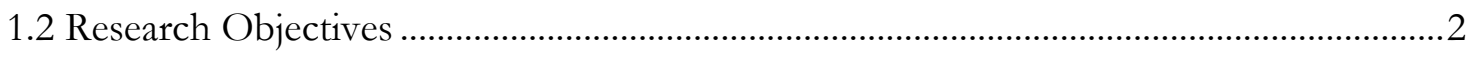

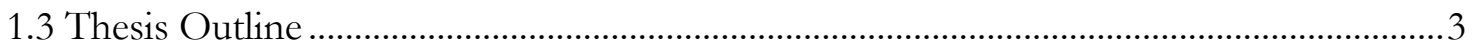

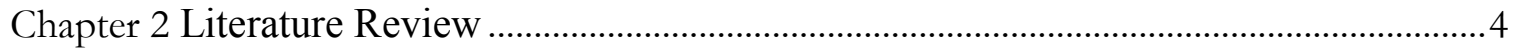

2.1 The Split-Hopkinson Pressure Bar ......................................................................................

2.1.1 SHPB Assumptions .....................................................................................

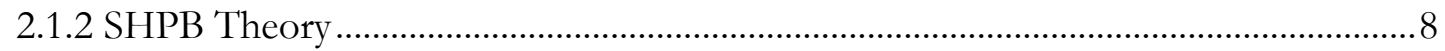

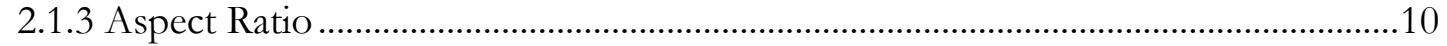

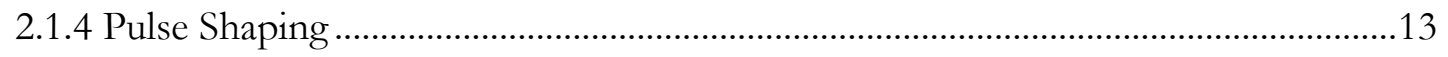

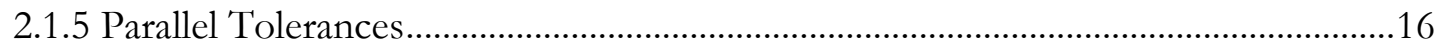

2.2 Ultra-High Performance Concrete (UHPC) .....................................................................17

2.2.1 History of UHPC ………………………………………………………………....

2.2.2 Composition of UHPC.................................................................................................18

2.2.3 Material Properties of UHPC ....................................................................................19

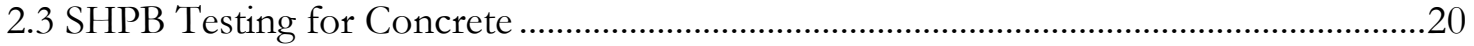

2.3.1 Plain Concrete ...........................................................................................................2

2.3.2 Fiber-Reinforced Concrete ………………………………………………………...21

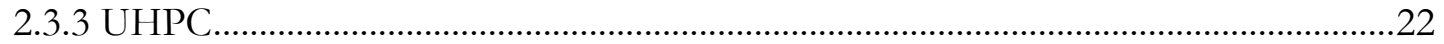

2.4 Dynamic Increase Factor (DIF) ..................................................................................23 


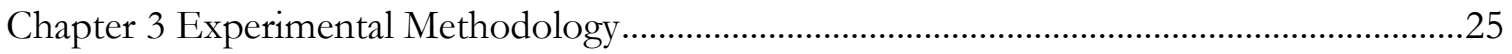

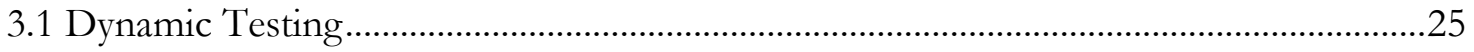

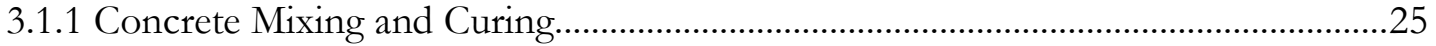

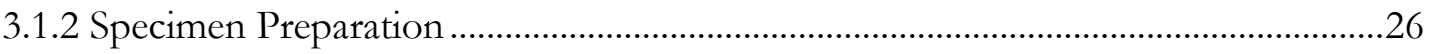

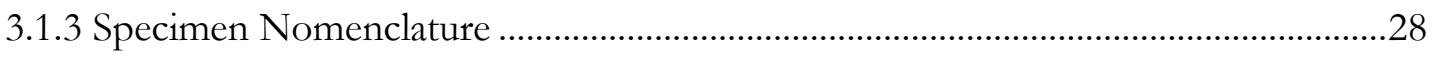

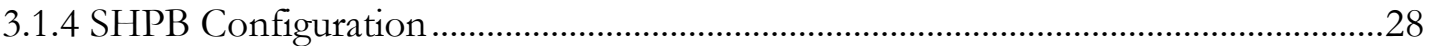

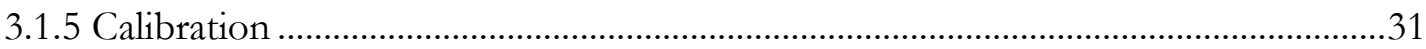

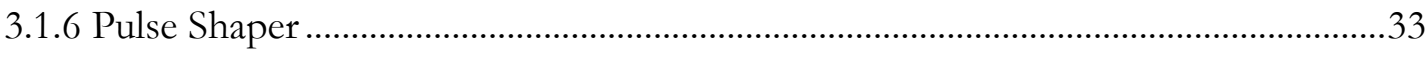

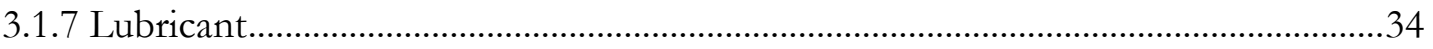

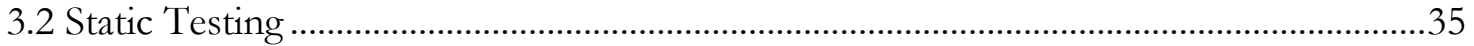

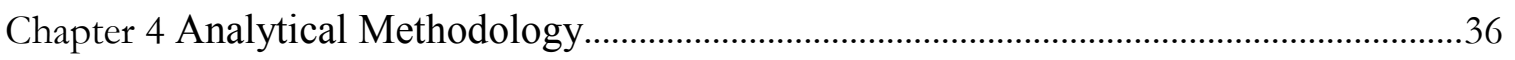

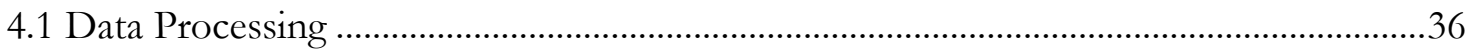

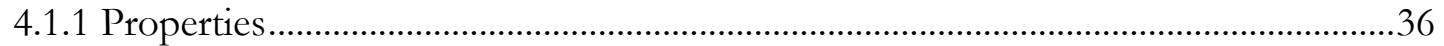

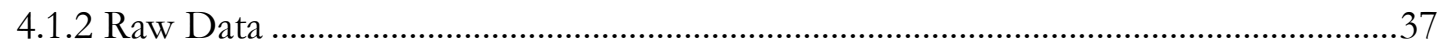

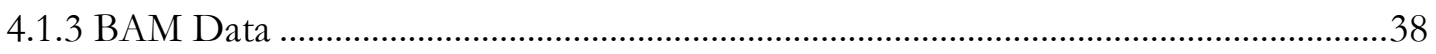

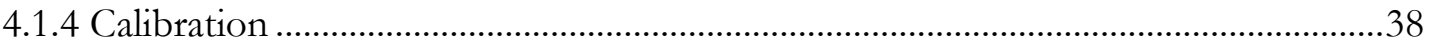

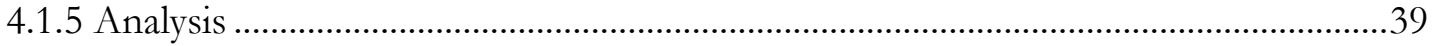

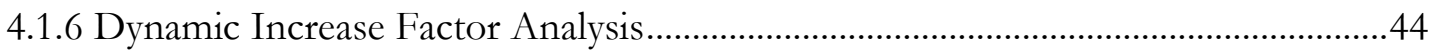

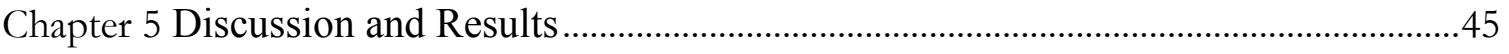

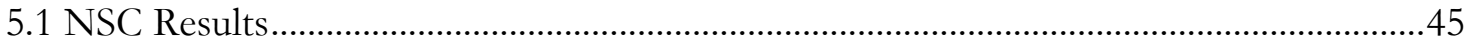

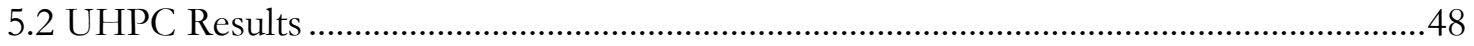

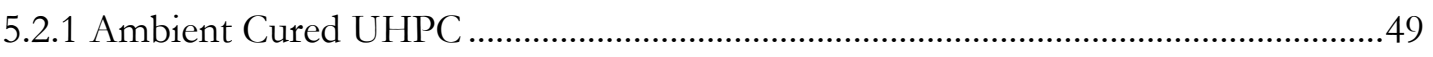

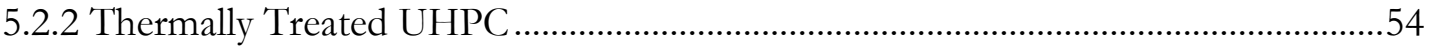

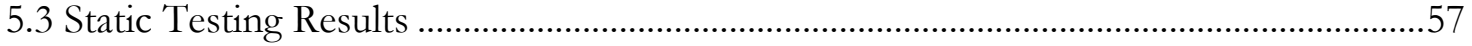

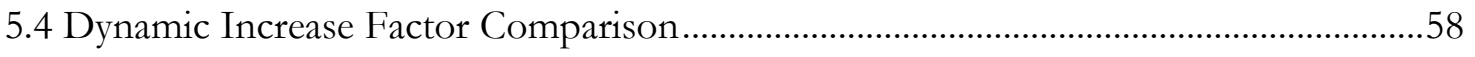

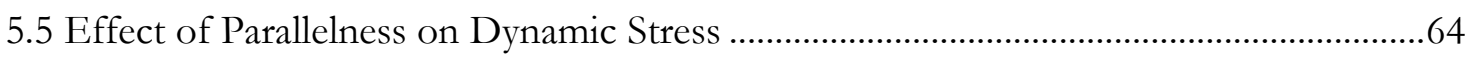

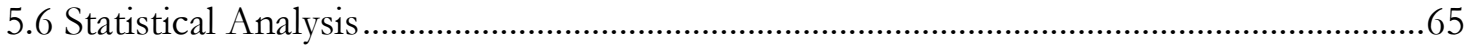


Chapter 6 Conclusions and Future Work …….........................................................................67

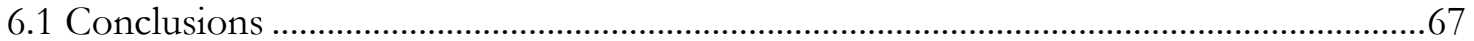

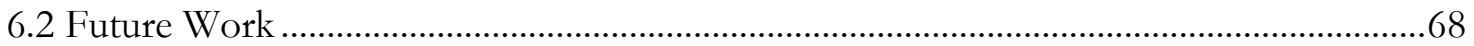

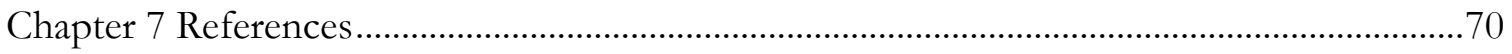

Appendix A: Parallelness Measurements .................................................................................

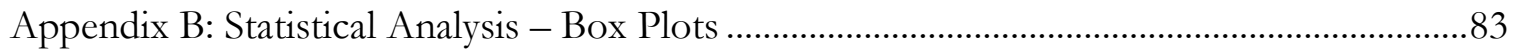

Appendix C: Permission for Use of Copyrighted Material ........................................................89 


\section{List of Figures}

Figure 2.1: Typical magnitudes of strain rates for different loading types.................................

Figure 2.2: Schematic drawing of typical SHPB ...........................................................................

Figure 2.3: Generic input pulse waves without and with pulse shaping ...................................14

Figure 2.4: Research of strain rate influence on concrete compressive strength (reprinted

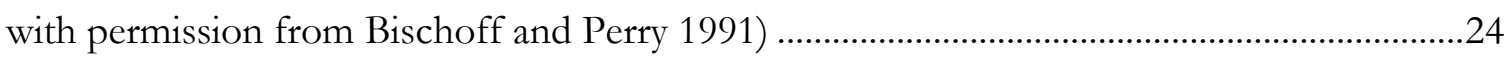

Figure 3.1: Location of measurements for parallelness data .........................................................27

Figure 3.2: Prepared UHPC specimens at aspect ratios of 2:1, 1:1, and $0.5: 1$........................27

Figure 3.3: Strain Gage/Channel Layout.......................................................................................29

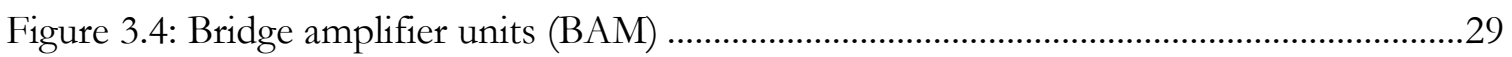

Figure 3.5: Chronograph used to measure striker bar velocity …....................................................30

Figure 3.6: Copper pulse shaper placed on impact face of input bar...........................................34

Figure 4.1: Screenshot of Properties worksheet in SHPB Excel program .................................37

Figure 4.2: Screenshot of Raw Data worksheet in SHPB Excel program ................................37

Figure 4.3: Screenshot of BAM Calibration worksheet in SHPB Excel program ....................38

Figure 4.4: Screenshot of Calibration worksheet in SHPB Excel program...............................39

Figure 4.5: Strain gage output (voltage versus time) in SHPB per channel ...............................40

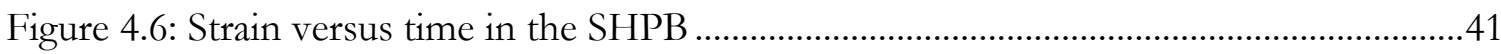

Figure 4.7: Screenshot of Analysis worksheet in SHPB Excel program ...................................42

Figure 4.8: Strain versus time for the individual waves in the SHPB - Channels A/B, typical

Figure 5.1: Typical NSC fragmentation following SHPB test ....................................................45

Figure 5.2: Typical dynamic stress-strain curve for NSC with 0.5:1 aspect ratio (sample N-

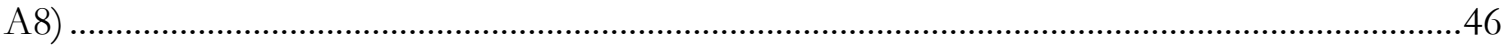

Figure 5.3: Typical fracture for UHPC at 2:1 aspect ratio............................................................48

Figure 5.4: Typical fracture of UHPC at 1:1 aspect ratio ..............................................................49

Figure 5.5: Typical fracture of UHPC at $0.5: 1$ aspect ratio ...........................................................49

Figure 5.6: Typical dynamic stress-strain curve for ambient cured UHPC at a 0.5:1 aspect

ratio. 
Figure 5.7: Typical dynamic stress-strain curve for sample ambient cured UHPC at a 1:1 aspect ratio

Figure 5.8: Typical dynamic stress-strain curve for ambient cured UHPC at a 2:1 aspect ratio

Figure 5.9: Typical dynamic stress-strain curve for UHPC thermal treated specimens (U-A6-

TT) 54

Figure 5.10: Influence of strain rate on compressive strength of NSC and UHPC for various aspect ratios.

Figure 5.11: Strain rate influence on compressive strength with strain rates between $10^{-8}$ and

$10^{3} 1 / \mathrm{sec}$.......

Figure B.1: Boxplot from ANOVA test for NSC specimens that either met or did not meet parallel tolerance.

Figure B.2: Boxplot from ANOVA test for ambient cured UHPC specimens that either met or did not meet parallel tolerance .84

Figure B.3: Boxplot from ANOVA test for thermally treated UHPC specimens that either met or did not meet parallel tolerance

Figure B.4: Boxplot from ANOVA test for NSC comparing DIF for each aspect ratio........85

Figure B.5: Boxplot from ANOVA test for ambient cured UHPC comparing DIF for each aspect ratio

Figure B.6: Boxplot from ANOVA test for ambient cured UHPC comparing DIF for each aspect ratio

Figure B.7: Boxplot from ANOVA test for NSC comparing strain rate for each aspect ratio

Figure B.8: Boxplot from ANOVA test for ambient cured UHPC comparing strain rate for each aspect ratio

Figure B.9: Boxplot from ANOVA test for thermally treated UHPC comparing strain rate for each aspect ratio.

Figure B.10: Boxplot from ANOVA test for each concrete type, comparing DIF .88 


\section{List of Tables}

Table 2.1: Aspect ratio used in previous SHPB research .........................................................12

Table 2.2: Pulse shapers used in previous SHPB research.......................................................16

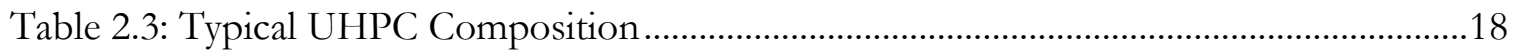

Table 2.4: Material properties and performance measures for varying concrete types............19

Table 3.1: Number of samples tested for each concrete type and aspect ratio..........................25

Table 3.2: Preliminary pulse shaper sizes........................................................................................

Table 5.1: Dynamic stress and strain data for NSC samples .....................................................47

Table 5.2: Dynamic stress and strain values for ambient cured UHPC samples.......................53

Table 5.3: Dynamic stress and strain values for thermally treated UHPC samples .................56

Table 5.4: Static strength for each concrete group.....................................................................57

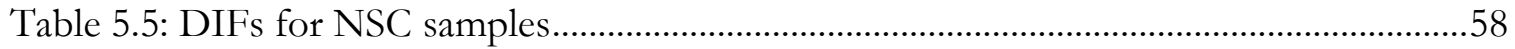

Table 5.6: DIFs for ambient cured UHPC samples...................................................................60

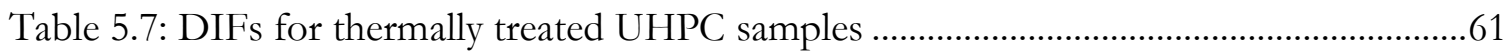

Table 5.8: P-values from ANOVA test for parallel end significance ........................................65

Table 5.9: P-values from ANOVA test for aspect ratio significance ……...................................66

Table 5.10: P-values from ANOVA test for aspect ratio significance on strain rate...............66

Table A.1: Parallel measurements for 2:1 NSC samples..............................................................76

Table A.2: Parallel measurements for 1:1 NSC samples..............................................................77

Table A.3: Parallel measurements for 0.5:1 NSC samples ............................................................78

Table A.4: Parallel measurements for 2:1 ambient UHPC samples.............................................79

Table A.5: Parallel measurements for 1:1 ambient UHPC samples.............................................79

Table A.6: Parallel measurements of 0.5:1 ambient UHPC samples ..........................................80

Table A.7: Parallel measurements for 2:1 thermally treated UHPC samples ............................81

Table A.8: Parallel measurements for 1:1 thermally treated UHPC samples ............................81

Table A.9: Parallel measurements for 0.5:1 thermally treated UHPC samples .........................82 


\section{Acknowledgements}

I would like thank my advisor, Dr. Tess Ahlborn, at Michigan Technological University, for her guidance and support throughout this project. I would also like to acknowledge my committee members, Dr. Stan Vitton and Dr. Paul Sanders, for their assistance throughout this research. This research was financially supported through the Michigan Technological University Center for Structural Durability, in association with the Michigan Department of Transportation (MDOT), and the Civil and Environmental Engineering Department at Michigan Technological University.

I am grateful for the guidance and assistance of my fellow graduate students, especially Khatereh and Mary. I would also like to thank Kiko for all of his help with lab work and equipment. Furthermore, I would like to thank Chris and Travis.

Finally, I would like to thank my family, my fiancée, Meghan, and my friends, for their love and support throughout everything, including this project. Without them none of this would have been possible. 


\begin{abstract}
Ultra-high performance concrete (UHPC) displays several enhanced material properties compared to normal strength concrete (NSC). In past research, Split-Hopkinson pressure bar (SHPB) tests have been used for normal strength concrete to determine material behavior at high strain rates. The behavior of advanced concrete materials, such as UHPC, under high strain rates has not been thoroughly investigated. While it is generally accepted that concrete materials experience increases in compressive strength under increasing strain rates, a preliminary investigation was conducted to gain insight into the compressive behavior of UHPC under high strain rate SHPB testing.
\end{abstract}

In this research, 50 specimens were tested in compression using the SHPB equipment at Michigan Technological University. Normal strength concrete, ambient cured UHPC, and thermally treated UHPC specimens were tested at 2:1, 1:1, and 0.5:1 aspect ratios. A dynamic increase factor (DIF), which shows the increase in strength between dynamic and static loading, was calculated for each specimen. Based on results of specimens meeting recommended tolerances, DIFs were found to be between 3.65 and 4 for NSC, 1.73 and 2.95 for ambient cured UHPC, and 1.21 and 2.45 for thermally treated UHPC for strain rates between $10^{2}$ and $10^{3} \mathrm{~s}^{-1}$. While UHPC experiences a relative increase in dynamic compressive strength, it is less strain rate sensitive than NSC and experiences a lower overall compressive strength increase. 


\section{Chapter 1 Introduction}

\subsection{Background}

As the number one most used building material in the world, concrete is very beneficial to the engineering industry (Mehta and Monteiro 2006). However, normal strength concrete (NSC) has limitations with durability and its ability withstand extreme loads (Mather 2004). These extreme loads, such as impacts and blasts, occur at high strain rates of loading, generating a large amount of energy. Normal strength concrete simply does not possess enough strength to endure such loadings.

Much advancement has been made in the area of concrete materials. Ultra-high performance concrete (UHPC) is one such advancement. Around since the 1990s, UHPC has shown enhanced material properties in many areas, including compression and tension strength and freeze/thaw durability, among others (Ahlborn et. al. 2003). An area of UHPC material behavior that has yet to be explored, however, is its performance under high strain rates of loading.

The desire to fully understand a material's behavior is essential for its proper and efficient use. As ultra-high performance concrete continues to be introduced as a structural material, the knowledge base for its material properties continues to expand. An important material characteristic is its behavior at high strain rates. It is generally accepted that concrete materials experience an increase in compressive strengths under dynamic loading scenarios (Bischoff and Perry 1991). However, many material properties of UHPC vary greatly from those of conventional concrete. Based on this information, an investigation of UHPC's dynamic properties, specifically strength, at high loading rates is necessary.

As structural design evolves, so too does the capability of structures and materials to withstand various loads and loading scenarios. More extreme loading cases include earthquakes, impacts, and blasts. These dynamic loads occur at increasing strain rates, resulting in three primary consequences: stress wave propagations within the impacted bodies, large inelastic deformations at high rates of deformation, and vibration issues caused 
by further excitement from the impact (Ramesh 2008). Therefore, high strain rate experiments are required to develop an understanding of material and structural response. A variety of experiments have been developed to measure dynamic material properties, specifically high strain rate behavior. One such development is the Split-Hopkinson pressure bar (SHPB). Through these high strain rate experiments, structural systems can be better designed to withstand more extreme loading scenarios. With limitations to conventional materials, it becomes even more important to investigate the behavior of advanced materials, such as UHPC, at these extreme loading conditions. The ability withstand high strain rates can be a tremendous benefit to the engineering and construction community, as well as the welfare of the public.

\subsection{Research Objectives}

The purpose of this thesis is defined by two objectives, which focus on previous research along with the presentation of new data and discussion.

The first objective of this thesis is to document the state of practice of Split-Hopkinson pressure bar testing on normal strength concrete. This is accomplished through a literature review of previous research regarding the use of the SHPB to test concrete at high strain rates. Through this literature review, comparisons are drawn between the new information presented in this thesis and the information of past research in the subject area. Furthermore, this helps confirm the SHPB equipment response and data at Michigan Technological University's Cement and Concrete Research Lab. By confirming the SHPB equipment's validity, further testing and research that extends beyond the scope of this thesis can take place.

The second objective of this thesis is to preliminarily characterize the material response of ultra-high performance concrete under high strain rates. As a relatively new material, it is necessary to fully understand the material behavior of UHPC as it becomes used throughout the industry. The data presented in this thesis compares the behavior of a UHPC to normal strength concrete during high strain rate loading through SHPB testing. With this data, 
dynamic increase factors, which are used to define a material's strength increase under elevated strain rate loading, are calculated for UHPC. While only a limited number of specimens are tested in this research, this factor further defines the material and provides additional research to the breadth of knowledge regarding UHPC material response at high strain rates.

\subsection{Thesis Outline}

Chapter 1 of this thesis provides background information regarding the research being presented. This includes an introduction to UHPC and Split-Hopkinson Pressure Bar testing. Furthermore, the goals and objectives are defined in the first chapter.

Chapter 2 discusses previous research in the area of concrete testing using a SHPB. This literature review covers SHPB testing methods and theory, along with the results and findings of previous work conducted on plain, fiber-reinforced, and ultra-high performance concrete.

Chapter 3 explains the experimental methods used for testing normal strength concrete and ultra-high performance concrete subjected to high strain rate loading using a SHPB.

Chapter 4 presents the analytical methods used in this research, including an overview of the data analysis process and calculation of the dynamic increase factor.

Chapter 5 presents test results and provides discussion for the previous research outlined in the literature review and the new data. Note that all UHPC specimens tested during this project were cast at Michigan Technological University using the Ductal ${ }^{\circledR}$ premix by LaFarge North America.

Chapter 6 completes the thesis with conclusions regarding the information previously presented and the impact of the new test data. Furthermore, recommendations for future work in this area of study are presented, both generally and specifically, as extensions of this project. 


\section{Chapter 2 Literature Review}

\subsection{The Split-Hopkinson Pressure Bar}

To fully understand a structural material and show where a material can best be used, its behavior under every loading type must be investigated. Material performance is also very dependent on the rate at which a load is applied. Figure 2.1 illustrates various loading scenarios based on strain rate (Bischoff and Perry 1991).

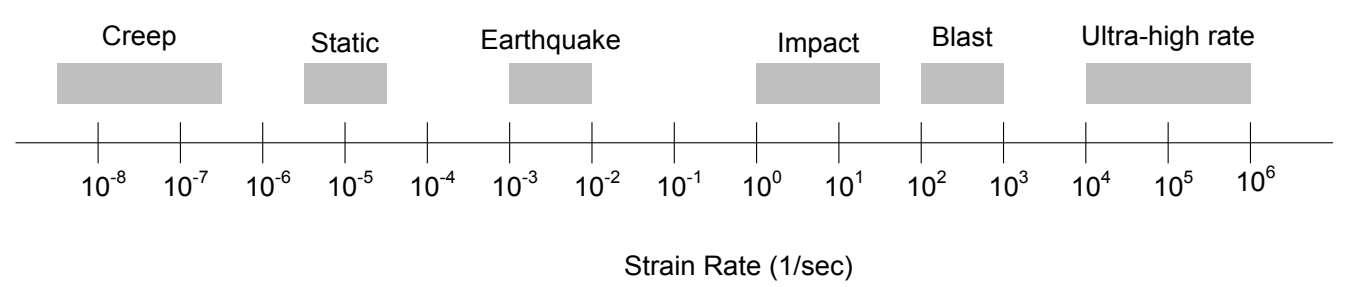

Figure 2.1: Typical magnitudes of strain rates for different loading types

Impact experiments can be considered as (a) high strain rate tests, (b) wave propagation tests through the material, (c) dynamic failure process within the material or structure, and (d) direct impact with broader impacts such as crash testing. The development of the SplitHopkinson pressure bar allows for dynamic material characterization at high strain rates ranging, from 1 to $10^{4} \mathrm{~s}^{-1}$. These high strain rate experiments can determine a material's response under impact and blast loading scenarios.

The Hopkinson pressure bar originated in 1872, when John Hopkinson investigated the effects of stress waves in iron wires (Gilbertson 2011). Later, in 1914, his son, Bertram Hopkinson, measured pressure through induced-wave propagation in a single elastic metal bar (Gray III 2000). This single bar apparatus was named the Hopkinson pressure bar as a result of Bertram Hopkinson's revolutionary work in dynamics. In 1949, R. M. Davies and Kolsky added another long, elastic metallic bar to the Hopkinson pressure bar and sandwiched specimens between the two bars (Gray III 2000). This piece of equipment, which was designed to measure the material stress-strain response under dynamic 
conditions, became known as the Split-Hopkinson pressure bar (SHPB), or Kolsky bar. Traditionally, the SHPB was designed to measure the dynamic compressive behavior of a material, while the Kolsky bar is a general term for various loading configurations (tension, compression, torsion, or combinations). Later developments and alterations led to the ability to measure dynamic material response in tension, shear, and torsion, using a modified SHPB arrangement. This thesis focuses solely on dynamic compressive SHPB testing.

Most Split-Hopkinson pressure bars follow the same general design and are comprised of the same elements. The main features are two long, elastic, metal bars, the input (incident) and output (transmitter) bars. The material sample is placed between these two bars. The pulse is generated by a striker bar fired from a cannon using compressed gas. Strain gages placed on the input and output bars measure the wave propagation and output information to be read by a data acquisition system. Below is a schematic drawing of a typical SHPB.

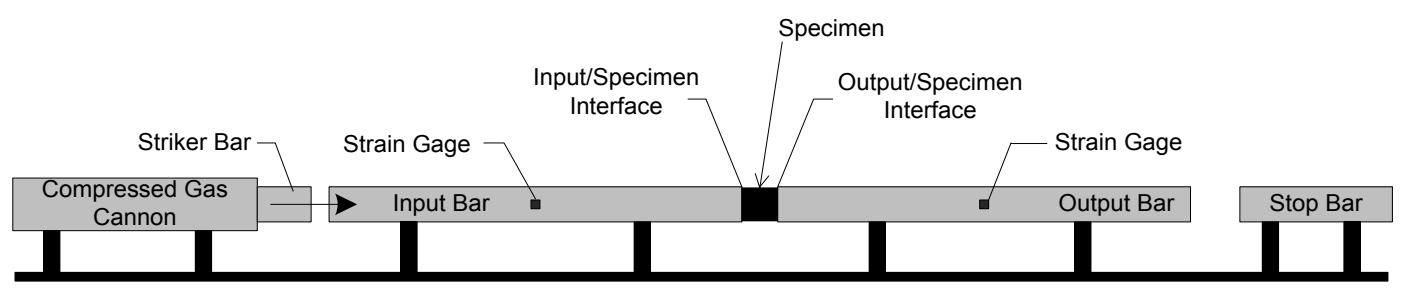

Figure 2.2: Schematic drawing of typical SHPB

Details regarding the SHPB used in this research and its configuration are discussed in Section 3.1.4.

\subsubsection{SHPB Assumptions}

Dynamics experiments have inherent variability in the results due to the equipment set up and alignment, as well as the specimen size, shape, and tolerances. While there is variability within SHPB tests, there are also several assumptions, or requirements that must be met to achieve valid test results. The following sections discuss these assumptions and the methods of satisfying them. 


\subsubsection{Specimen Stress Equilibrium}

Stress equilibrium within a specimen assumes that the stress measured on the output side of the specimen is the average stress within the specimen. This calculated stress, measured from the output wave, is representative of the average specimen stress (Ramesh 2008). In 1963, Davies and Hunter estimated that approximately three reverberations of the pulse within the specimen are required to satisfy stress equilibrium. This requirement is achieved through proper experiment and specimen design. To check this assumption, the normal forces at either side of the specimen $\left(\mathrm{P}_{1}\right.$ and $\left.\mathrm{P}_{2}\right)$ can be calculated and compared to one another. These values should be in agreement to satisfy specimen stress equilibrium.

\subsubsection{Friction Effects}

The second assumption for a valid SHPB experiment is a reduction of friction effects. Friction occurs along both input and output bar-specimen interfaces. Considerable friction can lead to increased strength that is not an accurate representation of the dynamic material properties. These friction effects can be designed out of SHPB experiments by increasing the length of the specimen. It has also been shown that friction is reduced as strain rate increases (Ramesh 2008).However, specimen length and length-to-diameter ratio need to remain small to achieve high strain rates, satisfying the aforementioned stress equilibrium assumption, and reducing inertial effects. Because a large specimen length or length-todiameter ratio is not feasible, lubricant is used at the interfaces to reduce the coefficient of friction to negligible values.

\subsubsection{Inertial Effects}

Specimens that undergo dynamic testing at strain rates greater than or equal to $10 \mathrm{~s}^{-1}$ are subject to inertial effects. Inertial effects can cause an increase in the dynamic strength of a material that is not truly reflective of the material's actual strength. Concrete is particularly sensitive to these effects due to its brittle nature and heterogeneity that features microcracks. Bischoff and Perry describe clearly the inertial effects, or lateral inertia confinement, in SHPB testing, stating:

"An elastic material loaded in compression will expand in the transverse direction as a result of Poisson's ratio effect. However, a cylinder loaded rapidly in the axial 
direction will not be able to expand instantaneously in the lateral direction because of inertial restraint, causing it to be initially in a state of uniaxial strain with corresponding lateral stresses that will act as a form of confinement. Expansion, or unloading, begins almost immediately from the free surface of the cylinder and propagates towards the centre as the material is accelerated in the outward radial direction. This reaction to inertia, commonly called lateral inertia confinement, produces a lateral confined stress on that part of the material which has not yet expanded, or unloaded, radially.” (Bischoff and Perry 1991)

Several methods exist to combat the inertial effects in dynamic testing, particularly SHPB tests. Modified split-Hopkinson pressure bars have been created that confine the specimen, both actively and passively (Gong and Malvern 1990). Furthermore, these effects can be greatly reduced using proper specimen design. A shorter specimen length, which equals a smaller aspect, or length-to-width ratio, helps reduce the effects of inertia. While Bischoff and Perry concluded that researchers are divided regarding whether or not the increase in strength is due to the increase in strain rate or inertial effects, Li and Meng (2003) agree that the increase in strength during dynamic testing due to lateral inertial forces can cause the specimen to deviate from a uniaxial stress state. However, Huang and Subhash (2003) rebutted this statement, verifying that strain rate effect of brittle solids is independent of lateral confinement at high strain rates.

\subsubsection{Dispersion Effects}

Longitudinal waves traveling through elastic bars are subject to geometric dispersion (Ramesh 2008). Although these dispersion effects can be accounted for through strenuous analysis, researchers typically ignore them. Rather than ignore these effects, which cause oscillations in the specimen loading and sharper rise times, a shaper material, or pulse shaper, can be used to effectively minimize dispersion. Pulse shaping, which is discussed in Section 2.1.4, reduces the rise time of the pulse resulting in minimal dispersion effects. 


\subsubsection{SHPB Theory}

A fundamental postulate of SHPB testing is the validity of one-dimensional elastic stress wave theory in the bars (Q.M. Li 2003). Ensuring elastic deformation in the SHPB bars is done by limiting the impact stresses and striker bar velocity. From this theory, the dynamic compression can be validated and analyzed.

During a uniaxial compression test, the striker bar impacting the open face of the input bar creates a compressive wave with a pulse length equal to twice that of the striker bar (Gama et. al. 2004). This pulse travels through the input bar at a speed defined by the bar material. The longitudinal wave velocity, $c$, is defined as:

$$
c=\sqrt{\frac{E}{\rho}}
$$

Where:

$$
\begin{aligned}
& E=\text { elastic modulus } \\
& \rho=\text { material density } .
\end{aligned}
$$

As the compressive pulse meets the input bar-specimen interface, a portion of the pulse enters the specimen while some of the pulse is reflected back through the input bar as a tension wave. As the initial compressive pulse passes through the specimen and reaches the output bar-specimen interface, a portion of the pulse continues into the output bar. The remainder of the pulse is reflected within the specimen. As mentioned before, the specimen must reach stress equilibrium. This is achieved as the pulse wave continues to pass back and forth through the specimen, remaining in the specimen due to its lower acoustic impedance compared to the steel input and output bars. The difference in acoustic impedance is also responsible for the reflected wave in the input bar. Acoustic impedance, $Z$, is defined as the degree at which a wave transmits through or reflects off of a material boundary (Gama et.al. 2004). It can be calculated using the following equation: 


$$
Z=\rho \cdot c
$$

Equation 2-2

Where:

$$
\begin{aligned}
& \rho=\text { material density } \\
& c=\text { longitudinal wave velocity. }
\end{aligned}
$$

The movement of the pulse wave is tracked through the SHPB by strain gages located at the midspan of the input and output bars. The individual input, output, and reflected waves, are utilized in the stress and strain analysis of the specimen.

There are multiple methods of analyzing data from SHPB testing. One-dimensional (1-D) wave propagation theory is most common, while two- and three-dimensional analyses have been developed (Gray III 2000). There are three main relationships used to define the 1-D analysis of the dynamic properties of a sample in a SHPB, with the ultimate goal of obtaining a dynamic stress-strain curve for the tested material. The strain in the specimen, $\boldsymbol{\varepsilon}_{s}$, is calculated as:

$$
\varepsilon_{s}=\frac{-2 \cdot c_{b}}{L_{s}} \cdot \int_{0}^{t} \varepsilon_{r} d t
$$

Where:

$$
\begin{aligned}
& c_{b}=\text { longitudinal wave velocity of the SHPB bars } \\
& L_{s}=\text { length of specimen } \\
& \varepsilon_{r}=\text { strain of reflected wave. }
\end{aligned}
$$

The dynamic specimen stress, $\sigma_{d}$, is calculated by the following equation:

$$
\sigma_{d}=E_{b} \cdot \frac{A_{b}}{A_{s}} \cdot \varepsilon_{t}
$$

Where:

$$
\begin{aligned}
& E_{b}=\text { elastic modulus of SHPB bars } \\
& A_{b}=\text { cross-sectional area of SHPB bars } \\
& A_{s}=\text { cross-sectional area of specimen } \\
& \varepsilon_{t}=\text { strain of transmitted (output) wave. }
\end{aligned}
$$


Aside from the specimen stress and strain, specimen strain rate is also calculated to characterize the loading type as defined by Figure 2.1. The specimen strain rate of the loading, $\dot{\varepsilon}_{s}$, is calculated by the following equation:

$$
\dot{\varepsilon}_{s}=\frac{-2 \cdot c_{b}}{L_{s}} \cdot \varepsilon_{r}
$$

Where:

$$
\begin{aligned}
& c_{b}=\text { longitudinal wave velocity of the SHPB bars } \\
& L_{s}=\text { length of specimen } \\
& \varepsilon_{r}=\text { strain of reflected wave. }
\end{aligned}
$$

\subsubsection{Aspect Ratio}

Aspect ratio is defined as the ratio of the length of a shape to the width of a shape. In the case of a cylindrical SHPB specimen, the aspect ratio pertains to the ratio of the length $(L)$ of the specimen compared to the diameter $(D)$ of the specimen $(L: D)$.

Specimen design is an important step in a SHPB test. There are many assumptions that must be met for a test to be valid, as mentioned in Section 2.1.1, and many of these can only be achieved through adequate specimen design. One of the assumptions is that the specimen is in stress equilibrium during the early duration of the test, or "ringing-up" period. To help minimize the "ringing-up" period, a minimum possible specimen length could be used. However, pulse shapers can be utilized to achieve equilibrium. Another assumption for a valid SHPB experiment is that friction and inertia effects are minimal. Specimen geometry plays a large role in achieving this criterion. Frictional effects occur at the interface between the bar and the specimen. Inertial effects occur as a result of the loading occurring faster than the specimen can expand laterally. This results in an increase in dynamic strength that does not accurately reflect the material's actual increase in dynamic strength when compared to static strength. 
An issue arises from the fact that the conditions for minimum friction and minimum inertia cannot be satisfied simultaneously. Longer specimens reduce the frictional effects but increase the inertial effects. Similarly, the shorter the specimen the smaller the inertial effects, but greater the frictional effects. Frictional effects can be minimized with the use of lubricants. Inertial effects are minimized primarily through aspect ratio. Some adaptations to the SHPB have been designed to either actively or passively confine the specimen in the radial direction. Inertia effects become an issue when the strain rate reaches or exceeds $10^{2}$ 1/sec (Malvern et. al. 1984). Generally, SHPB specimens, of all types of materials, have aspect ratios between $0.5: 1$ to $1: 1$ (Gray III 2000). This range is taken as a compromise between the two effects. The diameter of the specimen $\left(D_{s}\right)$ is limited by the diameter of the incident and transmission bars $\left(D_{b}\right)$. Consequently, the diameter of the specimen should not exceed the diameter of the bars.

According to Gama et al. (2004), along with other literature, the optimum length of a specimen depends on the rise time required to achieve an uniaxial stress state in the specimen. In 1963, Davies and Hunter proposed an optimum specimen geometry shown by Equation 2-6.

$$
\frac{L}{D}=\frac{\sqrt{3 \cdot v_{s}}}{2}
$$

Where:

$$
\begin{aligned}
& L=\text { length of specimen } \\
& D=\text { diameter of specimen } \\
& v_{S}=\text { Poisson's ratio of specimen. }
\end{aligned}
$$

Research has been done to determine whether or not the increase in strength under dynamic loading conditions is a true material characteristic or if it is due to the radial inertia effects. Some researchers believe that the effects of inertia cannot be completely designed out of an SHPB experiment through specimen geometry and must, therefore, be carefully analyzed (Zhang et. al. 2009). 
Table 2.1 is a compilation of SHPB research, primarily on concrete or other brittle materials. Outlined in the table is the aspect ratio used for each research project. Clearly, the 0.5:1 and 1:1 aspect ratios are the most commonly used specimen aspect ratios, regardless of the specimen length and diameter. Note that the "optimum equation" in Table 2.1 refers to the aspect ratio defined by Equation 2-6.

Table 2.1: Aspect ratio used in previous SHPB research

\begin{tabular}{|c|c|c|c|c|}
\hline Research & $\begin{array}{l}\text { Aspect Ratio } \\
\text { (L:D) }\end{array}$ & Length & Diameter & Material Tested \\
\hline Davies and Hunter (1963) & $\begin{array}{c}0.5: 1 \text { and optimum } \\
\text { equation }\end{array}$ & $\begin{array}{l}12.7 \mathrm{~mm} \\
(0.5 \mathrm{in})\end{array}$ & $\begin{array}{c}25.4 \mathrm{~mm} \\
(1.0 \mathrm{in})\end{array}$ & Metals and Polymers \\
\hline Ross et. al. (1989) & $1: 1$ & $\begin{array}{l}51 \mathrm{~mm} \\
(2.0 \mathrm{in})\end{array}$ & $\begin{array}{l}51 \mathrm{~mm} \\
(2.0 \mathrm{in})\end{array}$ & Concrete \\
\hline Malvern and Ross (1984) & $0.5: 1$ & $\begin{array}{c}10.16 \mathrm{~mm} \\
(0.4 \mathrm{in})\end{array}$ & $\begin{array}{l}19 \mathrm{~mm} \\
(0.75 \mathrm{in})\end{array}$ & Concrete \\
\hline Ross (1989) & $1: 1$ & $\begin{array}{l}51 \mathrm{~mm} \\
(2.0 \mathrm{in})\end{array}$ & $\begin{array}{l}51 \mathrm{~mm} \\
(2.0 \mathrm{in})\end{array}$ & Concrete \\
\hline Gong and Malvern (1990) & $0.667: 1$ & $\begin{array}{l}50.7 \mathrm{~mm} \\
(2.0 \mathrm{in})\end{array}$ & $\begin{array}{l}76 \mathrm{~mm} \\
(2.99 \mathrm{in})\end{array}$ & Concrete \\
\hline Bischoff and Perry (1991) & Optimum equation & $\mathrm{N} / \mathrm{A}$ & $\mathrm{N} / \mathrm{A}$ & Concrete \\
\hline Tang et. al. (1992) & $0.5: 1$ and $1: 1$ & Varied & $\begin{array}{c}76.2 \mathrm{~mm} \\
(3.0 \mathrm{in})\end{array}$ & Concrete \\
\hline Jerome (1991) & $1: 1$ & $\mathrm{~N} / \mathrm{A}$ & $\mathrm{N} / \mathrm{A}$ & $\mathrm{N} / \mathrm{A}$ \\
\hline Ross et. al. (1995) & $1: 1$ & $\begin{array}{l}51 \mathrm{~mm} \\
(2.0 \mathrm{in})\end{array}$ & $\begin{array}{l}51 \mathrm{~mm} \\
(2.0 \mathrm{in})\end{array}$ & Concrete \\
\hline Shan et. al. (2000) & $\begin{array}{l}\text { 1:1 (50 samples), } \\
\text { 1.5:1 (40 samples), } \\
\text { 2:1 (10 samples)* }\end{array}$ & Varied & $30 \mathrm{~mm}$ & $\begin{array}{c}\text { Rock (Marble and } \\
\text { Granite) }\end{array}$ \\
\hline Frew et. al. (2001) & $1: 1$ & $\begin{array}{c}12.7 \mathrm{~mm} \\
(0.5 \mathrm{in})\end{array}$ & $\begin{array}{c}12.7 \mathrm{~mm} \\
(0.5 \mathrm{in})\end{array}$ & Rock (Limestone) \\
\hline Vitton et. al. (2002) & $2: 1$ & $\begin{array}{l}37.5 \mathrm{~mm} \\
(1.48 \mathrm{in})\end{array}$ & $\begin{array}{l}75 \mathrm{~mm} \\
(2.95 \mathrm{in})\end{array}$ & $\begin{array}{c}\text { Concrete and } \\
\text { Aggregate }\end{array}$ \\
\hline Lok et. al. (2002) & $0.57: 1$ and $0.7: 1$ & Varied & $70 \mathrm{~mm}$ & Brittle Materials \\
\hline
\end{tabular}




\begin{tabular}{|c|c|c|c|c|}
\hline & & & (2.76 in) & \\
\hline Lok and Zhao (2004) & $0.5: 1$ & $\begin{array}{l}35 \mathrm{~mm} \\
(1.38 \mathrm{in})\end{array}$ & $\begin{array}{l}70 \mathrm{~mm} \\
(2.76 \mathrm{in})\end{array}$ & $\begin{array}{c}\text { Steel Fiber-Reinforced } \\
\text { Concrete }\end{array}$ \\
\hline Li and Meng $(2003)^{\dagger}$ & $0.5: 1$ & $\begin{array}{l}60 \mathrm{~mm} \\
(2.36 \mathrm{in})\end{array}$ & $\begin{array}{l}120 \mathrm{~mm} \\
(4.72 \mathrm{in})\end{array}$ & Concrete \\
\hline Wang et. al. (2008) & $0.5: 1$ & $\begin{array}{l}37 \mathrm{~mm} \\
(1.46 \mathrm{in})\end{array}$ & $\begin{array}{l}74 \mathrm{~mm} \\
(2.91 \mathrm{in})\end{array}$ & $\begin{array}{c}\text { Steel Fiber-Reinforced } \\
\text { Concrete }\end{array}$ \\
\hline Vecchio and Jiang (2007) & 1:1 & $\begin{array}{c}5 \mathrm{~mm} \\
(0.20 \mathrm{in})\end{array}$ & $\begin{array}{c}5 \mathrm{~mm} \\
(0.20 \mathrm{in})\end{array}$ & $\begin{array}{l}\text { 50-50 NiTi alloy, } 60 \\
\text { NiTi alloy, tungsten } \\
\text { single crystals, } \\
\text { interstitial-free steel, } \\
\text { MACOR }\end{array}$ \\
\hline Ramesh (2008) & $0.5: 1-1: 1$ & $\mathrm{~N} / \mathrm{A}$ & $\mathrm{N} / \mathrm{A}$ & $\mathrm{N} / \mathrm{A}$ \\
\hline Zhang et. al. (2009) & $0.5: 1$ and $0.35: 1$ & Varied & $\begin{array}{c}74,50,17 \mathrm{~mm} \\
(2.91,1.97,0.67 \mathrm{in})\end{array}$ & Concrete-like materials \\
\hline Frew et. al. (2010) & 1:1 & $\begin{array}{c}12.7 \mathrm{~mm} \\
(0.5 \mathrm{in})\end{array}$ & $\begin{array}{c}12.7 \mathrm{~mm} \\
(0.5 \mathrm{in})\end{array}$ & Rock (Limestone) \\
\hline Lu et. al. (2010) & $0.5: 1$ & $\begin{array}{l}37 \mathrm{~mm} \\
(1.46 \mathrm{in})\end{array}$ & $\begin{array}{l}74 \mathrm{~mm} \\
(2.91 \mathrm{in})\end{array}$ & Rock \\
\hline Wang et. al. (2011) & $0.5: 1$ & $\begin{array}{l}38.5 \mathrm{~mm} \\
(1.52 \mathrm{in})\end{array}$ & $\begin{array}{l}77 \mathrm{~mm} \\
(3.03 \mathrm{in})\end{array}$ & $\begin{array}{c}\text { Fiber-reinforced high- } \\
\text { strength concrete }\end{array}$ \\
\hline Gilbertson (2011) & $0.5: 1$ & $\begin{array}{l}37.5 \mathrm{~mm} \\
(1.48 \mathrm{in})\end{array}$ & $\begin{array}{l}75 \mathrm{~mm} \\
(2.95 \mathrm{in})\end{array}$ & Wood \\
\hline Gilbertson (2011) & $0.75: 1$ & $\begin{array}{l}37.5 \mathrm{~mm} \\
(1.48 \mathrm{in})\end{array}$ & $\begin{array}{l}75 \mathrm{~mm} \\
(2.95 \mathrm{in})\end{array}$ & Aluminum \\
\hline Zhigang et. al. (2012) & $0.5: 1$ & $\begin{array}{l}35 \mathrm{~mm} \\
(1.38 \mathrm{in})\end{array}$ & $\begin{array}{l}70 \mathrm{~mm} \\
(2.76 \mathrm{in})\end{array}$ & $\begin{array}{c}\text { Hybrid Fiber } \\
\text { Reinforced Concrete }\end{array}$ \\
\hline Chen et. al. (2013) & $0.5: 1$ & $\begin{array}{l}37 \mathrm{~mm} \\
(1.46 \mathrm{in})\end{array}$ & $\begin{array}{l}74 \mathrm{~mm} \\
(2.91 \mathrm{in})\end{array}$ & Silica Fume Concrete \\
\hline
\end{tabular}

\subsubsection{Pulse Shaping}

Pulse shaping is the creation of a ramp shaped incident pulse during a SHPB test. This is accomplished by placing a material on the open face of the incident bar in a manner that it 
deforms plastically upon contact with the striker bar. The ramp shaped incident pulse, as opposed to a rectangular/trapezoidal shaped pulse, is due to the reduction in rise time. Two generic incident waves are shown in Figure 2.3. The plot on the left is without pulse shaping, while the plot on the left is with pulse shaping. The effect of the pulse shaper is clearly evident in the second image.
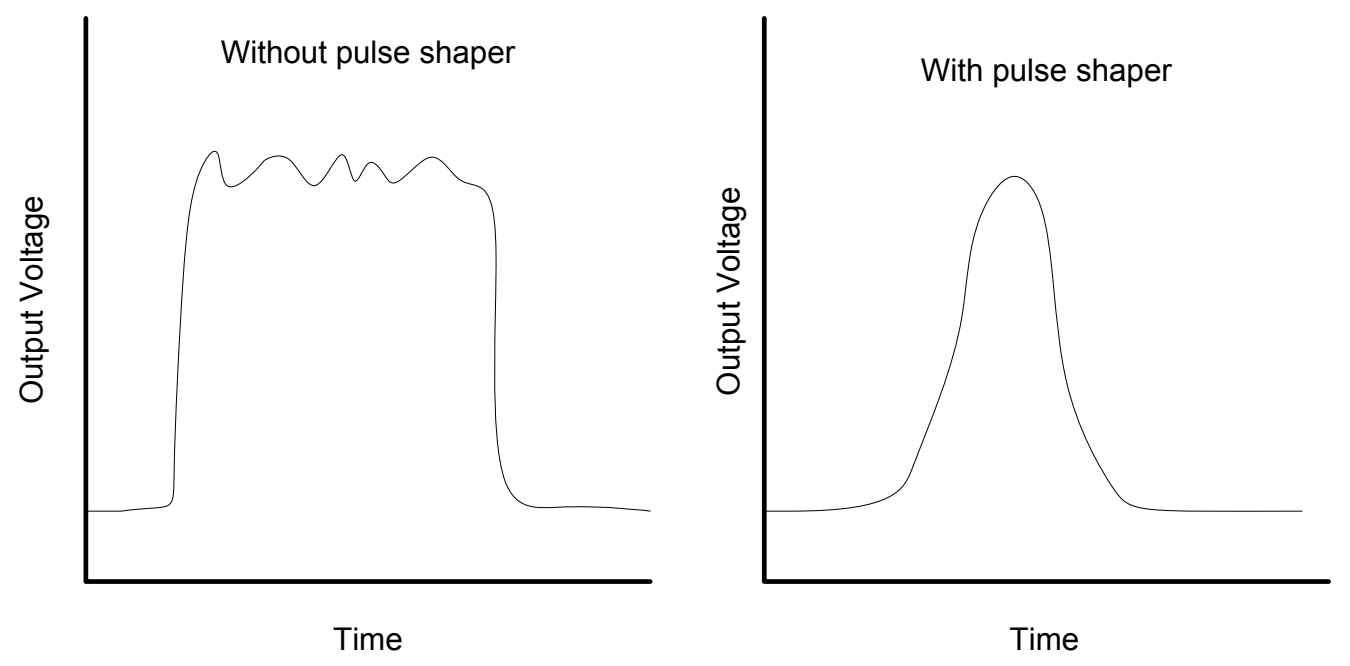

Figure 2.3: Generic input pulse waves without and with pulse shaping

Rise time is the estimated time required for $\pi$ reverberations in the specimen (Davies and Hunter 1963). The use of a pulse shaper generates a constant reflected pulse, which according to one-dimensional wave theory, represents a constant strain rate of the specimen, a consideration when discussing the validity of a SHPB test. Typical incident pulses are rectangular or slightly trapezoidal, with the specimen reaching maximum amplitude nearly instantaneously. This can result in high frequency oscillations, or Pochhammer Modes, which create dispersive effects in the data (Gama et. al. 2004). Pulse shaping minimizes these dispersive effects. Furthermore, as a result of the energy required to deform the pulse shaper, there is a reduction in achievable strain rate during an SHPB test. This must be taken into consideration when trying to attain high strain rates.

There are few criteria corresponding to the proper use of pulse shapers. First, the final pulse shaper size must not expand outside the diameter of the incident bar. This limits the size of 
the pulse shaper. Throughout the literature there are no existing size specifications, rather only recommendations used in practice by other researchers. Many researchers use varying thickness-to-diameter ratios to help determine the optimal size of the pulse shaper. Other researchers use varying diameters and thicknesses.

Typically, soft metals are used as pulse shapers. Table 2.2 is a compilation of previous work using the Split-Hopkinson pressure bar along with pulse shaper information. Outlined in the table are the pulse shaping materials and sizes, along with the material being tested with the SHPB. Based on the gathered information, it is evident that pure copper, hard or annealed, is the most popular pulse shaper material for any SHPB test material. However, paper and other metals have also been used. An exact size of the pulse shaper remains inconclusive. It is important to note that the smaller and thinner the pulse shaper, the less energy will be used to plastically deform it. 
Table 2.2: Pulse shapers used in previous SHPB research

\begin{tabular}{|c|c|c|c|}
\hline Research & Pulse Shaper Material & Tested Material & Pulse Shaper Size \\
\hline Wang et. al. (2011) & Aluminum & $\begin{array}{c}\text { Plain \&Fiber-reinforced } \\
\text { concrete }\end{array}$ & $30 \mathrm{~mm}$ diameter $\mathrm{x} 1 \mathrm{~mm}$ thick \\
\hline Forrestal et. al. (2006) & $\begin{array}{l}\text { Annealed and hard } \\
\text { C11000 copper }\end{array}$ & Plain concrete & $\begin{array}{c}3.97 \mathrm{~mm} \text { diameter } \times 0.79 \mathrm{~mm} \\
\text { thick }\end{array}$ \\
\hline Frew et. al. (2002) & $\begin{array}{l}\text { Annealed and hard } \\
\text { C11000 copper }\end{array}$ & Macor & $\begin{array}{l}\text { Diameter: } 3.16-4.81 \mathrm{~mm} \\
\text { Thickness: } 0.78-1.59 \mathrm{~mm}\end{array}$ \\
\hline Frew et. al. (2001) & $\begin{array}{l}\text { Annealed and hard } \\
\text { C11000 copper }\end{array}$ & Limestone & $\begin{array}{c}3.97 \mathrm{~mm} \text { diameter } \times 0.79 \mathrm{~mm} \\
\text { thick }\end{array}$ \\
\hline Frew et. al. (2010) & Annealed C11000 copper & Limestone & $\begin{array}{c}9.60 \mathrm{~mm} \text { diameter } \times 1.02 \text { and } 4.80 \\
\text { mm thick }\end{array}$ \\
\hline Lu et. al. (2010) & Unknown & Rock & Unknown \\
\hline Gilbertson (2011) & 8 sheets of typing paper & Wood & Full area of bar \\
\hline Zhang et. al. (2009) & Unknown & Mortar & Unknown \\
\hline $\begin{array}{l}\text { Abotula and } \\
\text { Chalivendra (2010) }\end{array}$ & $\begin{array}{c}\text { Copper-182 alloy and } \\
\text { annealed C11000 copper }\end{array}$ & $\begin{array}{c}\text { Aluminum, Macor, } \\
\text { Plexiglas, Synthetic foam }\end{array}$ & $\begin{array}{l}\text { Diameter: 3.175-6.35 mm } \\
\text { Thickness: } 1.13-3.0 \mathrm{~mm}\end{array}$ \\
\hline $\begin{array}{l}\text { Vecchio and Jiang } \\
(2007)\end{array}$ & HSHWHR material & Metals, Macor & $31.5 \mathrm{~mm}^{\wedge} 2$ area \\
\hline
\end{tabular}

\subsubsection{Parallel Tolerances}

An important characteristic of the specimen tested in an SHPB setup is that the specimen has parallel ends. The ends of the specimen meet with the input and output bars to make up the input bar/specimen interface and the output bar/specimen interface, respectively. To ensure uniform stress and consistency of the data, it is important to meet parallel tolerances. However, there are no standards or set regulations regarding the parallel tolerances for SHPB specimens. It is recommended that the specimen ends be machined parallel within a 0.001 inch tolerance (Gray III 2000). Furthermore, Gray III suggests a tolerance of 0.0001 inch for brittle materials. According to Ductal ${ }^{\circledR}$ reference T 009, the standard Operating Procedure Cylinder End Preparation, UHPC specimens must be within a maximum degree 
difference less than or equal to 0.5 degrees. The ASTM C39 Standard Test Method for Compressive Strength of Cylindrical Concrete Specimens also requires specimen ends to be within 0.5 degrees difference (ASTM C39, 2013).

\subsection{Ultra-High Performance Concrete (UHPC)}

\subsubsection{History of UHPC}

Ultra-high performance concrete (UHPC) was first introduced in France in the early 1990's (Ahlborn et. al. 2003). An alternative to conventional concrete, UHPC offers enhanced material characteristics. UHPC utilizes an extremely dense microstructure as well as a very low water-to-cement ratio to obtain compressive strengths exceeding 22,000 psi (150 MPa), among other improved material properties, including high tensile strength, long-term durability, and post fracture strain. As a relatively new material, UHPC has been the subject of a great deal of research throughout the world. However, the concrete has yet to become a common material in the construction industry, particularly in the United States.

Several projects across the world have taken advantage of UHPC's strength and durability characteristics. The first bridge using UHPC was a pedestrian bridge completed in 1997 in Quebec, Canada (Blaise and Couture 1999). Since then several other bridges have been constructed using UHPC, including the first highway bridges in Bourg-les-Valence, France in 2002 and the Footbridge of Peace in Seoul, South Korea in 2002. The first bridge completed in the United States was in Wapello County, Iowa in 2006 (Endicott 2006). It utilizes UHPC I-shaped girders and waffle deck panels. Because precast construction best suits UHPC, its applications often include bridge girders and deck elements. However, UHPC is also used for other structural components as well as architecturally. Tokyo's Haneda Airport Runway D expansion project is one of the largest UHPC projects to date. It included $24,000 \mathrm{~m}^{3}$ $\left(847,522 \mathrm{ft}^{3}\right)$ of UHPC slabs (Tanaka et. al. 2009). Architectural applications of UHPC include facades, lattices, and sunshades among other aesthetic components (Batoz and Behoul 2009). 
Currently, there are proprietary UHPC mixtures available on the United States market including Ductal ${ }^{\circledR}$ and Taktl ${ }^{\circledR}$. Furthermore, several universities are working to develop their own material blend of ultra-high performance concrete. As UHPC knowledge expands, along with design guidelines and codes, so too will its popularity grow.

\subsubsection{Composition of UHPC}

Although characterized as concrete, UHPC varies in composition compared to conventional, or even high strength, concrete. Using similar mixture constituents, the proportions vary compared to other concrete mixtures to produce its high performance material properties. A typical composition of UHPC is shown below in Table 2.3 (Graybeal 2006).

Table 2.3: Typical UHPC Composition

\begin{tabular}{lcc}
\hline \multicolumn{1}{c}{ Material } & Amount $\left.\left(\mathbf{k g} / \mathbf{m}^{3} \mathbf{(} \mathbf{l b} / \mathbf{y d} \mathbf{d}^{3}\right)\right)$ & Percent by Weight \\
\hline Portland Cement & $712(1,200)$ & 28.5 \\
Fine Sand & $1020(1,720)$ & 40.8 \\
Silica Fume & $231(390)$ & 9.3 \\
Ground Quartz & $211(355)$ & 8.4 \\
Superplasticizer & $30.7(51.8)$ & 1.2 \\
Accelerator & $30.0(50.5)$ & 1.2 \\
Steel Fibers & $156(263)$ & 6.2 \\
Water & $109(184)$ & 4.4 \\
\hline $1 \mathrm{~kg} / \mathrm{m}^{3}=1.686 \mathrm{lb} / \mathrm{yd}^{\mathbf{3}}$ & &
\end{tabular}

UHPC features a low water-to-cement ratio $(\mathrm{w} / \mathrm{c} \approx 0.20)$ and extremely dense microstructure. The dense microstructure of UHPC is a direct result of the small particle sizes of the cement and cementitious materials in the mixture, along with the exclusion of coarse aggregate. Essentially, UHPC could be considered a mortar due to the exclusion of coarse aggregate as a constituent. A low water-to-cement ratio is achievable with the use of a high range water reducing admixture (HRWRA), also known as superplasticizer. Also, UHPC features steel fibers, improving its tensile capacity and ductility. The fibers are generally about 0.008 inches in diameter by 0.5 inches long. With the addition of these steel fibers, UHPC is considered a fiber reinforced concrete (FRC). Accelerator admixtures are optional based on construction parameters. 


\subsubsection{Material Properties of UHPC}

With many similarities to conventional and high strength concretes, UHPC is defined primarily by its material properties. American Concrete Institute (ACI) Committee 239UHPC has proposed a common definition for UHPC, pending ACI approval, as concrete that has a minimum specified compressive strength of $150 \mathrm{MPa}(22,000 \mathrm{psi})$ with specified durability, tensile ductility and toughness requirements; fibers are generally included to achieve specified requirement. There are many other material properties that differentiate it from other variations of concrete. Since its creation, extensive research has helped to clearly define the mechanical properties of UHPC. However, as with any material there are ranges that outline UHPC's properties (Ahlborn et. al. 2003). Table 2.4 summarizes the various properties of UHPC as compared to normal strength concrete (NSC) and high performance concrete (HPC).

Table 2.4: Material properties and performance measures for varying concrete types

\begin{tabular}{|l|c|c|c|}
\hline \multicolumn{1}{|c|}{ Material Property } & NSC & HPC & UHPC \\
\hline Compressive Strength (ksi) & $3.0-6.0$ & $6.0-14.0$ & $22.0-33.0$ \\
\hline w/c Ratio & $0.40-0.70$ & $0.24-0.35$ & $0.14-0.27$ \\
\hline $\begin{array}{l}\text { Split Cylinder Tensile Strength } \\
\text { (ksi) }\end{array}$ & $0.36-0.45$ & - & $1.0-3.5$ \\
\hline Maximum Aggregate Size (in) & $0.75-1.00$ & $0.38-0.50$ & $0.016-0.024$ \\
\hline Porosity (\%) & $20.0-25.0$ & $10.0-15.0$ & $2.0-6.0$ \\
\hline Pore Diameter (in) & - & - & $<6 * 10^{-7}$ \\
\hline Ductility & - & - & $250 \mathrm{x}>\mathrm{NSC}$ \\
\hline Fracture Energy (k-in/in ${ }^{2}$ ) & $0.00057-0.00086$ & - & $0.057-0.228$ \\
\hline Young's Modulus (ksi) & $2000-6000$ & $4500-8000$ & $8000-9000$ \\
\hline Modulus of Rupture 1 $^{\text {st }}$ Crack (ksi) & $0.4-0.6$ & $0.8-1.2$ & $2.4-3.2$ \\
\hline Ultimate Flexure Strength (ksi) & - & - & $3.0-9.0$ \\
\hline Poisson's Ratio & $0.11-0.21$ & - & $0.19-0.24$ \\
\hline Creep Coefficient, Cu & 2.35 & $1.6-1.9$ & $0.2-0.8$ \\
\hline Percent Air (\%) & $4.0-8.0$ & $2.0-4.0$ & 0 \\
\hline
\end{tabular}

Table 2.4 clearly illustrates that not only does UHPC provide superior compressive strength, but UHPC also performs at much higher levels in many mechanical properties compared to 
NSC and HPC. In regards to the dynamic behavior of UHPC at elevated strain rates, the most important characteristics to note are its compressive strength, ductility, flexure strength, and fracture energy.

\subsection{SHPB Testing for Concrete}

The Split-Hopkinson pressure bar was originally designed for, and is most often used, to test metals. However, researchers have used it to examine the dynamic properties of brittle materials, including concrete. While other testing methods exist to test the impact and dynamic properties of materials, such as the ACI Drop Weight-Impact Test (Myers and Tinsley 2013), the SHPB test exceeds the capabilities of these test methods for high-strain rate experiments. The following sections discuss the current body of research regarding the use of the SHPB testing on concrete materials.

\subsubsection{Plain Concrete}

Ross et. al. (1989) first expanded on the minimal dynamic concrete research, using a 2-inch SHPB to test 100 concrete and mortar samples in tension and compression configurations. Dynamic increase factors were reported for strain rates ranging from $10^{-7}$ to $10^{2} \mathrm{sec}^{-1}$. Ross et. al. (1989) found as strain rate increases, dynamic increase factors for splitting tension, direct tension, and compression tests also increase. Furthermore, concrete exhibits larger dynamic increase factors than that of mortar tests.

In 1991, Bischoff and Perry reported a comprehensive review of dynamic compressive behavior. Included are the strain rate ranges and dynamic increase factors for the breadth of the research. This includes research completed using methods other than the SHPB for a variety of NSC specimen sizes. However, it is generally accepted that there is an increase in dynamic compressive strength at increasing strain rates (Bischoff and Perry 1991).

Zhang et. al. (2009) investigated the dynamic strength increase of concrete using solid and tubular cylinders in SHPB experiments. The research suggests that radial confinement had a 
greater influence on the dynamic increase in compressive strength of concrete than strain rate effect. This research applies to strain rates in the range of $1 \mathrm{~s}^{-1}$ to $10^{3} \mathrm{~s}^{-1}$.

Tang et. al. (1992) observed compressive strain rate dependence for two high strength concretes with static strengths of 14,000 psi (97 MPa). This experiment was completed on a 3 inch $(76.5 \mathrm{~mm})$ SHPB at a range of strain rates between 0 and $200 \mathrm{~s}^{-1}$. The authors also utilized dispersion correction analysis techniques that resulted in more accurate stress wave results. Dispersion correction also created smoother output as well as ramp incident pulse waves. This dispersive analysis can be similarly achieved through the use of a pulse shaper material. Furthermore, the research investigated the effect of lateral stress on the dynamic compressive strength of the concrete. A calculated estimation of the contributing lateral specimen stress was between $0.1-0.2 \%$, which is considered trivial compared to the total dynamic compressive strength.

\subsubsection{Fiber-Reinforced Concrete}

While some fiber-reinforced concrete consists of higher strength concrete than plain concrete, normal strength concrete can still be fiber-reinforced. Wang et. al. (2011) concluded that fiber-reinforced high strength concrete (FRHSC) had better impact resistance than plain high strength concrete (HSC). The research consisted of plain and fiber reinforced high strength concrete, with compressive strengths between 11,600 psi (80 MPa) and 13,000 psi (90 MPa), under SHPB testing. The FRHSC contained 0.5\% fiber content. Strain rates for the testing ranged from $40 \mathrm{~s}^{-1}$ to $300 \mathrm{~s}^{-1}$. It can also be concluded from Wang et. al. (2011) that the FRHSC displays a larger amount of energy absorption compared to the plain HSC. Furthermore, the dynamic increase factors (DIF) for compressive strength, critical strain, and elastic modulus increased for both the FRHSC and the HSC as strain rates increased.

Wang et. al. (2008) investigated the effects of fiber reinforcement content under dynamic compression using the Split-Hopkinson pressure bar. Fiber-reinforced concrete samples were tested with varying levels of steel fiber content, specifically $0.0 \%, 3.0 \%$, and $6.0 \%$ percentage by volume. Strain rates during this research ranged from $40 \mathrm{~s}^{-1}$ to $100 \mathrm{~s}^{-1}$. The 
research shows that both a higher steel content and higher strain rate result in a higher dynamic compressive strength. Dynamic increase factors were not reported.

Zhigang et. al. (2012) used the SHPB to investigate the mechanical capability of steelpolypropylene hybrid fiber-reinforced concrete (HRFC) as compared to steel fiberreinforced concrete (SFRC). These samples were tested at strain rates ranging from $20 \mathrm{~s}^{-1}$ to $120 \mathrm{~s}^{-1}$. The plain concrete nearly reached static compressive strengths of 8,700 psi (60 MPa). HRFC performed better than SFRC. DIFs for the SFRC ranged between 1.11 and 1.27, while DIFs for the HFRC ranged between 1.11 and 1.39. For both materials, the DIFs increased as strain rate increased.

Lok and Zhao (2004) tested steel fiber-reinforced concrete (SFRC) using the SHPB to determine its ability to resist impact, concluding that the compressive strength of SFRC increases in the same manner as plain concrete at high strain rates. More specifically, dynamic compressive strength increased as strain rate increased. DIFs also increased as strain rate increased, ranging between 1.02 and 1.71 . Strain rates between $20 \mathrm{~s}^{-1}$ to $100 \mathrm{~s}^{-1}$ were reached during testing.

\subsubsection{UHPC}

While research has been conducted to show the effects of fiber reinforcement on dynamic response, little SHPB testing has been done on concretes with strengths higher than 13,000 psi. With its improved material properties, UHPC tends to behave quite differently than other concretes. For that reason, along with the need for comprehensive material behavior characterization on UHPC, it is essential to continue the dynamic studies of UHPC using the SHPB.

Millon et. al. (2012) used Hopkinson bar experiments to conclude that the dynamic tensile and dynamic fracture energy of UHPC reach higher values than those of normal concrete and high-performance concrete. The research investigates these two properties and their relationship with fiber content. UHPC without any fiber content behaved similar to 
conventional concrete. However, with just $1.0 \%$ and $2.5 \%$ fiber content, the dynamic tensile strength and dynamic fracture increased greatly. It should be noted that these dynamic properties were determined at strain rates up to $180 \mathrm{~s}^{-1}$.

In 2006, Cavill et. al. presented on the capability of UHPC, specifically Ductal ${ }^{\circledR}$, as a material to resist and mitigate the effects of blasts and impacts. A part of these proceedings included a "Constitutive Model for Ductal ${ }^{\circledR}$ at High Loading Rates". The research concluded an increase in compressive strength up to 1.5 times between the dynamic and static loading. Cavill et. al. also concluded that UHPC is less rate sensitive than normal strength concrete and high strength concrete. This experimental program, which is based on only 3 specimens, provided the basis for a strain-rate dependent constitutive model proposal. The model is only applicable for compressive strengths between about $4600 \mathrm{psi}(32 \mathrm{MPa})$ and $23000 \mathrm{psi}$ $(160 \mathrm{MPa})$ at strain rates not exceeding $300 \mathrm{~s}^{-1}$.

\subsection{Dynamic Increase Factor (DIF)}

An important aspect in comparing static and dynamic strengths is the dynamic increase factor (DIF). Also known as the dynamic impact factor, it is defined as the ratio of the ultimate dynamic stress to the ultimate static stress. Abrams (1917) first observed the strength increase in concrete at increased strain rates (Li and Meng 2003). Since then, this material response is generally accepted for concretes and concrete-like materials.

Bischoff and Perry (1991) compiled various information regarding the influence of strain rate on dynamic compressive strength. Figure 2.4 is a compilation of previous research measuring the DIF of plain concrete. 


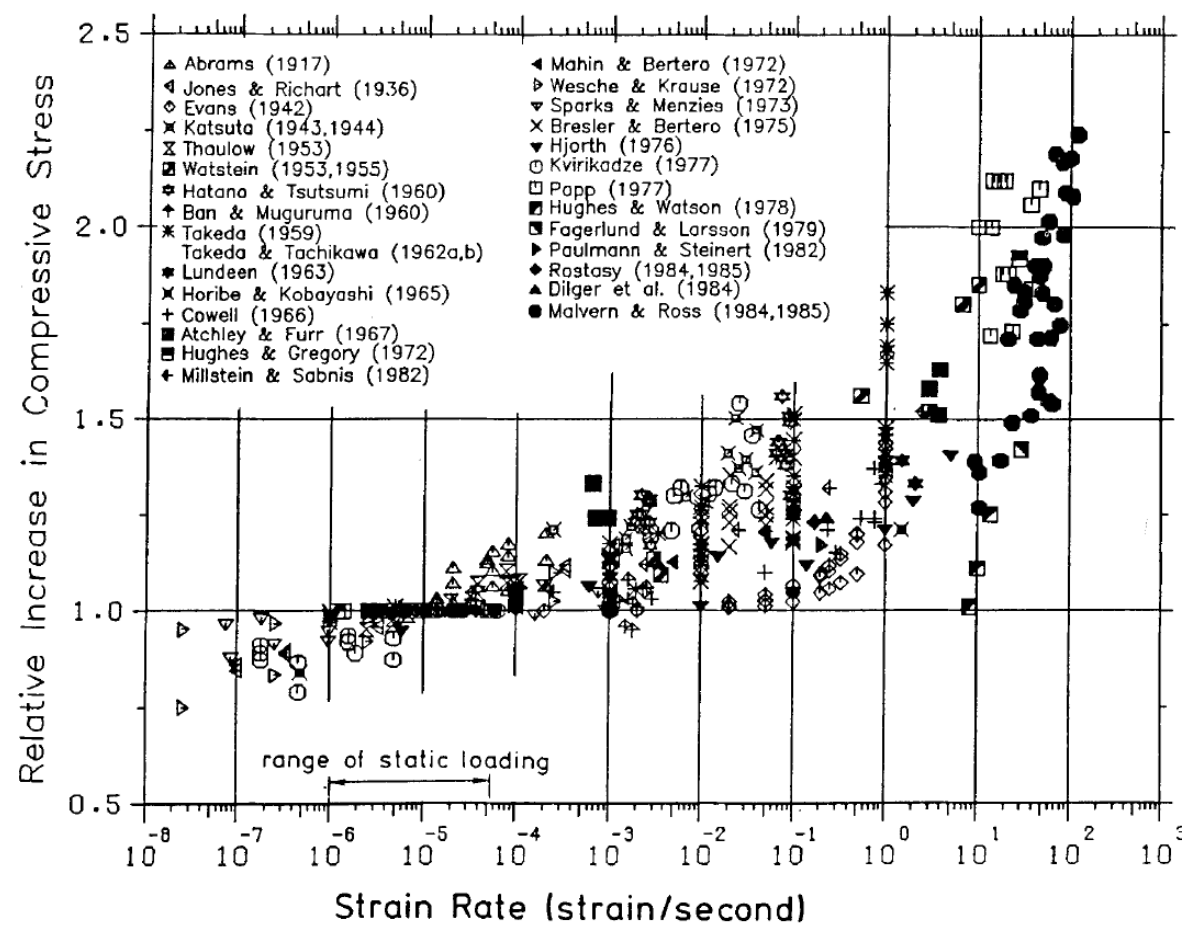

Figure 2.4: Research of strain rate influence on concrete compressive strength (reprinted with permission from Bischoff and Perry 1991)

There is uncertainty regarding the data outlined in Figure 2.4 due to the different testing techniques, specimen size effect, material differences, and boundary effects ( $\mathrm{Li}$ and Meng 2003). However, from Bischoff and Perry's study on the influence of strain rate on the compressive strength of concrete, the clear trend is an increase in compressive strength as strain rate increases. Note that the DIFs reach about 2.25 as the body of data ends. From graphical interpolation, DIFs can be expected to continue to exponentially increase at strain rates above $10^{2} \sec ^{-1}$. As such, a less rate sensitive material, such as UHPC, will not experience increased strengths as rapidly as strain rate increases. This high strain rate range is especially important as "the SHPB-based experimental results suggest $[. .$.$] that the strain-$ rate influence on DIF becomes significant when the strain-rate is beyond a critical value between $10^{1}$ and $10^{2} \mathrm{~s}^{-11}$ ( $\mathrm{Li}$ and Meng 2003). Further research is required to better understand the material behavior of concrete above these critical strain rates. 


\section{Chapter 3 Experimental Methodology}

\subsection{Dynamic Testing}

The dynamic testing consisted of a uniaxial compression test using the SHPB equipment at Michigan Technological University. Testing consisted of multiple specimens of 0.5:1, 1:1, and 2:1 aspect ratios. Normal strength concrete was tested to allow for baseline data and equipment verification. After completing the SHPB testing on normal strength concrete, two sets of UHPC specimens were tested. One set was cured in ambient conditions, while the other was thermally treated according to standard operating procedures as recommended by the supplier. Table 3.1 below shows the number of specimens tested using the SHPB for each aspect ratio as well as each type of concrete.

Table 3.1: Number of samples tested for each concrete type and aspect ratio

\begin{tabular}{|c|c|c|c|}
\hline Aspect Ratio & NSC & UHPC - Ambient & UHPC - Thermal Treatment \\
\hline $0.5: 1$ & 8 & 8 & 7 \\
\hline $1: 1$ & 6 & 7 & 7 \\
\hline $2: 1$ & 3 & 3 & 3 \\
\hline
\end{tabular}

\subsubsection{Concrete Mixing and Curing}

The normal strength concrete used for this research was delivered by Superior Sand \& Gravel in Hancock, Michigan. The concrete was placed in 3"x6" cylinders according to ASTM C192 Making and Curing Concrete Test Specimens in the Laboratory. Cylinders were covered for 24 hours, at which time they were removed from molds and left to ambient cure. Static compressive strength data used in this research was taken at 28 days. The NSC samples were tested in the SHPB at 35 days.

Both of the UHPC concrete batches were mixed at Michigan Technological University's Cement and Concrete Research Lab. Standard mixing procedures were followed using Ductal $^{\circledR}$, a UHPC premix produced by LaFarge North America. The 3"x6" cylinders were filled by allowing the concrete to flow down the side of the tilted cylinder until full, utilizing 
UHPC's ability to self-consolidate. The difference between the two UHPC mixes is the curing regime. The first mix was ambient cured. This included a steam cure at $140^{\circ} \mathrm{F}$ for 24 hours following casting. After the steam cure the cylinders were de-molded and left to ambient cure. The ambient cured UHPC cylinders were tested in the SHPB and for static compressive strength at 54 days, well after the recommended 28 day curing time.

The second UHPC batch was thermally treated according to Ductal ${ }^{\circledR}$ Standard Operating Procedures (Peuse 2008), which begins with 48 hours of ambient curing, followed by demolding. The cylinders were then placed in a cure chamber for another 48 hours. The cure chamber increases temperature at about $20^{\circ} \mathrm{F} /$ hour until holding at $194^{\circ} \mathrm{F}$. The first time this batch of UHPC was placed in the cure chamber, the cure chamber was unable to reach the proper $194^{\circ} \mathrm{F}$ and maintain its heat over the 48 hour time period. As a result, the same batch was properly thermally treated again, ensuring the proper temperatures and time frames were attained. Once the thermally treated UHPC has cooled to ambient temperatures, the material properties are locked in and it can be tested at any time.

\subsubsection{Specimen Preparation}

Prior to testing with the SHPB, each specimen must undergo significant preparation. This preparation ensures consistency and accuracy of testing. Once the concrete specimens were mixed and cured, the next step in preparing the concrete specimens was to cut the 3 " 66 " cylinders to the correct size based on the selected aspect ratio. The cylinders were cut transversely using a water-cooled concrete saw. Once the samples are cut to size, the ends must be ground until smooth and parallel with one another. This was done using a Reid Surface Grinder.

As previously mentioned, the parallelness of the specimen is very important in SHPB testing. However, there are no specific regulations for SHPB concrete specimens, only recommendations (Gray III 2000). The parallelness of each specimen was checked using a micrometer. Relative specimen height was measured at 5 different points, as shown in Figure 3.1. 


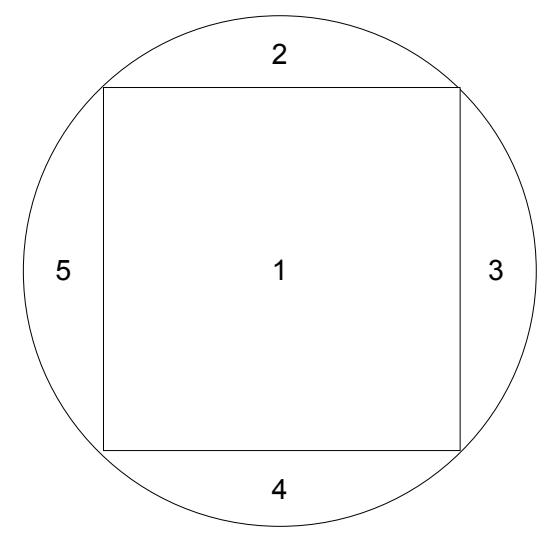

Figure 3.1: Location of measurements for parallelness data

The parallel measurement data can be found in Appendix A. Of the 50 total specimens, 20 samples, or $40 \%$, did not meet the $0.5^{\circ}$ degree tolerance recommendation by at least 1 point of measurement following extensive surface grinding.

The final steps of specimen preparation prior to testing were to record length and diameter measurements and assign an ID for data processing for each sample. Figure 3.2 is a photo of prepped samples of each aspect ratio.

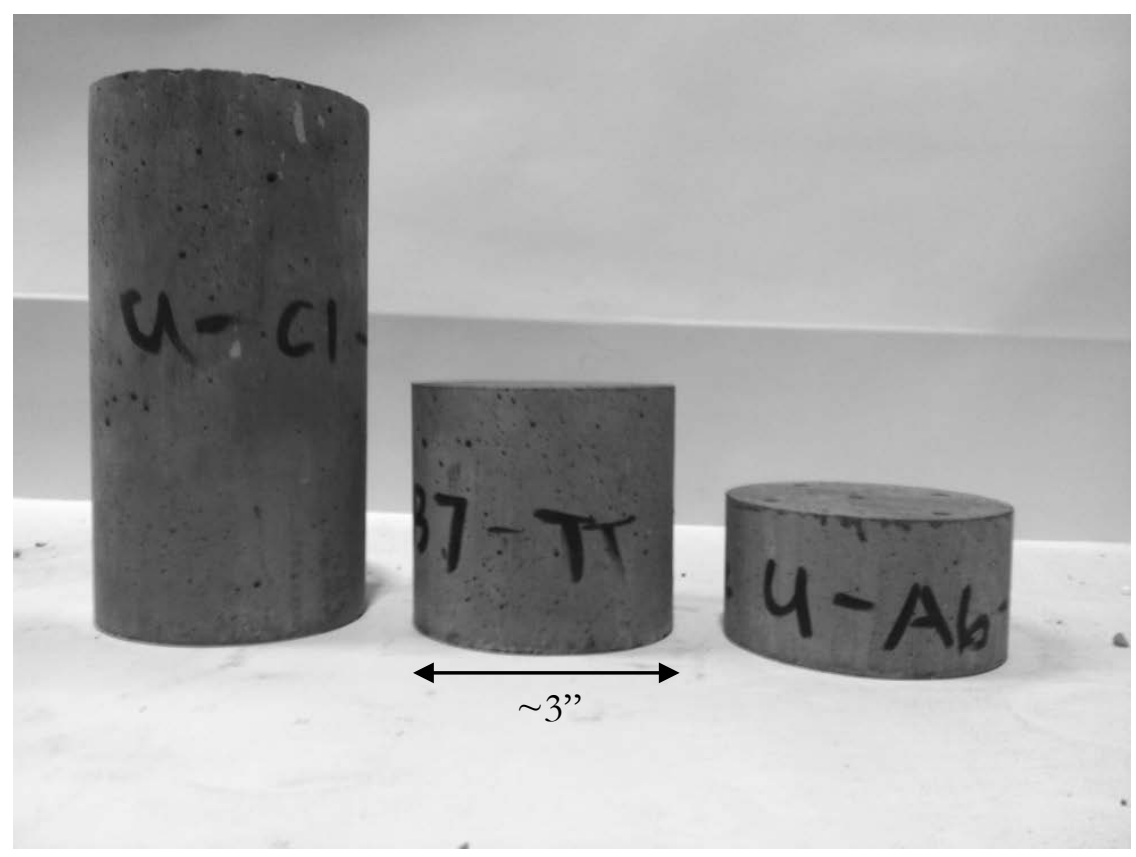

Figure 3.2: Prepared UHPC specimens at aspect ratios of 2:1, 1:1, and 0.5:1 


\subsubsection{Specimen Nomenclature}

Each prepared specimen was given a unique identification to distinguish the various properties and test data of the samples. The first letter denotes either normal strength concrete or UHPC with either a "N" or "U", respectively. Following a hyphen is an "A", "B", or " $\mathrm{C}$ ". This letter represents the aspect ratio of the specimen, $0.5: 1,1: 1$, or 2:1, respectively. After the letter representing the aspect ratio is the sample number for that given aspect ratio. For NSC specimens, the aforementioned information concludes the identifying process. However, with two different curing regimes for the UHPC, another hyphen is added followed by "AMB" for ambient cured specimens or "TT" for thermally treated specimens.

\subsubsection{SHPB Configuration}

The SHPB testing equipment at Michigan Technological University's Cement and Concrete Research Lab features an input and output bar, each 3 inches in diameter and 12 feet long. These are made of $1045 \mathrm{~S}$ steel, which carries a minimum strength of $91 \mathrm{ksi}(630 \mathrm{MPa})$ and a yield stress of $77 \mathrm{ksi}(530 \mathrm{MPa}$ ) (Gilbertson 2011). It also includes five various sizes of striker bars made of the same material. Each striker bar is 3 inches in diameter, but has various lengths of 12, 18, 24, 36, 48 inches $(305,457,610,914,1,219 \mathrm{~mm})$ long. The striker bar is fired using compressed nitrogen gas.

Both the input bar and output bar have 4 Vishay Micro-Measurements EA-06-125AC-350 strain gages attached at midspan, 90 degrees from each other. Each gage corresponds to the gage opposite it, creating a channel in the data acquisition system. Figure 3.3 shows a schematic of the strain gage layout and corresponding channels. Only 1 pair of strain gages is needed on the input and output bars. However, 2 pairs of strain gages are used for redundancy. 

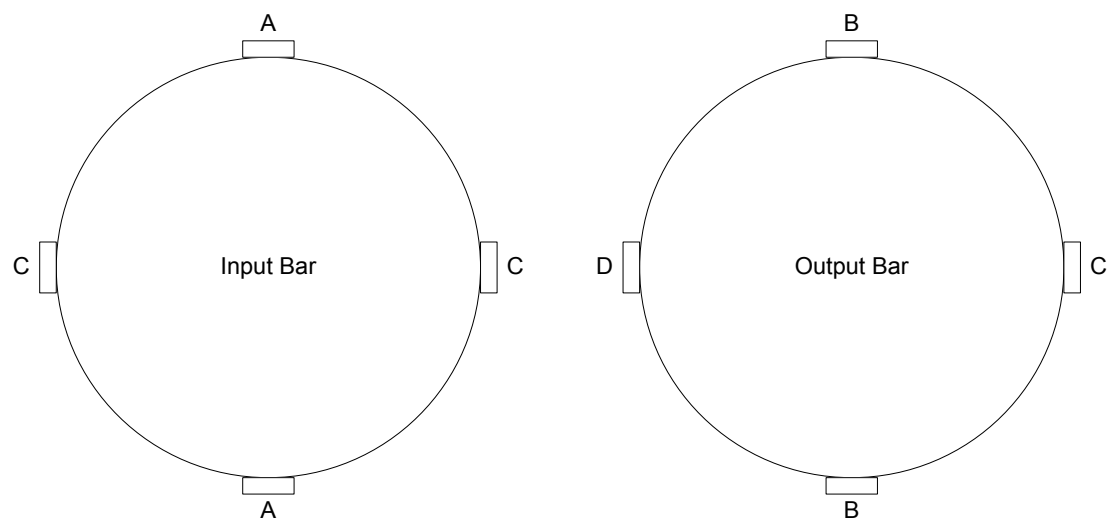

Figure 3.3: Strain Gage/Channel Layout

Four Vishay or Ellis Associates Bridge Amplifier and Meter-1 (BAM-1) are used for signal conditioning and amplification of the strain gages. Figure 3.4 is a photo of the BAM-1 units under the current SHPB configuration.

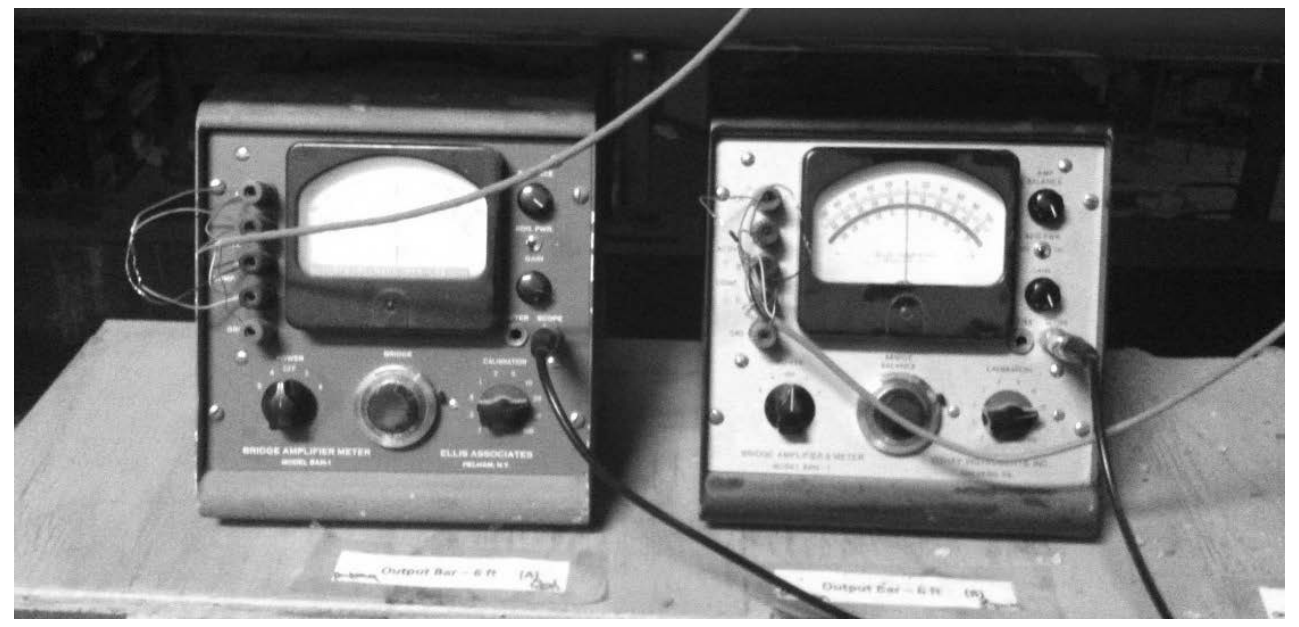

Figure 3.4: Bridge amplifier units (BAM)

The strain gages attached to the bar are connected to the BAM-1 units in full Wheatstone bridge configuration. At rest the Wheatstone bridge is balanced. An output voltage is recorded when the bridge becomes unbalanced, as is the case during the SHPB test. 
Data acquisition and analog-to-digital conversion was accomplished using a digital oscilloscope. A Picoscope 4424, from Pico Technology, allows for precise measurement of small voltage values at high speeds (Gilbertson 2011). The oscilloscope settings were selected based on previous work with this equipment and estimation of test results. Each channel appears concurrently, with a color code to differentiate between them. The Picoscope is set to record 2000 samples with a maximum output voltage of \pm 5 volts. Prior to each test a trigger point is established at $200 \mu \mathrm{s}$ and 0.4 volts to indicate when to initiate data acquisition during each test.

The velocity of the striker bar is another test characteristic used in data processing. A Shooting Chrony - Beta Master chronograph is mounted between the cannon and input bar to measure the striker bar velocity. The chronograph measures the time it takes for an object to pass between two sensors based on disturbances in light. Due to space limitations the chronograph is mounted 6 inches apart, as shown in Figure 3.5, instead of 12 inches apart as recommended. Therefore, the measured velocity reading is double the striker bar velocity. This is accounted for in the data analysis process.

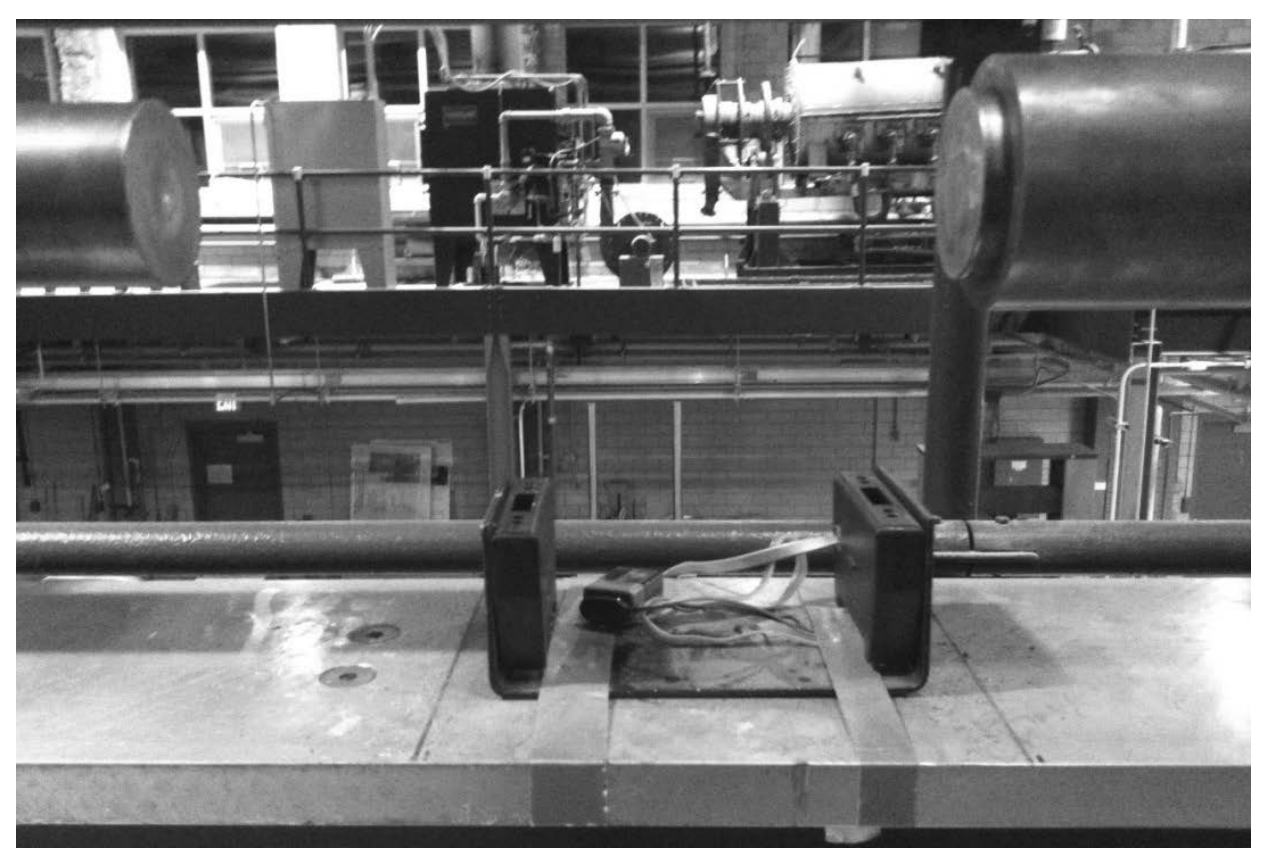

Figure 3.5: Chronograph used to measure striker bar velocity 
If the chronograph could not detect a change in light, the velocity would not record. If the velocity was not recorded for a given test, the average striker bar velocity for a group of tests was used in the data analysis process.

\subsubsection{Calibration}

A series of calibration tests are required prior to specimen testing for any given day.

\subsubsection{BAM Calibration}

The first calibration step is to balance the BAM-1 units and simulate a strain by shunting the unit's internal resistor. This ensures the most consistent and accurate results across all four channels and each unit individually. Using the balance knob, the bridge is balanced both on the unit analog meter as well as digitally on the oscilloscope.

After balancing each unit, the amplifiers are shunted internally. This simulates an estimated strain value and is done by pressing inward and holding down the calibration knob. The shunting of the internal resistor causes an imbalance in the Wheatstone bridge resulting in an output voltage, similar to what will occur during an actual test. The amount of output voltage is dependent on the resistor values as well as the calibration value.

Equation 3-1, found in the BAM-1 unit instruction manual, is used to calculate the simulated strain, $\mu \varepsilon_{C A L}$.

$$
\mu \varepsilon_{C A L}=\frac{R_{g} \cdot C A L S E T}{G F \cdot N}
$$

Where:

$$
\begin{aligned}
& R_{g}=\text { gage resistance (ohms) } \\
& C A L S E T=\text { position of Calibration switch } \\
& G F=\text { exact gage factor of gages } \\
& N=\text { number of fully-active gages. }
\end{aligned}
$$


Based on the strain gage characteristics, the gage resistance is equal to $350 \mathrm{ohms}$. The gage factor for these particular gages is 2.11. Based on the bridge configuration, the number of fully-active gages is equal to 1. Lastly, the Calibration switch on the BAM-1 units was set to 20 , resulting in an output voltage of about 1.6 volts. According to the equation above, the simulated micro-strain is $3317.5 \mu \varepsilon$. This simulated strain value is later used in data processing to convert the output voltage to strain.

\subsubsection{Bars Together}

Once the bridge amplifier units are calibrated, two tests are run on the SHPB without samples. The first test is conducted with the input and output bars together. Performing this test results in a constant wave moving through both the input and output bars without a reflected wave. This allows for a stress correction factor, $K_{o}$, to be calculated as follows:

$$
K_{\sigma}=\frac{\varepsilon_{b(\text { theoretical })}}{\varepsilon_{b \text { (measured })}} \quad \text { Equation 3-2 }
$$

Where:

$$
\begin{aligned}
& \varepsilon_{b(\text { theoretical })}=\text { theoretical strain in } \mathrm{SHPB} \\
& \varepsilon_{b(\text { measured })}=\text { measured strain in SHPB. }
\end{aligned}
$$

The measured value of strain is taken as the average strain during the time of the pulse. The theoretical strain value, $\boldsymbol{\varepsilon}_{b(\text { theortical })}$, is a function of the SHPB bar material and the velocity of the striker bar.

$$
\varepsilon_{b(\text { theoretical })}=\frac{v_{s b}}{2 \cdot c_{b}}
$$

Where:

$$
\begin{aligned}
& v_{s b}=\text { striker bar velocity } \\
& c_{b}=\text { longitudinal wave velocity of SHPB bars. }
\end{aligned}
$$

The stress correction factor is applied during the data analysis process to correct the output wave data. 


\subsubsection{Bars Apart}

The final calibration test is run without a sample, but keeping the input and output bars apart from one another. The "bars apart" test results in the strain gages only recording input and reflected waves because there is no path for the pulse wave to reach the output bar. This allows for a strain correction factor, $K_{\mathcal{E}}$, to be calculated as follows:

$$
K_{\varepsilon}=\frac{\varepsilon_{b(\text { theoretical })}}{\varepsilon_{b(\text { measured })}} \quad \text { Equation 3-4 }
$$

Where:

$$
\begin{aligned}
& \varepsilon_{b(\text { theoretical })}=\text { theoretical strain in } \mathrm{SHPB} \\
& \varepsilon_{b(\text { measured })}=\text { measured strain in } \mathrm{SHPB}
\end{aligned}
$$

The measured value of strain is taken as the average strain during the time of the pulse. The theoretical strain value is calculated using Equation 3-3 above. The strain correction factor is applied during the data analysis process to correct the input and reflected wave data.

\subsubsection{Pulse Shaper}

Prior to any testing, including calibration tests, the selected pulse shaper should be adhered to the impact face of the input bar. A small amount of lube was applied to the C1100 copper pulse shaper and then placed in the center of the open face of the input bar. The placement of the pulse shaper is shown in Figure 3.6. 


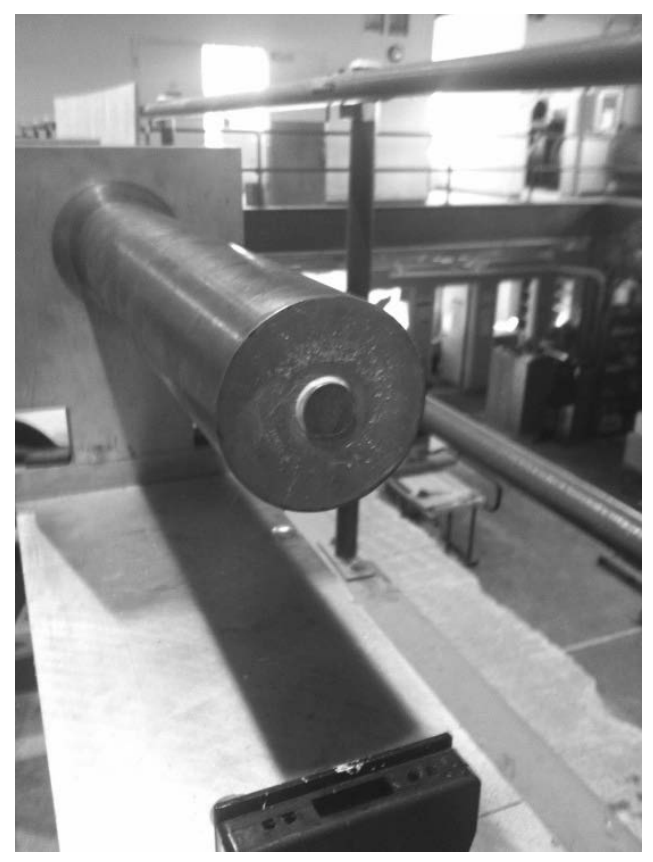

Figure 3.6: Copper pulse shaper placed on impact face of input bar

Four pulse shaper sizes were initially investigated through preliminary testing. These tests considered two thicknesses and two diameters. Table 3.2 shows the pulse shaper sizes used in preliminary testing.

Table 3.2: Preliminary pulse shaper sizes

\begin{tabular}{|c|c|c|}
\hline Pulse Shaper & Thickness (in.) & Diameter (in.) \\
\hline 1 & 0.025 & 0.75 \\
\hline 2 & 0.085 & 0.75 \\
\hline 3 & 0.25 & 1.5 \\
\hline 4 & 0.085 & 1.5 \\
\hline
\end{tabular}

The thicker pulse shaper with the smaller diameter, pulse shaper \#2, was chosen as the sole pulse shaper for further testing, as it presented the most reliable and consistent results for modifying the high strain rate pulse and lengthening the ringing up time.

\subsubsection{Lubricant}

As mentioned in Section 2.1.1.2, friction effects can cause erroneous results during SHPB testing. However, lubricant can reduce the friction at the specimen-bar interfaces. For the research presented herein, DuPont ${ }^{\mathrm{TM}}$ Teflon ${ }^{\circledR}$ Non-Stick Dry-Film Lubricant was used. The 
lubricant was sprayed on the ends of the input and output bars prior to placing the specimen between the bars.

\subsection{Static Testing}

Static testing was performed on the concrete specimens to obtain the static compressive strengths of each mix. This data offers valuable insight when comparing how the concrete behaves dynamically and statically. With this information dynamic increase factors can be calculated for the concrete materials. Static testing on the NSC specimens was performed according to the specifications outlined in ASTM C39 Standard Test Method for Compressive Strength of Cylindrical Concrete Specimens. Static testing of UHPC specimens was performed using an increased loading rate as described by Peuse (2008). 


\section{Chapter 4 Analytical Methodology}

\subsection{Data Processing}

Along with proper experimental design and SHPB configuration, data processing is an essential step in SHPB testing. Not only does the analyzed data reveal the dynamic material behavior that is desired, but it also reassures the legitimacy of the testing procedures and confirms previous work in the field.

The acquired data from the Picoscope, which displays voltage for each channel over time, was imported into an analysis program using Microsoft Office Excel. The program used for this research is a modified version of the spreadsheet developed by Gilbertson (2011). In an effort to streamline the process of data analysis and organization thereof, multiple spreadsheets were combined into a single workbook to serve as a template for each individual test. The following subsections provide an overview of the analysis program and each component within it.

\subsubsection{Properties}

The first worksheet in the program, titled "Properties", is meant to provide specific information relevant to each test. This includes unique test identification along with specimen and SHPB equipment constants. The input values are then used further along in the analysis when necessary. Many of these values do not change from test to test, such as material constants of the SHPB equipment. However, this section of the program provides a snapshot view of all of the properties being used in the analysis. Also included is specific information related to testing, such as the striker bar length being used and the cannon pressure. The measured striker velocity is also input in this worksheet. Figure 4.1 shows a screenshot of the aforementioned Properties worksheet. 


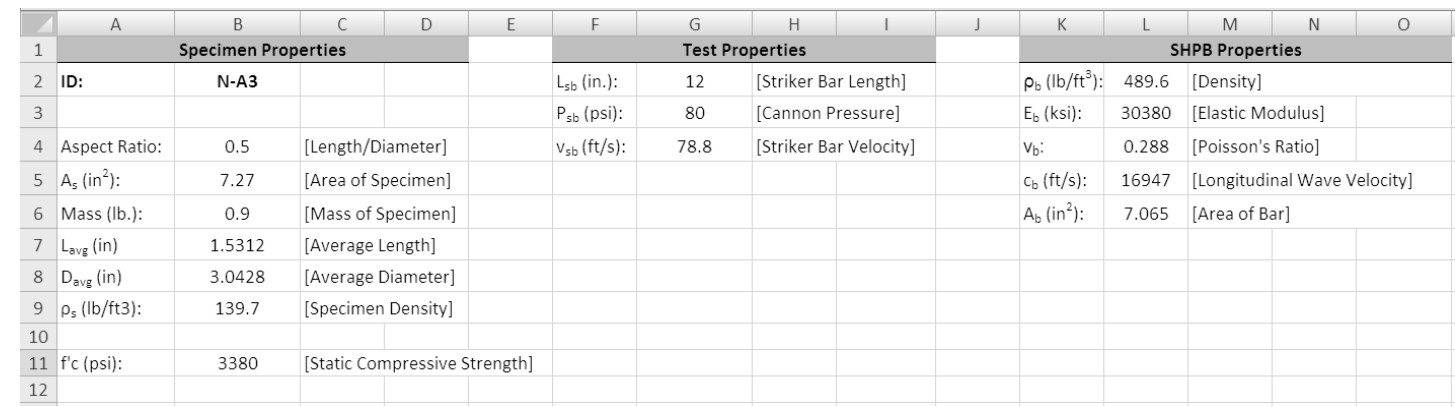

Figure 4.1: Screenshot of Properties worksheet in SHPB Excel program

\subsubsection{Raw Data}

The next worksheet is dedicated solely to the raw data retrieved from the Picoscope software and copied into the spreadsheet. Combining and organizing the test data into a single file is important because the raw data is saved in individual files through the data acquisition software. The three sets of data shown in Figure 4.2 represent the typical raw data acquired by the Picoscope during the individual test along with 2 sets of calibration data from SHPB tests conducted with the bars apart and the bars together without a specimen in place.

\begin{tabular}{|c|c|c|c|c|c|c|c|c|c|c|c|c|c|c|c|c|c|}
\hline & A & B & c & D & $\mathrm{E}$ & $\mathrm{F}$ & G & $\mathrm{H}$ & 1 & J & k & L & M & $\mathrm{N}$ & 0 & $p$ & Q \\
\hline 1 & \multicolumn{5}{|c|}{ N-A3 } & & \multicolumn{5}{|c|}{ Bars Apart Data } & & \multicolumn{5}{|c|}{ Bars Together Data } \\
\hline 2 & Time & Channel A & Channel B & Channel C & Channel D & & Time & Channel A & Channel B & Channel C & $\begin{array}{l}\text { Channel D } \\
\text {. }\end{array}$ & & Time & Channel A & Channel B & Channel C & Channel D \\
\hline 3 & (ms) & (V) & (V) & (V) & (V) & & (ms) & (V) & (V) & (V) & (V) & & (ms) & (V) & (V) & (V) & (V) \\
\hline 4 & & & & & & & & & & & & & & & & & \\
\hline 5 & -0.2006 & 0.0207545 & 0.0103772 & 0.0598218 & -0.1098767 & & -0.2007 & 0.1294103 & 0.017092 & 0.144671 & -0.03907 & & -0.200672 & 0.1086558 & 0.006715 & 0.0952265 & -0.02869 \\
\hline 6 & -0.1996 & 0.0207545 & 0.0134294 & 0.0598218 & -0.1135392 & & -0.1997 & 0.1294103 & 0.010377 & 0.137956 & -0.03907 & & -0.199672 & 0.1190331 & 0.010377 & 0.0848492 & -0.017702 \\
\hline 7 & -0.1986 & 0.0207545 & 0.0103772 & 0.0598218 & -0.1135392 & & -0.1987 & 0.1294103 & 0.017092 & 0.141008 & -0.03907 & & -0.198672 & 0.1153705 & 0.010377 & 0.0915639 & -0.035405 \\
\hline 8 & -0.1976 & 0.0311317 & 0.0134294 & 0.0598218 & -0.1135392 & & -0.1977 & 0.1367354 & 0.013429 & 0.130631 & -0.03907 & & -0.197672 & 0.111708 & 0.006715 & 0.0848492 & -0.035405 \\
\hline 9 & -0.1966 & 0.0207545 & 0.0030521 & 0.0598218 & -0.1098767 & & -0.1967 & 0.1330729 & 0.020754 & 0.144671 & -0.0354 & & -0.196672 & 0.1013307 & 0.010377 & 0.0915639 & -0.039067 \\
\hline 10 & -0.1956 & 0.0207545 & 0.0134294 & 0.0561592 & -0.1098767 & & -0.1957 & 0.1330729 & 0.006715 & 0.141008 & -0.03907 & & -0.195672 & 0.1049933 & 0.010377 & 0.0811867 & -0.032353 \\
\hline 11 & -0.1946 & 0.0347943 & 0.0103772 & 0.0634843 & -0.1165914 & & -0.1947 & 0.1367354 & 0.013429 & 0.137956 & -0.0354 & & -0.194672 & 0.1013307 & 0.006715 & 0.0879014 & -0.032353 \\
\hline 12 & -0.1936 & 0.024417 & 0.0170919 & 0.0561592 & -0.1135392 & & -0.1937 & 0.1153 & 0.013429 & 0.130631 & -0.03907 & & -0 . & 0.1013307 & 0.006715 & 0.0915639 & -0.032353 \\
\hline 13 & -0.1926 & 0.0311317 & 0.0067147 & 0.0634843 & -0.1165914 & & -0.1927 & 0.1257478 & 0.006715 & 0.134294 & -0.0354 & & -0.192672 & 0.1013307 & 0.017092 & 0.0915639 & -0.039067 \\
\hline 14 & -0.1916 & 0.024417 & 0.0103772 & 0.0598218 & -0.1062141 & & -0.1917 & 0.1257478 & 0.010377 & 0.134294 & -0.03235 & & -0.191672 & 0.1153705 & 0.006715 & 0.0879014 & -0.025027 \\
\hline 15 & -0.1906 & 0.024417 & 0.0030521 & 0.0494445 & -0.1135392 & & -0.1907 & 0.1257478 & 0.006715 & 0.144671 & -0.02869 & & -0.190672 & 0.0976682 & 0.006715 & 0.0848492 & -0.035405 \\
\hline 16 & -0.1896 & 0.024417 & 0.0067147 & 0.0524966 & -0.1098767 & & -0.1897 & 0.1257478 & 0.003052 & 0.141008 & -0.03907 & & -0.189672 & 0.0976682 & 0.003052 & 0.0738616 & -0.032353 \\
\hline 17 & -0.1886 & 0.0134294 & 0.0067147 & 0.0598218 & -0.1062141 & & -0.1887 & 0.1226956 & 0.010377 & 0.137956 & -0.03907 & & -0.188672 & 0.111708 & 0.013429 & 0.0775241 & -0.035405 \\
\hline 18 & -0.1876 & 0.024417 & 0.0134294 & 0.0671469 & -0.1098767 & & -0.1877 & 0.1294103 & 0.017092 & 0.137956 & -0.03907 & & -0.187672 & 0.0976682 & 0.013429 & 0.0671469 & -0.032353 \\
\hline 19 & -0.1866 & 0.0207545 & 0.0067147 & 0.0598218 & -0.1025516 & & -0.1867 & 0.1226956 & 0.006715 & 0.137956 & -0.03907 & & -0.186672 & 0.1049933 & 0.003052 & 0.070199 & -0.032353 \\
\hline 20 & -0.1856 & 0.0170919 & 0.0067147 & 0.0561592 & -0.1239165 & & -0.1857 & 0.1330729 & 0.017092 & 0.144671 & -0.03907 & & -0.185672 & 0.1013307 & 0.006715 & 0.0634843 & -0.032353 \\
\hline 21 & -0.1846 & 0.024417 & 0.0134294 & 0.0671469 & -0.1202539 & & -0.1847 & 0.1257478 & 0.006715 & 0.134294 & -0.02869 & & -0.184672 & 0.1153705 & 0.010377 & 0.0738616 & -0.021365 \\
\hline 22 & -0.1836 & 0.024417 & 0.0134294 & 0.0671469 & -0.1098767 & & -0.1837 & 0.1257478 & 0.017092 & 0.134294 & -0.0354 & & -0.183672 & 0.1086558 & 0.006715 & 0.0738616 & -0.046392 \\
\hline
\end{tabular}

Figure 4.2: Screenshot of Raw Data worksheet in SHPB Excel program 


\subsubsection{BAM Data}

Similar to the Raw Data worksheet, the BAM Data worksheet is a collection of data acquired from the Picoscope software displaying the shunted voltage values for each BAM-1 unit. An average of these shunted values is taken for each channel for use in converting the measured output voltage to strain in the SHPB bars. Because the calibration procedures are performed for each day of testing, the BAM data will not frequently change between individual tests.

However, this worksheet is still useful for each test as a point of quick reference and consistency. Figure 4.3 is a screenshot of the BAM data worksheet.

\begin{tabular}{|c|c|c|c|c|c|c|c|c|c|c|}
\hline 4 & A & B & C & D & $E$ & $\mathrm{~F}$ & G & H & 1 & $」$ \\
\hline 1 & \multicolumn{10}{|c|}{ BAM Calibration Data } \\
\hline 2 & Time & Channel A & Channel B & Channel $\mathrm{C}$ & Channel D & & Channel A & Channel B & Channel C & Channel D \\
\hline 3 & (s) & (V) & (V) & (V) & (V) & & (V) & (V) & (V) & (V) \\
\hline \multicolumn{11}{|l|}{4} \\
\hline 5 & 0 & 0.0031742 & 0.0073251 & -0.010011 & 0.0041509 & & 1.59858 & 1.59004 & 1.61006 & 1.593945 \\
\hline 6 & 0.003053 & 0.0019534 & 0.0073251 & -0.013185 & 0.0019534 & & 1.59858 & 1.58882 & 1.61006 & 1.592724 \\
\hline 7 & 0.006106 & 0.0009767 & 0.008546 & -0.011964 & 0.0019534 & & 1.59761 & 1.58784 & 1.60786 & 1.593945 \\
\hline 8 & 0.009159 & 0.0019534 & 0.0073251 & -0.011964 & 0.0041509 & & 1.59639 & 1.58882 & 1.60908 & 1.593945 \\
\hline 9 & 0.012212 & 0.0009767 & 0.0073251 & -0.011964 & 0.0019534 & & 1.59761 & 1.58882 & 1.60908 & 1.591747 \\
\hline 10 & 0.015265 & 0.0019534 & 0.0073251 & -0.011964 & 0.0031742 & & 1.59981 & 1.59004 & 1.60689 & 1.593945 \\
\hline 11 & 0.018318 & 0.0019534 & 0.0073251 & -0.013185 & 0.0053718 & & 1.59639 & 1.59004 & 1.61006 & 1.592724 \\
\hline 12 & 0.021371 & 0.0009767 & 0.008546 & -0.011964 & 0.0053718 & & 1.59639 & 1.58784 & 1.60786 & 1.593945 \\
\hline 13 & 0.024424 & 0.0019534 & 0.008546 & -0.011964 & 0.0041509 & & 1.59639 & 1.59004 & 1.61006 & 1.592724 \\
\hline 14 & 0.027477 & 0.0019534 & 0.0073251 & -0.010011 & 0.0041509 & & 1.59761 & 1.58882 & 1.60908 & 1.591747 \\
\hline 15 & 0.03053 & 0.0019534 & 0.0063484 & -0.015383 & 0.0053718 & & 1.59981 & 1.58882 & 1.60908 & 1.593945 \\
\hline 16 & 0.033583 & 0.0009767 & 0.008546 & -0.011964 & 0.0041509 & & 1.59858 & 1.58662 & 1.60786 & 1.593945 \\
\hline 17 & 0.036636 & 0.0019534 & 0.008546 & -0.011964 & 0.0041509 & & 1.59981 & 1.58784 & 1.60786 & 1.591747 \\
\hline 18 & 0.039689 & 0.0031742 & 0.0073251 & -0.013185 & 0.0041509 & & 1.59639 & 1.58882 & 1.60908 & 1.592724 \\
\hline 19 & 0.042742 & 0.0019534 & 0.0073251 & -0.011964 & 0.0041509 & & 1.59639 & 1.58784 & 1.60908 & 1.592724 \\
\hline 20 & 0.045795 & 0.0019534 & 0.008546 & -0.013185 & 0.0041509 & & 1.59858 & 1.58882 & 1.61006 & 1.593945 \\
\hline 21 & 0.048848 & 0.0019534 & 0.0073251 & -0.010988 & 0.0041509 & & 1.59981 & 1.58882 & 1.60908 & 1.591747 \\
\hline 22 & 0.051901 & 0.0009767 & 0.0073251 & -0.015383 & 0.0031742 & & & & & \\
\hline 23 & 0.054954 & 0.0019534 & 0.0073251 & -0.00879 & 0.0041509 & & 1.59788702 & 1.588816951 & 1.610024073 & 1.593123024 \\
\hline
\end{tabular}

Figure 4.3: Screenshot of BAM Calibration worksheet in SHPB Excel program

\subsubsection{Calibration}

The Calibration worksheet is the last set of calculations needed before the primary analysis takes place. It pulls information from the previous worksheets and performs the necessary calculations needed to convert output voltage in the strain gages to strain in the SHPB bars. Using Equation 3-1 and properties specific to the strain gages being used and the BAM-1 unit settings, a conversion factor for each channel is developed to obtain strain values. Figure 4.4 displays the Calibration worksheet and the conversion being calculated. 


\begin{tabular}{|c|c|c|c|c|c|c|c|c|c|}
\hline 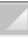 & A & B & C & D & $\mathrm{E}$ & $\mathrm{F}$ & G & $\mathrm{H}$ & 1 \\
\hline 1 & \multicolumn{2}{|c|}{ Simulated Strain } & & & \multicolumn{5}{|c|}{ Voltage/ $\mu \varepsilon$ Conversion } \\
\hline 2 & GF: & 2.11 & & & & Channel A & Channel B & Channel C & Channel D \\
\hline 3 & Rg (ohms): & 350 & & & Voltage & 1.597887024 & 1.588816951 & 1.610024073 & 1.593123024 \\
\hline 5 & CalSet: & 20 & & & & & & & \\
\hline 6 & & & & & $\mu \varepsilon / V$ Conversion: & 2076.2 & 2088.1 & 2060.6 & 2082.4 \\
\hline 9 & & & & & & & & & \\
\hline
\end{tabular}

Figure 4.4: Screenshot of Calibration worksheet in SHPB Excel program

\subsubsection{Analysis}

The final worksheet, aside from various graphs and outputted displays, consists of incorporating the calibration and material properties previously described. Essentially, this spreadsheet completes the analysis of the specimen that was tested in the SHPB and outputs the stress, strain, and strain rate values based on one-dimensional wave propagation theory over a given time period, as presented in Section 2.1.2.

Several graphs are presented throughout the analysis process as a result of the data processing. These plots aid in the analysis process as well as graphically presenting the data to better depict the experimental results. The first graph, shown below, shows the outputted raw data, as seen on the Picoscope. Each line represents a channel, or a pair of strain gages, on either the input or output bar of the SHPB equipment. During the test, changes in voltage are recorded and outputted to the oscilloscope as displayed in Figure 4.5. 


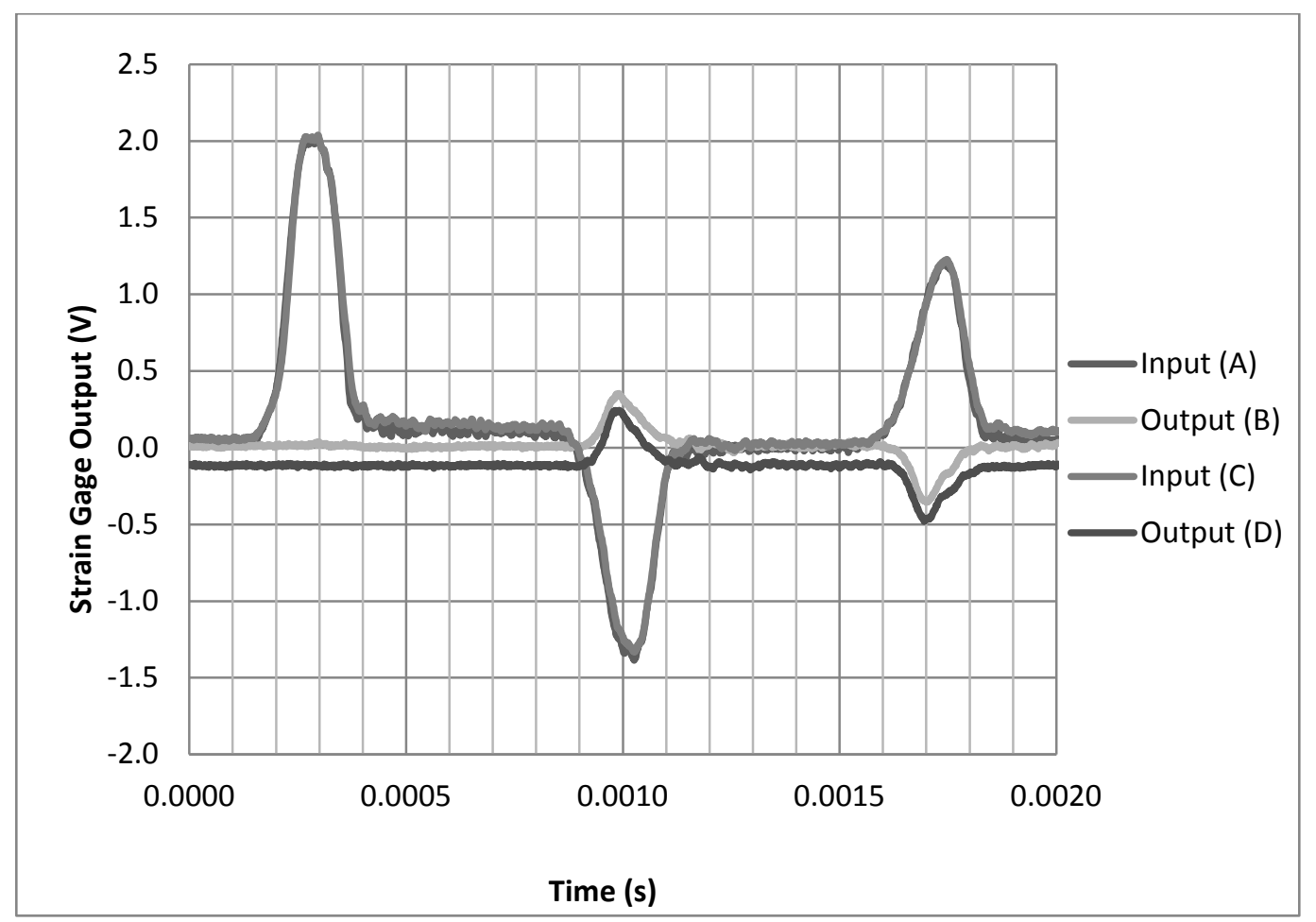

Figure 4.5: Strain gage output (voltage versus time) in SHPB per channel

Similar to the strain gage output, the SHPB strain graph illustrates the same wave types. However, instead of change in voltage, the data has been converted to strain in the SHPB bars, using Equation 3-1 (Figure 4.6). These strain values have been corrected for any misbalance in the BAM units, as described in Section 3.1.5.1. Also note, the SHPB equipment is verified through a comparison between the various strain gage channels, with one overlaying the other. 


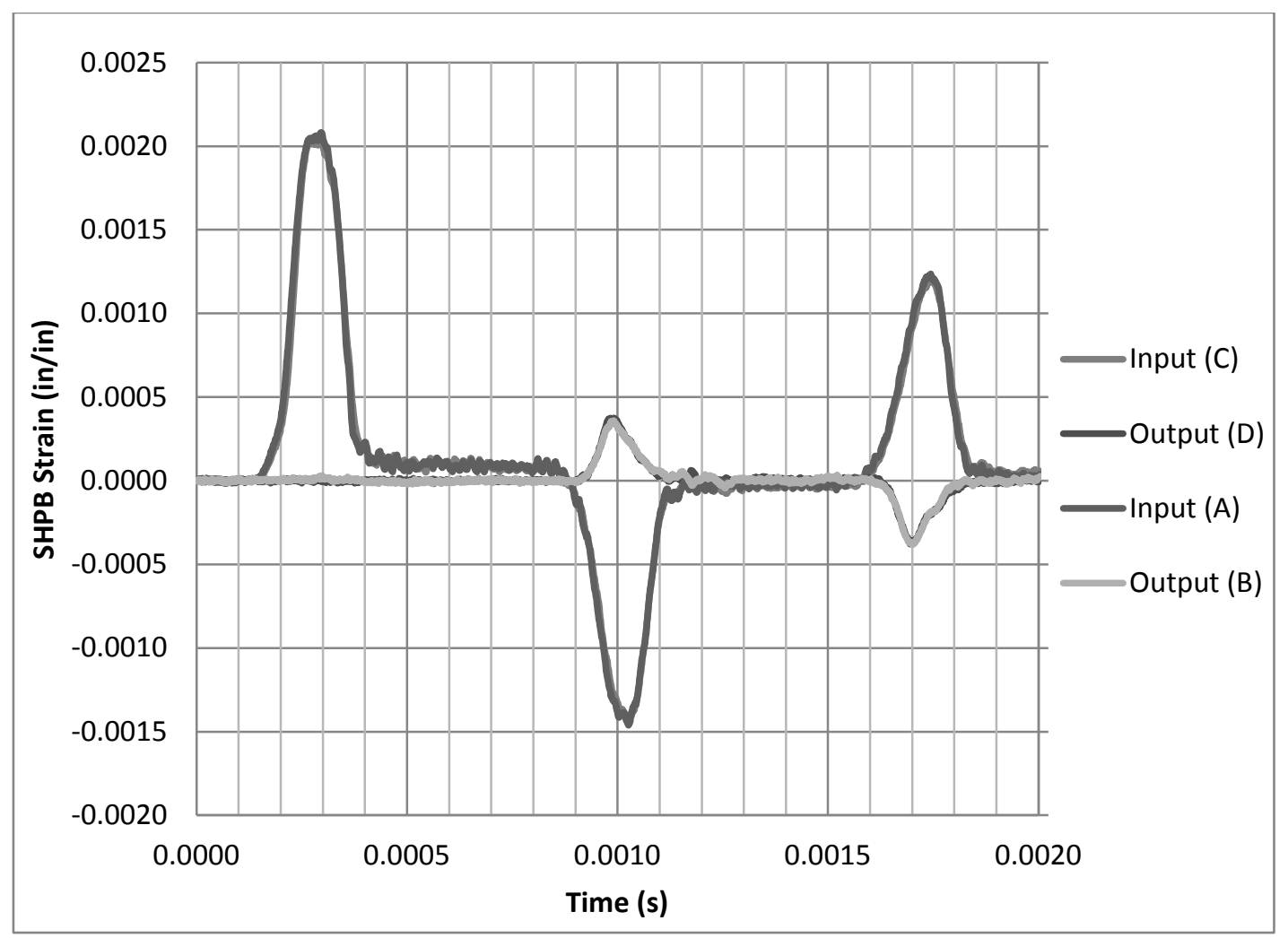

Figure 4.6: Strain versus time in the SHPB

The analysis worksheet also performs the same data manipulation for the "bars apart" and "bars together" calibration tests. The worksheet calls the data from the bars apart calibration test discussed in Section 3.1.5.3, and performs one-dimensional wave propagation analysis on the SHPB system data. With this data, strain correction factors for the input and reflected strain values are determined using Equation 3-4. Similarly, the worksheet uses the data acquired from the bars together calibration test discussed in Section 3.1.5.2 to calculate a stress correction factor for the output waves. Screenshots of the Analysis worksheet are shown in Figure 4.7. Some components vary between calibration tests and actual specimen tests. However, the data processing procedure remains the same. 


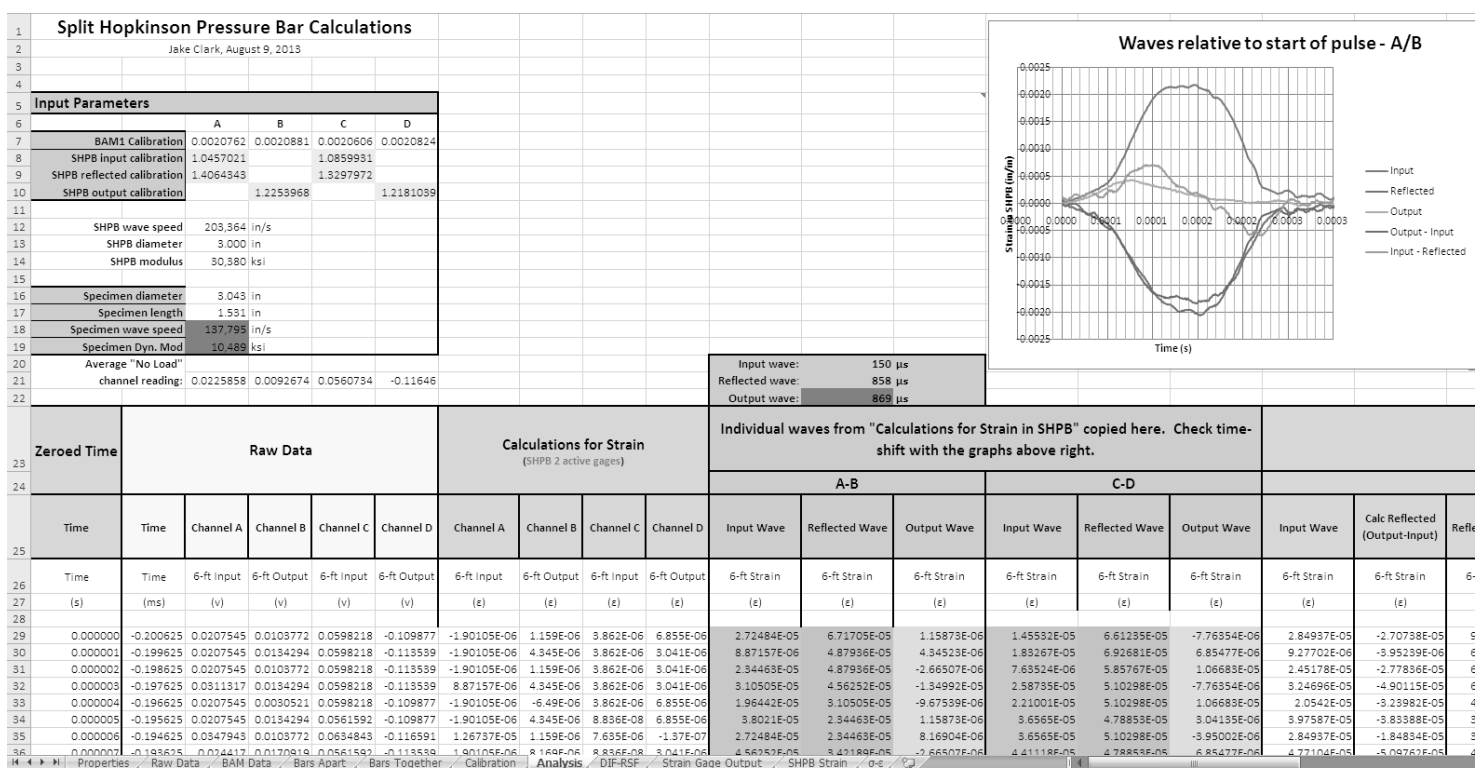

Figure 4.7: Screenshot of Analysis worksheet in SHPB Excel program

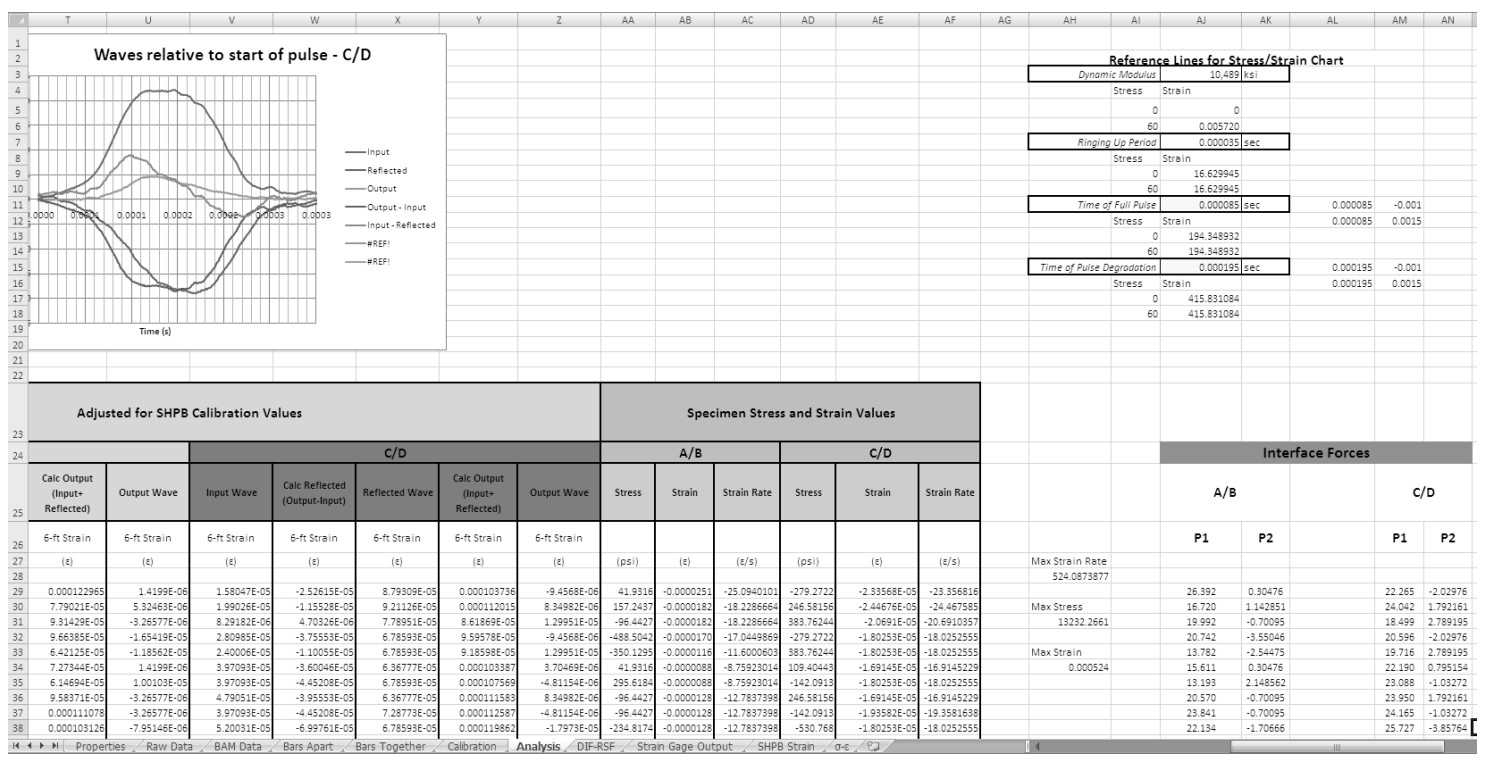

Figure 4.7, continued.

Although this worksheet gathers a large amount of information from each of the previous worksheets, there are a few manual steps that must be taken to properly analyze the dynamic response of the specimen. The main step that must be completed manually is to identify the individual waves within the data and separate them out. After the raw data is converted from 
voltage to strain, the individual waves are located and copy and pasted to their respective columns. It is essential to use the "Paste Special" function in Excel and paste only the values. This eliminates any issues associated with altering the built-in formulas and calculations.

Once the individual waves are located, they are each graphed relative to the pulse at a zeroed time for each channel group (A/B or C/D), as shown in Figure 4.8.

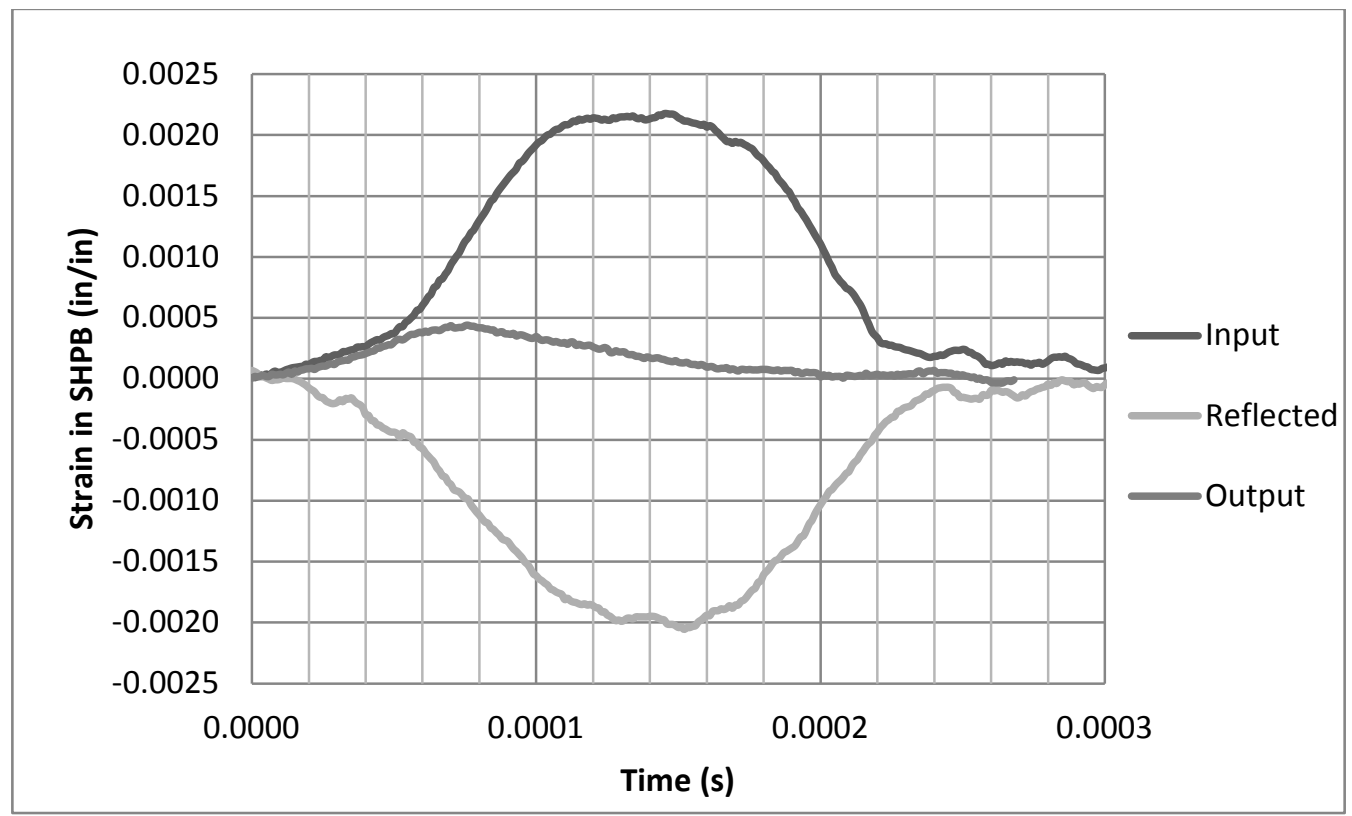

Figure 4.8: Strain versus time for the individual waves in the SHPB - Channels A/B, typical

Visual inspection of strain versus time, such as shown in Figure 4.8, allows each wave to be checked to ensure that the time shift is correct and each wave was properly located. This time shift could vary based on what material is being tested and how long it takes for the pulse wave to pass from one end of the specimen to the other. The respective correction factors are then applied to the individual waves; the input, output, and reflected waves. From these corrected values of strain measured in the SHPB, the specimen strain, stress, and strain rate are back calculated using the Equations 2-3, 2-4, and 2-5, respectively. The strain values for the input and reflected waves are used to calculate the strain in the sample, while the output wave strain values are used to calculate the specimen stresses. 


\subsubsection{Dynamic Increase Factor Analysis}

Using current data from this research and previous research of DIFs for concrete, the influence of strain rate on compressive strength can be compared. The dynamic increase factor is defined as:

$$
D I F=\frac{\sigma_{d}}{\sigma_{s}} \quad \text { Equation } 4-1
$$

Where:

$$
\begin{aligned}
& \sigma_{d}=\text { ultimate dynamic stress } \\
& \sigma_{s}=\text { ultimate static stress. }
\end{aligned}
$$

For each sample tested, a DIF is calculated using the maximum dynamic stress achieved during SHPB testing and the average static compressive strength of the concrete. These calculated DIFs are presented and compared to previous research in the next chapter. 


\section{Chapter 5 Discussion and Results}

\subsection{NSC Results}

The SHPB results of the normal strength concrete (NSC) samples are presented in this section. For NSC, 3 samples were tested for the 2:1 aspect ratio, 6 samples for the 1:1 aspect ratio, and 8 samples for 0.5:1 aspect ratio. Data for sample N-A6 was disregarded because the specimen slipped prior to impact and was therefore not properly tested.

Visually, each NSC sample was extremely fragmented following each test. Only very small

pieces of cement paste and aggregate remained after impact, as shown in Figure 5.1. For the longer samples, at the 2:1 aspect ratio, there was slightly less fragmentation and a few unbroken aggregates (about $1 / 2$ inch in diameter). However, these larger unbroken pieces were very rare.

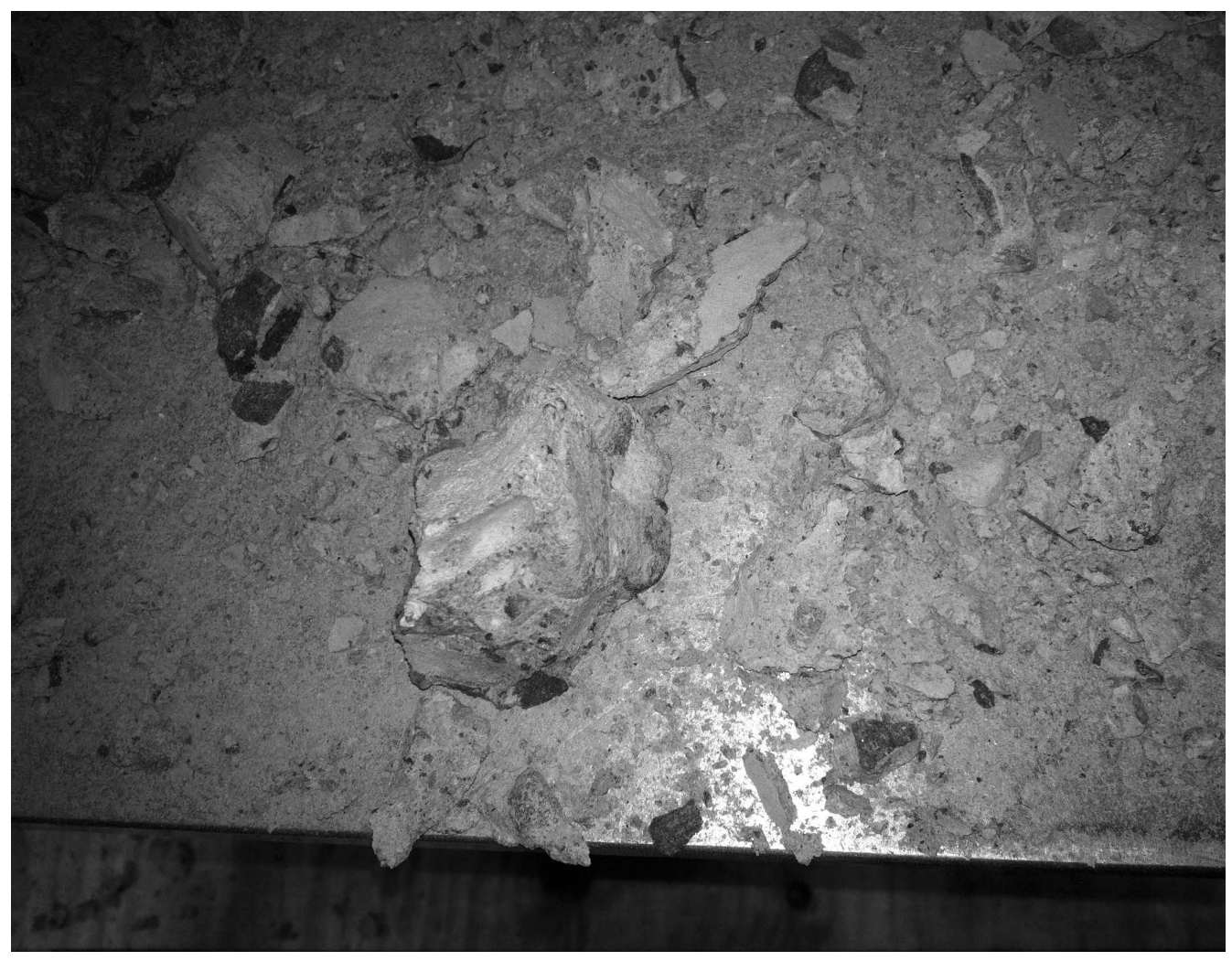

Figure 5.1: Typical NSC fragmentation following SHPB test 
As presented in Section 2.1.2, the specimen stress and strain curves are calculated using onedimensional wave propagation theory. These values of specimen stress and strain are then plotted to obtain a dynamic stress-strain curve for each sample. Figure 5.2 is a typical dynamic stress-strain curve for one of the NSC samples.

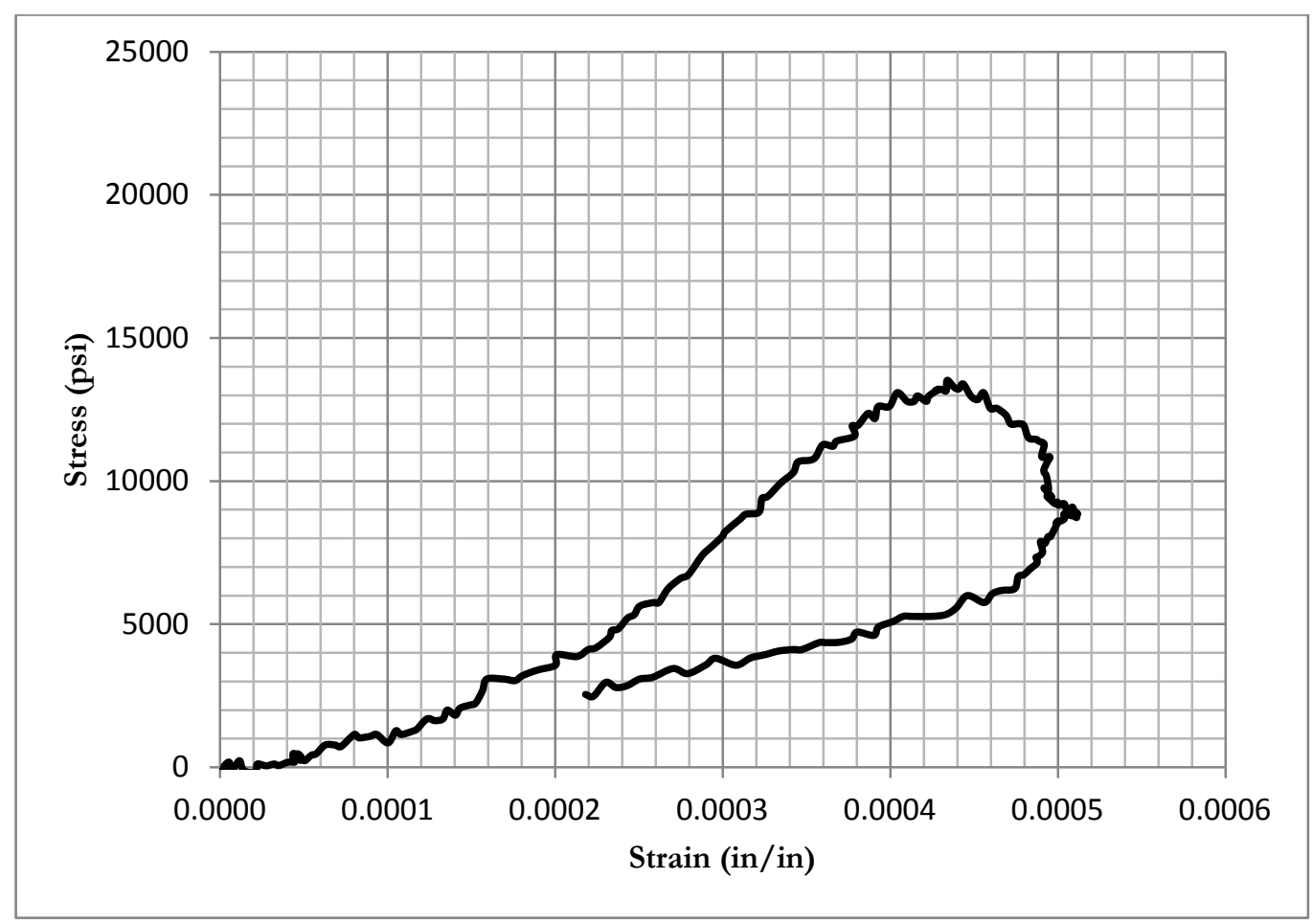

Figure 5.2: Typical dynamic stress-strain curve for NSC with 0.5:1 aspect ratio (sample N-A8)

Overall, the dynamic stress-strain curves for the normal strength concrete cylinders maintained similar trends. Each curve features a concave segment at the beginning followed by the curve moving to the right, or clockwise, and back down toward zero. This curve shape is expected because concrete is a heterogeneous material that features micro cracks. During a static compressive strength test, the stress propagates through the micro cracks causing larger cracks and eventually failure. At elevated strain rates, these micro cracks close prior to the material entering the elastic range, creating an initial concave shape.

Table 5.1 presents a summary of the results acquired from the SHPB tests on each NSC sample. The group average, standard deviation and coefficient of variation are also tabulated. 
In general, the results for NSC tests were consistent, as shown by the coefficient of variations (COV) less than 10\% for ultimate stress and maximum strain results. Note that samples marked with an asterisk did not meet parallelness tolerance recommendations and were not included in the statistical analysis.

Table 5.1: Dynamic stress and strain data for NSC samples

\begin{tabular}{|c|c|c|c|c|c|}
\hline $\begin{array}{l}\text { Aspect } \\
\text { Ratio }\end{array}$ & ID & $\begin{array}{c}\text { Ultimate } \\
\text { Stress (psi) }\end{array}$ & $\begin{array}{c}\text { Max. Strain Rate } \\
(1 / \mathrm{sec})\end{array}$ & $\begin{array}{l}\text { Max. } \\
\text { Strain } \\
\text { (in/in) }\end{array}$ & $\begin{array}{c}\text { Strain@ } \\
\text { Ultimate Stress } \\
(\text { in } / \text { in })\end{array}$ \\
\hline \multirow{6}{*}{$2: 1$} & N-C1 & 11834 & 128.8 & 0.000128 & 0.000113 \\
\hline & N-C2* & 10605 & 139.3 & 0.000139 & 0.000135 \\
\hline & $\mathrm{N}-\mathrm{C} 3$ & 13646 & 144.3 & 0.000144 & 0.000130 \\
\hline & Avg. & 12740 & 136.6 & 0.000136 & 0.000122 \\
\hline & Std. Dev. & 906 & 7.8 & 0.000008 & 0.000009 \\
\hline & $\mathrm{COV}$ & 0.071 & 0.057 & 0.059 & 0.070 \\
\hline \multirow{9}{*}{$1: 1$} & N-B1* & 11546 & 287.0 & 0.000287 & 0.00024 \\
\hline & N-B2 & 12846 & 282.0 & 0.000282 & 0.00022 \\
\hline & N-B3* & 11053 & 275.8 & 0.000276 & 0.00025 \\
\hline & N-B4 & 12536 & 293.1 & 0.000293 & 0.00019 \\
\hline & N-B5 & 11617 & 269.2 & 0.000296 & 0.00024 \\
\hline & N-B6* & 13021 & 288.0 & 0.000288 & 0.00026 \\
\hline & Avg. & 12333 & 281.4 & 0.000290 & 0.00022 \\
\hline & Std. Dev. & 522 & 9.8 & 0.000006 & 0.00002 \\
\hline & $\mathrm{COV}$ & 0.042 & 0.035 & 0.021 & 0.095 \\
\hline \multirow{11}{*}{$0.5: 1$} & N-A1* & 11762 & 549 & 0.000549 & 0.00053 \\
\hline & N-A2 & 13538 & 502 & 0.0005 & 0.00038 \\
\hline & N-A3 & 13232 & 524 & 0.00052 & 0.00046 \\
\hline & N-A4* & 15094 & 529 & 0.000529 & 0.00050 \\
\hline & N-A5* & 12662 & 558 & 0.000558 & 0.00048 \\
\hline & N-A6 & $\mathrm{x}$ & $\mathrm{x}$ & $\mathrm{x}$ & $\mathrm{x}$ \\
\hline & N-A7 & 14010 & 510 & 0.00051 & 0.00051 \\
\hline & N-A8 & 13523 & 512 & 0.000512 & 0.00050 \\
\hline & Avg. & 13576 & 512.0 & 0.000511 & 0.00046 \\
\hline & Std. Dev. & 279 & 7.9 & 0.000007 & 0.00005 \\
\hline & $\mathrm{COV}$ & 0.021 & 0.015 & 0.014 & 0.111 \\
\hline
\end{tabular}

*Sample did not meet parallelness tolerance 
From these results, the most noticeable similarity between the aspect ratios of the specimens is the ultimate stress. The ultimate stress varies by about $1000 \mathrm{psi}$ (7-8\%) across all aspect ratios, with the largest stresses appearing within the shorter specimens. Another important trend of the results to note is that a shorter sample reaches a higher strain rate. The changes in strain and strain rate across the various sample lengths are due to the fact that both of these values are functions of specimen length according to one-dimensional wave propagation theory. However, Table 5.1 reveals the consistency between samples within each aspect ratio for all values of stress, strain and strain rate.

\subsection{UHPC Results}

The following sections describe the results of the ultra-high performance concrete specimens, both ambient cured and thermally treated. Visually, the UHPC specimens experienced much less fragmentation and remained fairly intact. Figures 5.3 - 5.5 show typical fractures of UHPC specimens for each aspect ratio.

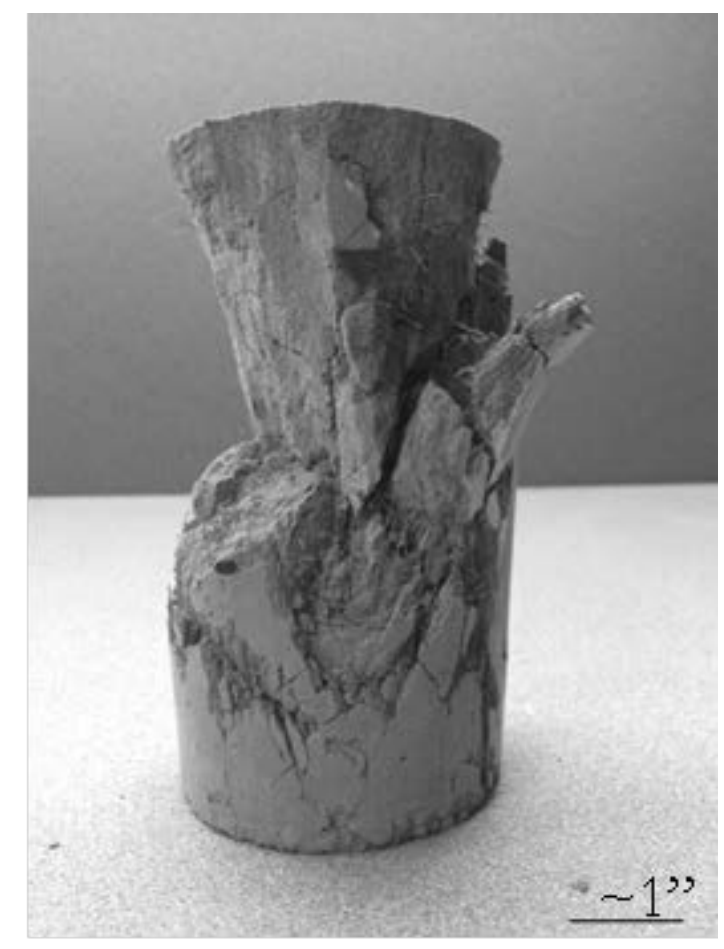

Figure 5.3: Typical fracture for UHPC at 2:1 aspect ratio 


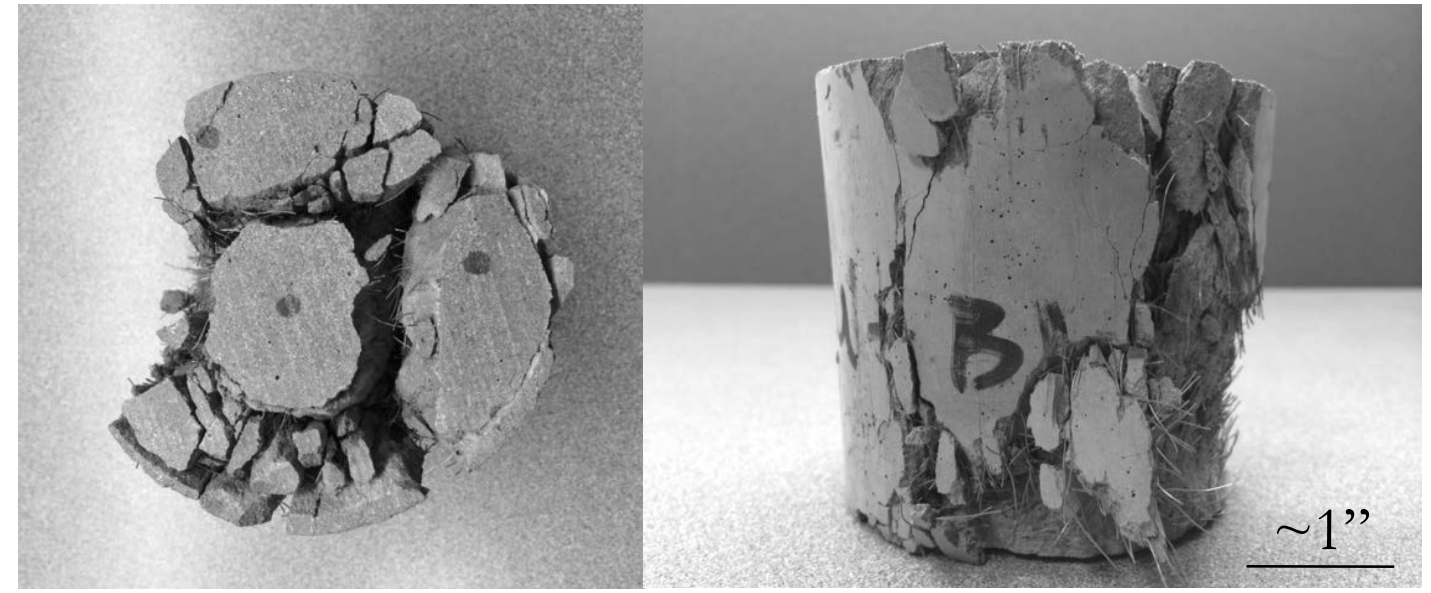

Figure 5.4: Typical fracture of UHPC at 1:1 aspect ratio

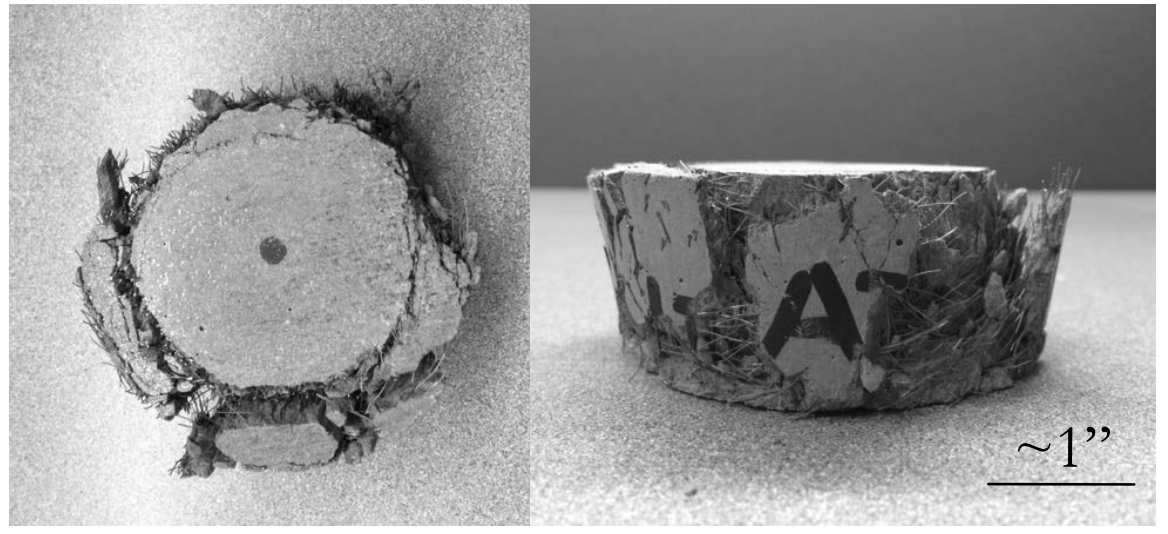

Figure 5.5: Typical fracture of UHPC at 0.5:1 aspect ratio

\subsubsection{Ambient Cured UHPC}

The results of the ambient cured UHPC samples are presented in this section. For these samples, 3 samples were tested for the 2:1 aspect ratio, 7 samples for the 1:1 aspect ratio, and 8 samples for 0.5:1 aspect ratio. Data for sample U-A2-AMB was inadvertently not recorded.

Using the same data processing methods as the NSC samples, the dynamic stress-strain curves were graphed for the ambient UHPC samples. A representative plot for ambient UHPC specimens with aspect ratios of 0.5:1 (from sample U-A4-AMB) is shown in Figure 5.6. 


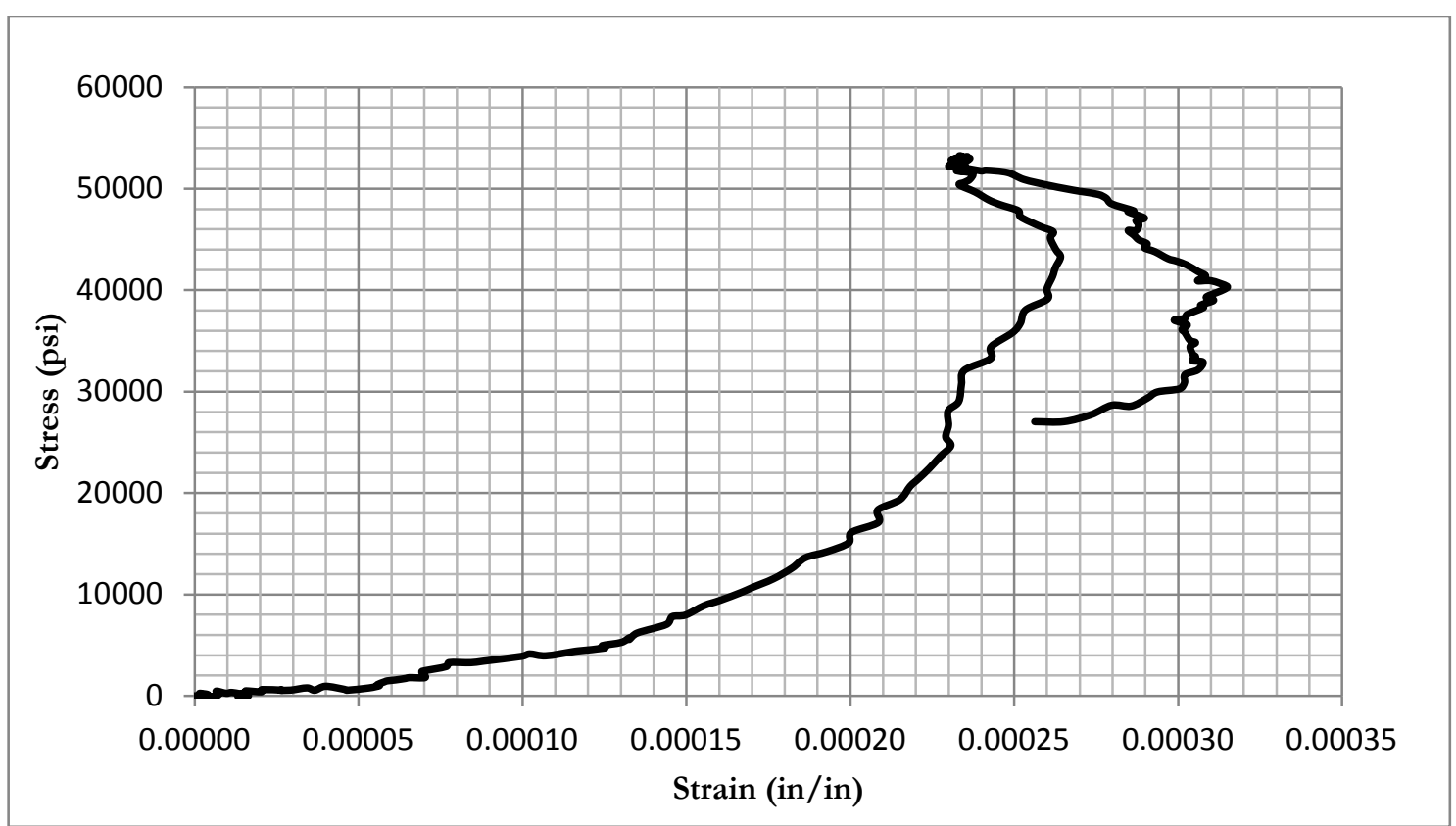

Figure 5.6: Typical dynamic stress-strain curve for ambient cured UHPC at a 0.5:1 aspect ratio

The above dynamic stress-strain curve for ambient cured UHPC at a $0.5: 1$ aspect ratio is similar in shape to the aforementioned NSC curve. However, the stresses are much higher, about a 370\% increase, and the strains are smaller, about a 36\% decrease. The curve also continues to the right, or clockwise, after reaching ultimate. There was some discrepancy for the UHPC samples for this curve characteristic. For specimens remaining fairly intact, curves continued to the left, or counterclockwise, after reaching maximum stress, exhibiting the ability to absorb impact energy. Aside from higher compressive strengths, UHPC's ability to absorb energy without totally failing can be credited to the steel fibers to keep the UHPC specimens intact. The next two dynamic stress-strain curves better illustrate the effect of the steel fibers within the UHPC. Figure 5.7 and Figure 5.8 represent the 1:1 and 2:1 aspect ratios, respectively. 


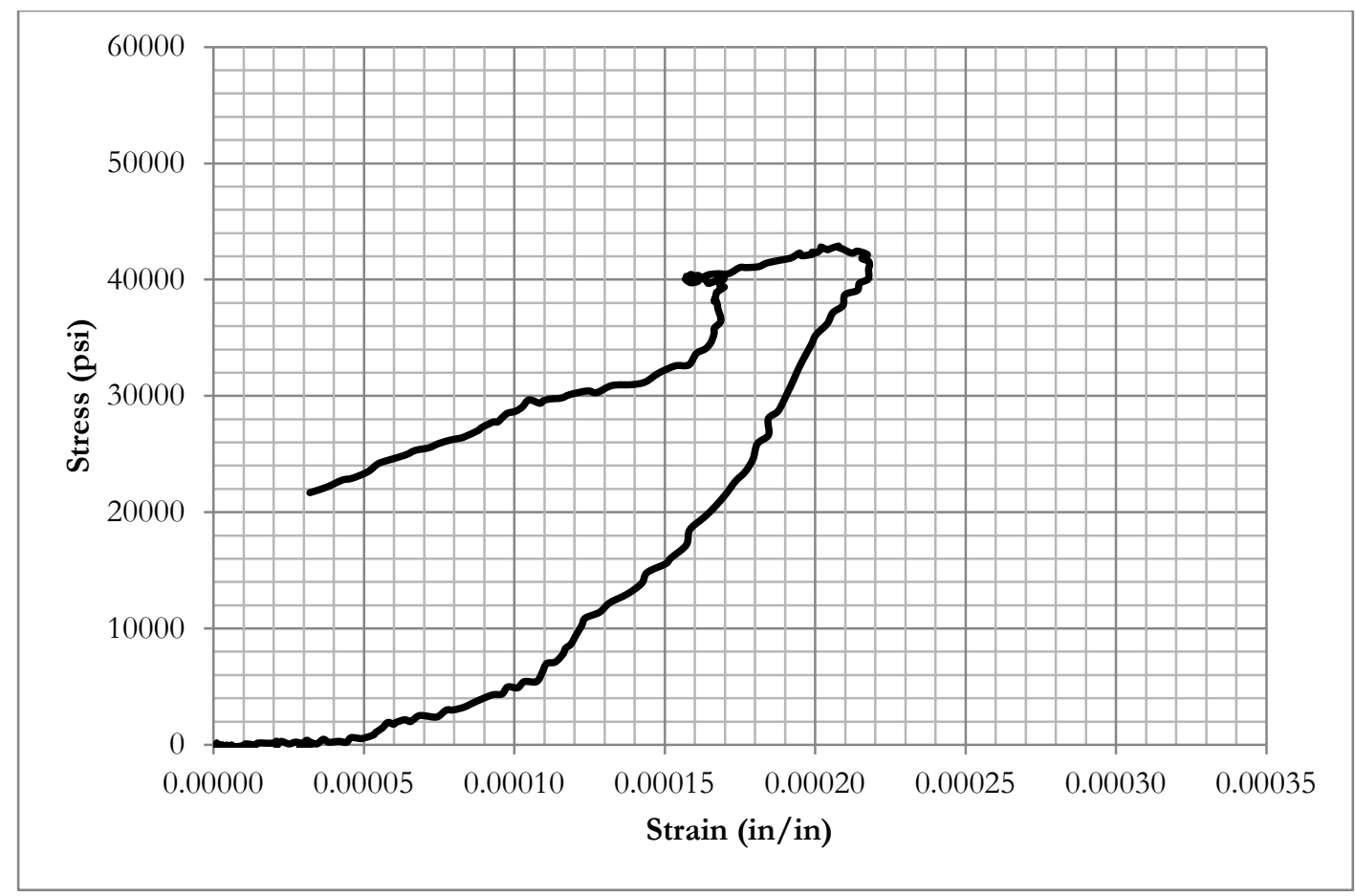

Figure 5.7: Typical dynamic stress-strain curve for sample ambient cured UHPC at a 1:1 aspect ratio

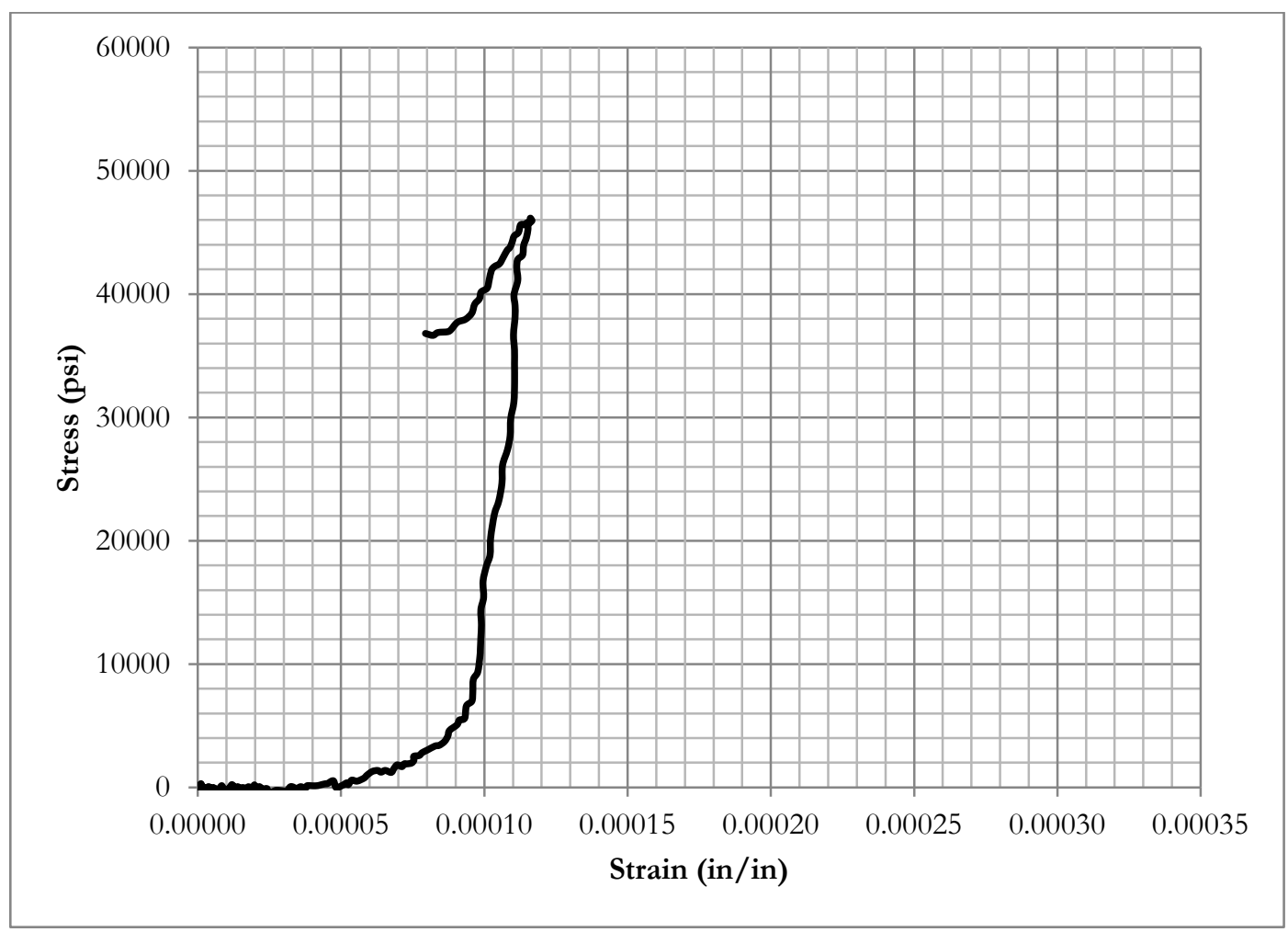

Figure 5.8: Typical dynamic stress-strain curve for ambient cured UHPC at a 2:1 aspect ratio 
Although aspect ratio shows little difference between ultimate dynamic stress, the strains are reduced as the specimen length increases. These graphs also illustrate the counterclockwise motion of the dynamic stress-strain curves after reaching the ultimate dynamic strength. This trend occurred with most of the ambient cured UHPC samples, with a few exceptions for samples that suffered more severe fragmentation.

A summary of the results calculated for the ambient cured UHPC samples is tabulated below. Similar to NSC, ambient cured UHPC specimens also had consistent results, with COVs less than $10 \%$ for ultimate stress. Strain values varied slightly more, with a maximum COV of $15.9 \%$. Recall, samples that did not meet parallelness tolerance recommendations were not included in the statistical analysis. 
Table 5.2: Dynamic stress and strain values for ambient cured UHPC samples

\begin{tabular}{|c|c|c|c|c|c|}
\hline $\begin{array}{c}\text { Aspect } \\
\text { Ratio }\end{array}$ & ID & $\begin{array}{c}\text { Ultimate } \\
\text { Stress (psi) }\end{array}$ & $\begin{array}{c}\text { Max. Strain Rate } \\
(1 / \text { sec })\end{array}$ & $\begin{array}{l}\text { Max Strain } \\
\text { (in/in) }\end{array}$ & $\begin{array}{c}\text { Strain@ } \\
\text { Ultimate Stress } \\
\text { (in/in) } \\
\end{array}$ \\
\hline \multirow{6}{*}{$2: 1$} & U-C1-AMB & 46156 & 118.0 & 0.000115 & 0.00011 \\
\hline & U-C2-AMB & 45648 & 116.0 & 0.000116 & 0.000116 \\
\hline & U-C3-AMB & 44243 & 115.0 & 0.000111 & 0.000111 \\
\hline & Avg. & 45349 & 116.3 & 0.000114 & 0.000112 \\
\hline & Std. Dev. & 809 & 1.2 & 0.000002 & 0.000003 \\
\hline & $\mathrm{COV}$ & 0.018 & 0.011 & 0.019 & 0.023 \\
\hline \multirow{10}{*}{ 1:1 } & U-B1-AMB & 47872 & 162.3 & 0.000162 & 0.000140 \\
\hline & U-B2-AMB & 42889 & 218.0 & 0.000218 & 0.000210 \\
\hline & U-B3-AMB* & 35160 & 264.0 & 0.000264 & 0.000230 \\
\hline & U-B4-AMB* & 35166 & 231.2 & 0.000231 & 0.000231 \\
\hline & U-B5-AMB & 46010 & 188.3 & 0.000188 & 0.000170 \\
\hline & U-B6-AMB & 48233 & 174.1 & 0.000174 & 0.000150 \\
\hline & U-B7-AMB & 49733 & 176.2 & 0.000176 & 0.000160 \\
\hline & Avg. & 46947 & 183.8 & 0.000184 & 0.000166 \\
\hline & Std. Dev. & 2350 & 19.0 & 0.000019 & 0.000024 \\
\hline & $\mathrm{COV}$ & 0.050 & 0.103 & 0.104 & 0.146 \\
\hline \multirow{11}{*}{$0.5: 1$} & U-A1-AMB & 55504 & 293.9 & 0.000294 & 0.000220 \\
\hline & U-A2-AMB & $\mathrm{x}$ & $\mathrm{x}$ & $\mathrm{x}$ & $\mathrm{x}$ \\
\hline & U-A3-AMB* & 32477 & 436.4 & 0.000436 & 0.000410 \\
\hline & U-A4-AMB & 53239 & 314.9 & 0.000315 & 0.000235 \\
\hline & U-A5-AMB & 46955 & 417.4 & 0.000417 & 0.000325 \\
\hline & U-A6-AMB* & 46225 & 424.7 & 0.000425 & 0.000360 \\
\hline & U-A7-AMB & 55162 & 266.2 & 0.000266 & 0.000240 \\
\hline & U-A8-AMB & 43777 & 352.3 & 0.000352 & 0.000330 \\
\hline & Avg. & 50927 & 328.9 & 0.000329 & 0.000270 \\
\hline & Std. Dev. & 4714 & 52.4 & 0.000052 & 0.000047 \\
\hline & $\mathrm{COV}$ & 0.093 & 0.159 & 0.159 & 0.176 \\
\hline
\end{tabular}

*Sample did not meet parallelness tolerance

Based on the results for the ambient cured UHPC specimens, the dynamic ultimate stresses are similar regardless of aspect ratio, with the exception of a couple 0.5:1 samples reaching about 55,000 psi. However, the same size specimens had the lowest dynamic ultimate stress 
of any ambient UHPC sample at about 32,400 psi, which could be due to unparallel ends. Furthermore, the strain rates and strain values followed the same trend as the NSC samples. Lastly, the shorter specimens reached higher strain rates as well as larger strain values.

\subsubsection{Thermally Treated UHPC}

The results of the thermally treated UHPC samples are presented in this section. For this curing scenario, 3 samples were tested at the 2:1 aspect ratio, 7 samples at the 1:1 aspect ratio, and 7 samples at 0.5:1 aspect ratio. A representative dynamic stress-strain curve, from sample U-A6-TT, is shown below in Figure 5.9 and compared to previously discussed dynamic stress-strain curves.

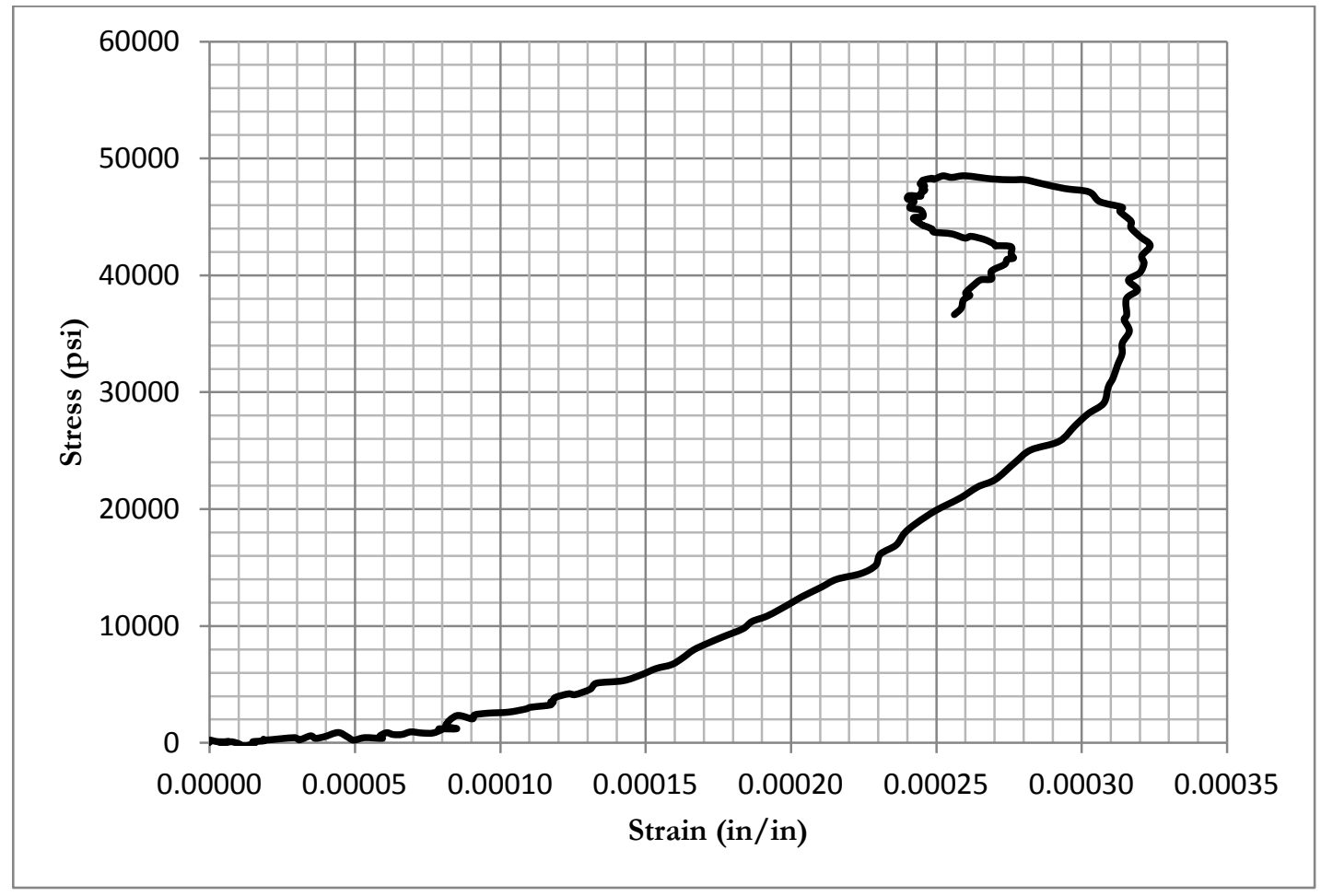

Figure 5.9: Typical dynamic stress-strain curve for UHPC thermal treated specimens (U-A6-TT)

All of the dynamic stress-strain curves for the thermally treated UHPC were similar to one another. Each featured a counterclockwise curve at its peak. This is related to each sample physically absorbing the energy for the SHPB test and not suffering extreme fragmenting, due in part to the steel fibers as well as the increased static compressive strength. The 
thermally treated UHPC samples also followed the same trends as the other two mixes (NSC and ambient cured UHPC) in terms of strain values. As the specimen length increased, the specimen strain decreased.

Results are summarized for the thermally treated UHPC samples in Table 5.3 below. The variation of the ultimate stress increased for thermally treated specimens is below $10 \%$, excluding samples not meeting parallelness tolerance. The consistency in ultimate stress for thermally treated UHPC is comparable to that of both ambient cured UHPC and NSC. Similar to the ambient cured UHPC, the thermally treated UHPC experienced a $15-18 \%$ variation in strain. 
Table 5.3: Dynamic stress and strain values for thermally treated UHPC samples

\begin{tabular}{|c|c|c|c|c|c|}
\hline $\begin{array}{c}\text { Aspect } \\
\text { Ratio }\end{array}$ & ID & $\begin{array}{c}\text { Ultimate } \\
\text { Stress (psi) }\end{array}$ & $\begin{array}{l}\text { Max. Strain } \\
\text { Rate }(1 / \text { sec })\end{array}$ & $\begin{array}{c}\text { Max. } \\
\text { Strain } \\
\text { (in/in) }\end{array}$ & $\begin{array}{c}\text { Strain@ } \\
\text { Ultimate Stress } \\
(\text { in } / \text { in })\end{array}$ \\
\hline \multirow{6}{*}{$2: 1$} & U-C1-TT* & 51713 & 120.3 & 0.000120 & 0.000119 \\
\hline & U-C2-TT* & 37303 & 126.3 & 0.000126 & 0.000126 \\
\hline & U-C3-TT & 50938 & 114.7 & 0.000115 & 0.000028 \\
\hline & Avg. & 50938 & 115 & 0.000115 & 0.000028 \\
\hline & Std. Dev. & 0.0 & 0.0 & 0.0 & 0.0 \\
\hline & $\mathrm{COV}$ & 0.0 & 0.0 & 0.0 & 0.0 \\
\hline \multirow{10}{*}{$1: 1$} & U-B1-TT & 59230 & 144.4 & 0.000144 & 0.000082 \\
\hline & U-B2-TT & 49402 & 200.0 & 0.000200 & 0.000170 \\
\hline & U-B3-T'T* & 45451 & 183.6 & 0.000184 & 0.000175 \\
\hline & U-B4-TT & 58440 & 147.0 & 0.000147 & 0.000100 \\
\hline & U-B5-TT* & 36135 & 229.9 & 0.000230 & 0.000220 \\
\hline & U-B6-TT* & 42325 & 218.9 & 0.000219 & 0.000180 \\
\hline & U-B7-T'T* & 25474 & 307.5 & 0.000307 & 0.000307 \\
\hline & Avg. & 55691 & 163.8 & 0.000164 & 0.000117 \\
\hline & Std. Dev. & 4458 & 25.6 & 0.000026 & 0.000038 \\
\hline & $\mathrm{COV}$ & 0.080 & 0.156 & 0.157 & 0.324 \\
\hline \multirow{10}{*}{$0.5: 1$} & U-A1-TT* & 35314 & 410.7 & 0.000411 & 0.00034 \\
\hline & U-A2-TT & 48009 & 301.3 & 0.000301 & 0.00023 \\
\hline & U-A3-TT* & 41175 & 454.0 & 0.000454 & 0.00039 \\
\hline & U-A4-TT* & 25791 & 531.9 & 0.000532 & 0.00050 \\
\hline & U-A5-TT & 46343 & 414.7 & 0.000415 & 0.00028 \\
\hline & U-A6-TT & 48514 & 323.5 & 0.000324 & 0.00025 \\
\hline & U-A7-TT & 38431 & 465.5 & 0.000466 & 0.00042 \\
\hline & Avg. & 45324 & 376.3 & 0.00038 & 0.00030 \\
\hline & Std. Dev. & 4060 & 66.8 & 0.00007 & 0.00007 \\
\hline & $\mathrm{COV}$ & 0.090 & 0.178 & 0.178 & 0.252 \\
\hline
\end{tabular}

*Sample did not meet parallelness tolerance

The thermally treated UHPC samples follow the same patterns as the NSC and ambient cured UHPC, including seeing higher strain rates and strain values as the specimen length decreases. Stress values for thermally treated UHPC were about 330\% higher than NSC and about 10\% lower than ambient cured UHPC. However, the dynamic ultimate stresses are 
more inconsistent as a whole. This may be due to the larger number of specimens that did not meet parallel end tolerance requirements. The greater variation of results confirms this notion. Moreover, the average dynamic ultimate stress is lowest for samples with a $0.5: 1$ aspect. This directly contrasts the other two concrete mixes, which experienced the highest average ultimate stress at the $0.5: 1$ aspect ratio.

\subsection{Static Testing Results}

The static test results, according to the procedure outlined in Section 3.2, are shown in Table 5.4. For each group of concrete, 3 cylinders were tested. The average of the 3 compressive strengths for each group is used in further analysis, specifically the calculation of dynamic increase factors.

Table 5.4: Static strength for each concrete group

\begin{tabular}{|c|c|}
\hline \multicolumn{2}{|c|}{ NSC } \\
\hline Test No. & Static Strength (psi) \\
\hline 1 & 3239 \\
\hline 2 & 3427 \\
\hline 3 & 3476 \\
\hline Average & 3380 \\
\hline \multicolumn{2}{|c|}{ UHPC - Ambient } \\
\hline Test No. & Static Strength (psi) \\
\hline 1 & 18637 \\
\hline 2 & 17605 \\
\hline 3 & 20140 \\
\hline Average & 18790 \\
\hline \multicolumn{2}{|c|}{ UHPC - TT } \\
\hline Test No. & Static Strength (psi) \\
\hline 1 & 20017 \\
\hline 2 & 17996 \\
\hline 3 & 25341 \\
\hline Average & 21120 \\
\hline
\end{tabular}




\subsection{Dynamic Increase Factor Comparison}

A comparison of the DIFs for each type of concrete and curing scenario tested is completed for each sample tested, using Equation 4-1. Tables 5.5, 5.6, and 5.7 show the DIF for each sample and the information used to calculate it, including the average static compressive strength of representative cylinders from each group, denoted as $\sigma_{s}$ at the end of each table.

Table 5.5: DIFs for NSC samples

\begin{tabular}{|c|c|c|c|c|}
\hline $\begin{array}{c}\text { Aspect } \\
\text { Ratio }\end{array}$ & ID & $\begin{array}{c}\sigma_{\mathrm{d}} \\
(\mathrm{psi})\end{array}$ & DIF & $\begin{array}{c}\text { Strain Rate } \\
(1 / \text { sec })\end{array}$ \\
\hline \multirow{4}{*}{$2: 1$} & N-C1 & 11834 & 3.50 & 128.8 \\
\hline & $\mathrm{N}-\mathrm{C} 2 *$ & 10605 & 3.14 & 139.3 \\
\hline & N-C3 & 13646 & 4.04 & 144.3 \\
\hline & Avg. & 12740 & 3.77 & 136.6 \\
\hline \multirow{7}{*}{ 1:1 } & $\overline{\mathrm{N}-\mathrm{B} 1 *}$ & 11546 & 3.42 & $\overline{287.0}$ \\
\hline & N-B2 & 12846 & 3.80 & 282.0 \\
\hline & N-B3* & 11053 & 3.27 & 275.8 \\
\hline & N-B4 & 12536 & 3.71 & 293.1 \\
\hline & N-B5 & 11617 & 3.44 & 269.2 \\
\hline & N-B6* & 13021 & 3.85 & 288.0 \\
\hline & Avg. & 12333 & 3.65 & 281.4 \\
\hline \multirow{9}{*}{$0.5: 1$} & N-A1* & 11762 & 3.48 & 549.4 \\
\hline & N-A2 & 13538 & 4.01 & 502.1 \\
\hline & N-A3 & 13232 & 3.91 & 524.1 \\
\hline & N-A4* & 15094 & 4.47 & 529.2 \\
\hline & N-A5* & 12662 & 3.75 & 557.6 \\
\hline & N-A6 & $\mathrm{x}$ & $\mathrm{x}$ & $\mathrm{x}$ \\
\hline & N-A7 & 14010 & 4.14 & 510.0 \\
\hline & N-A8 & 13523 & 4.00 & 511.9 \\
\hline & Avg. & 13576 & 4.02 & 512.0 \\
\hline
\end{tabular}

For the normal strength concrete samples, the DIFs range from about 3 to 4 with averages ranging between 3.65 and 4.0. Samples with aspect ratios of 0.5:1 tended to have higher DIFs due to the higher ultimate dynamic stresses. As a strain rate sensitive material, concrete 
has an increase in strength at higher loading rates. As the strain rates increase so too do the dynamic strengths, resulting in higher DIFs.

DIF values were also calculated for the ambient cured UHPC samples as shown in Table 5.6. The ambient cured UHPC samples experienced higher dynamic strengths than the normal strength concrete, but also had much higher static compressive strengths. As a result, the DIFs were smaller, ranging between 1.73 and 2.95, compared with NSC DIF values of 3.144.47, for similar strain rates of loading. The results between the various aspect ratios tested for ambient cured UHPC samples remain unclear as both larger and smaller DIFs exist within each group. Typically, for higher strain rates, as are found in 0.5:1 aspect ratio specimens, higher dynamic compressive strengths should be calculated. However, the ultimate dynamic stresses tend to remain relatively consistent throughout each aspect ratio. 
Table 5.6: DIFs for ambient cured UHPC samples

\begin{tabular}{|c|c|c|c|c|}
\hline $\begin{array}{c}\text { Aspect } \\
\text { Ratio }\end{array}$ & ID & $\begin{array}{c}\sigma_{\mathrm{d}} \\
(\mathrm{psi})\end{array}$ & DIF & $\begin{array}{c}\text { Strain } \\
\text { Rate } \\
(1 / \text { sec })\end{array}$ \\
\hline \multirow{4}{*}{$2: 1$} & U-C1-AMB & 46156 & 2.46 & 118.0 \\
\hline & U-C2-AMB & 45648 & 2.43 & 116.0 \\
\hline & U-C3-AMB & 44243 & 2.35 & 115.0 \\
\hline & Avg. & 45349 & 2.41 & 116.3 \\
\hline \multirow{8}{*}{ 1:1 } & U-B1-AMB & 47872 & 2.55 & 162.3 \\
\hline & U-B2-AMB & 42889 & 2.28 & 218.0 \\
\hline & U-B3-AMB* & 35160 & 1.87 & 264.0 \\
\hline & U-B4-AMB* & 35166 & 1.87 & 231.2 \\
\hline & U-B5-AMB & 46010 & 2.45 & 188.3 \\
\hline & U-B6-AMB & 48233 & 2.57 & 174.1 \\
\hline & U-B7-AMB & 49733 & 2.65 & 176.2 \\
\hline & Avg. & 46947 & 2.50 & 183.8 \\
\hline \multirow{9}{*}{ 0.5:1 } & U-A1-AMB & 55504 & 2.95 & 293.9 \\
\hline & U-A2-AMB & $\mathrm{x}$ & $\mathrm{x}$ & $\mathrm{x}$ \\
\hline & U-A3-AMB* & 32477 & 1.73 & 436.4 \\
\hline & U-A4-AMB & 53239 & 2.83 & 314.9 \\
\hline & U-A5-AMB & 46955 & 2.5 & 417.4 \\
\hline & U-A6-AMB* & 46225 & 2.46 & 424.7 \\
\hline & U-A7-AMB & 55162 & 2.94 & 266.2 \\
\hline & U-A8-AMB & 43777 & 2.33 & 352.3 \\
\hline & Avg. & 50927 & 2.71 & 328.9 \\
\hline
\end{tabular}

The DIFs for the thermally treated UHPC specimens are shown in Table 5.7. Compared to the ambient cured UHPC specimens, the DIFs for the thermally treated UHPC vary slightly, ranging from 1.21 to 2.45 . It can be concluded that the thermally treated UHPC samples have the lowest DIFs of all concrete mixes tested. However, similar to the ambient UHPC, there is no definite correlation between the DIFs and the aspect ratios or strain rates for the thermally treated UHPC specimens. In fact, DIFs on the lower end of the range tend to occur at the higher strain rates. This is unexpected since theoretically the dynamic strength should increase as strain rate increases. Based on this notion, a stronger material, statically, 
should obtain higher dynamic strengths. However, these results suggest that there may be a maximum strength increase that a material may see regardless of a further increase in strain rate.

Table 5.7: DIFs for thermally treated UHPC samples

\begin{tabular}{|c|c|c|c|c|}
\hline $\begin{array}{c}\text { Aspect } \\
\text { Ratio }\end{array}$ & ID & $\begin{array}{c}\sigma_{\mathrm{d}} \\
(\mathrm{psi})\end{array}$ & DIF & $\begin{array}{c}\text { Strain } \\
\text { Rate } \\
(1 / \text { sec })\end{array}$ \\
\hline \multirow{4}{*}{$2: 1$} & U-C1-TT* & 51713 & 2.45 & 120.3 \\
\hline & U-C2-TT* & 37303 & 1.77 & 126.3 \\
\hline & U-C3-TT & 50938 & 2.41 & 114.7 \\
\hline & Avg. & 50938 & 2.41 & 114.7 \\
\hline \multirow{8}{*}{ 1:1 } & U-B1-T'T & 59230 & 2.80 & 144.4 \\
\hline & U-B2-TT & 49402 & 2.30 & 200.0 \\
\hline & U-B3-TT* & 45451 & 2.15 & 183.6 \\
\hline & U-B4-TT & 58440 & 2.77 & 147.0 \\
\hline & U-B5-TT* & 36135 & 1.71 & 229.9 \\
\hline & U-B6-TT* & 42325 & 2.00 & 218.9 \\
\hline & U-B7-T'T* & 25474 & 1.21 & 307.5 \\
\hline & Avg. & 55691 & 2.62 & 163.8 \\
\hline \multirow{8}{*}{$0.5: 1$} & U-A1-T'T* & 35314 & 1.67 & 410.7 \\
\hline & U-A2-TT & 48009 & 2.27 & 301.3 \\
\hline & U-A3-TT* & 41175 & 1.95 & 454.0 \\
\hline & U-A4-T'T* & 25791 & 1.22 & 531.9 \\
\hline & U-A5-TT & 46343 & 2.19 & 414.7 \\
\hline & U-A6-T'T & 48514 & 2.3 & 323.5 \\
\hline & U-A7-TT & 38431 & 1.82 & 465.5 \\
\hline & Avg. & 45324 & 2.15 & 376.3 \\
\hline
\end{tabular}

Figure 5.10 graphically illustrates the influence of strain rate on compressive strength for the NSC and UHPC samples tested herein. Comparing the normal strength concrete specimens to the UHPC ambient cured and thermally cured specimens collectively, it is evident based on the smaller DIFs at similar strain rates that UHPC is a less rate sensitive material in terms 
of compressive strength. However, little research exists for NSC and UHPC concrete specimens at such high strain rates as conducted in this research, particularly for UHPC.

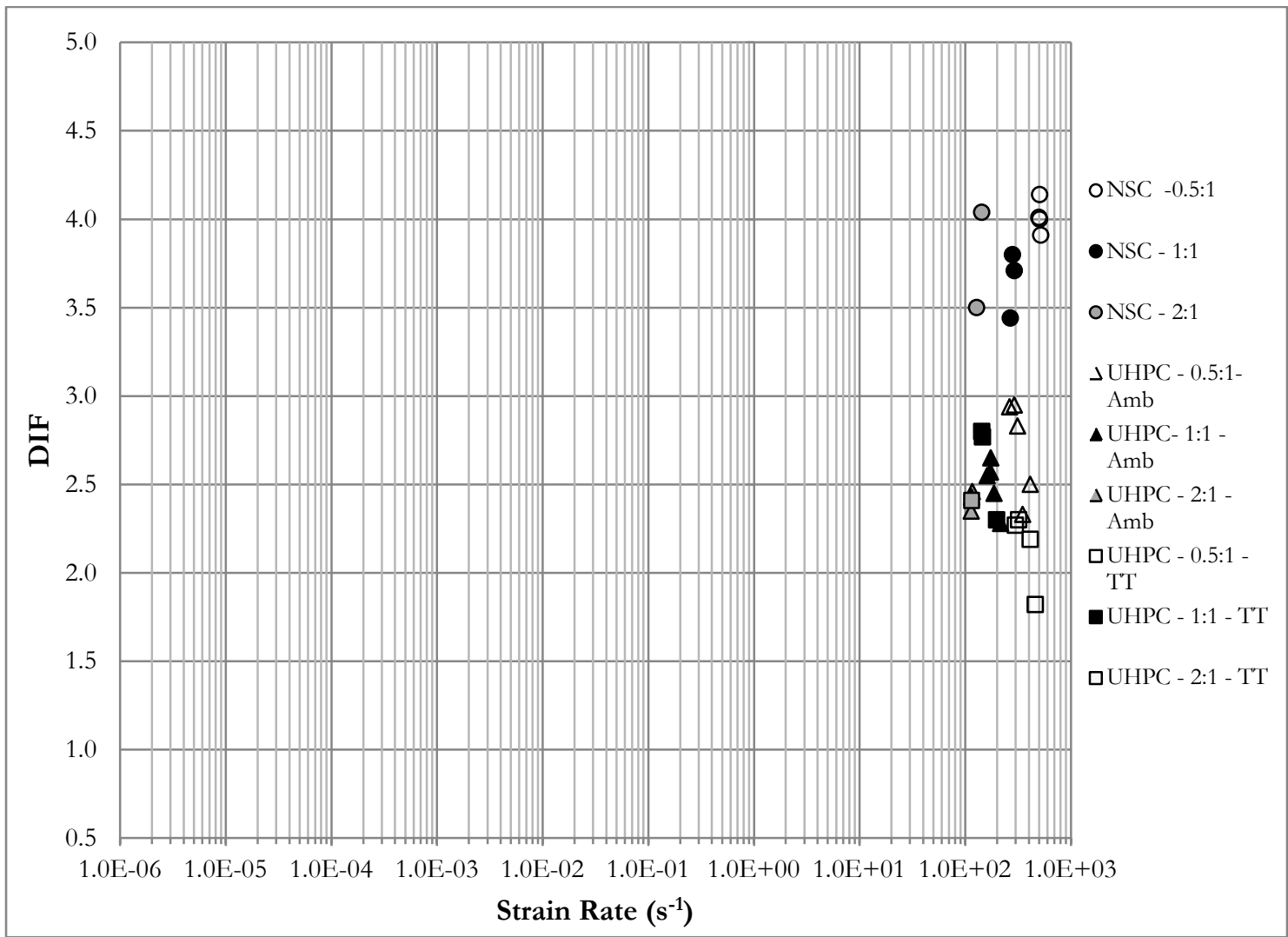

Figure 5.10: Influence of strain rate on compressive strength of NSC and UHPC for various aspect ratios

Normal strength concrete is more rate sensitive than UHPC, evident by the larger DIFs. A less rate sensitive material, such as UHPC, does not experience increased strengths as rapidly at high strain rates. Furthermore, the thermally treated UHPC, which has the highest static compressive strength is the least rate sensitive, with smaller DIFs than both the NSC and the ambient cured UHPC specimens. Another important result illustrated in Figure 5.10 is the ability to achieve higher strain rates through shorter specimens. For each concrete type, the shorter specimens, at the 0.5:1 aspect ratio, achieved higher strain rates than longer specimens using the same test set-up. Conversely, the longest specimens, at the 2:1 aspect ratio, reached the lowest strain rates. 
The results of this research confirm the hypotheses that DIFs for normal strength concrete continue to increase as the strain rate of loading increases, as Bischoff and Perry (1991) illustrated in Figure 2.4, and that UHPC is a less rate sensitive material compared to normal strength concrete. Figure 5.11 superimposes results from data collected herein with the Bischoff and Perry synthesis. Although previous DIF data for UHPC has not been reported in this context, it is still appropriate to include the DIFs for UHPC from this research because the data is normalized as a result of the DIF calculation.

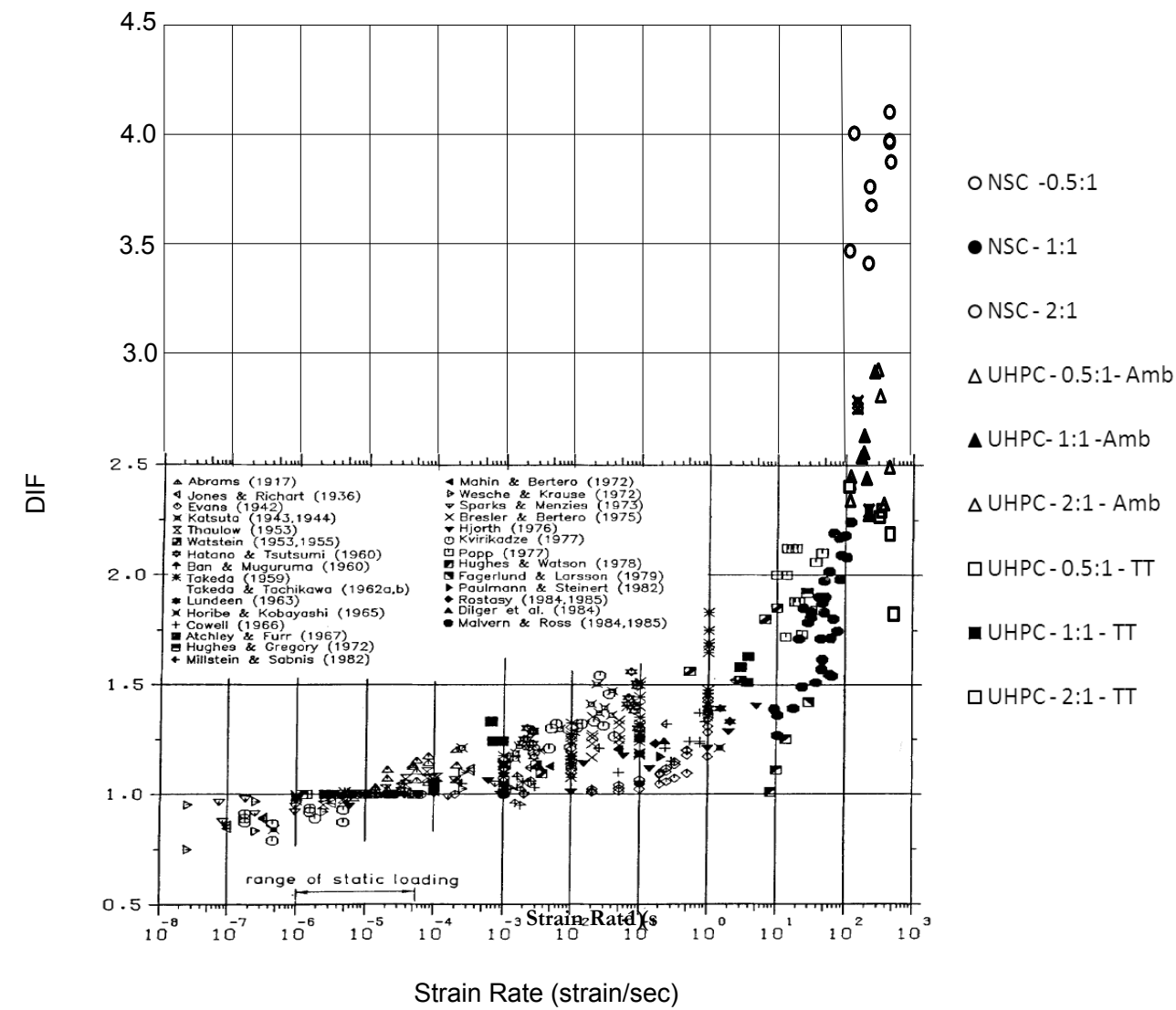

Figure 5.11: Strain rate influence on compressive strength with strain rates between $10^{-8}$ and $10^{3} 1 / \mathrm{sec}$

NSC specimens tested for this research extend past the range of the original Bischoff and Perry graph, as they experience strength increases above a factor of 2.5. The trend follows an exponential curve, reaching higher DIFs very rapidly at strain rates exceeding $10^{2} \mathrm{sec}^{-1}$. While the UHPC samples, both ambient cured and thermally treated, do see an increase in 
compressive strength at high strain rates of loading, UHPC does not achieve the same relative strength increase due to the reduced influence strain rate has on higher strength concrete materials. These results confirm the findings previously stated from Cavill et. al. (2006).

\subsection{Effect of Parallelness on Dynamic Stress}

While there are no requirements for parallel ends of an SHPB sample, there are recommendations regarding specimen tolerance (Gray III 2000). Furthermore, parallel ends are necessary to achieve uniform stress throughout the sample. As noted in Section 3.1.2, $40 \%$ of the samples did not meet the recommended parallel tolerance of a degree difference less than $0.5^{\circ}$. While these samples may have impacted the results, they also allow conclusions to be drawn regarding the relationship between parallelness and dynamic strength using the SHPB. When comparing the dynamic strength results of the concretes considering the parallel measurements taken, it is evident that the samples that do not meet the parallel recommendations deviate from the average dynamic strength. This holds true for each type of concrete tested for this research. The primary difference between samples that meet the parallel recommendations and those that do not is a decrease in dynamic compressive strength for the latter. Samples with 2 or more measurements not meeting criteria experienced a greater decrease in dynamic compressive strength than samples with only 1 measurement not meeting criteria. The decreases in dynamic compressive strength could be a result of stress irregularity. From this information it can be concluded that parallel ends are required for valid SHPB tests. Further statistical analysis is provided in Section 5.6. A specific tolerance requirement does not exist; therefore, parallel tolerances can be based only on recommendations. The data presented in this thesis does include every sample tested. However, samples that did not meet Gray III's parallel tolerance recommendation if a degree difference less than $0.5^{\circ}$ were identified and excluded from average, standard deviation, and coefficient of variation calculations. 


\subsection{Statistical Analysis}

Basic statistical analysis was performed to better understand the effects of parallel ends and aspect ratio. This was achieved using MiniTab software, which performs the specified statistical analysis for using data from the testing results. An analysis of variance (ANOVA) was used to compare multiple sample sets of data simultaneously. From the ANOVA analysis, box plots and P-values reveal the significance or insignificance of the tested condition between sample sets. All but one group of statistical calculations uses the DIF results for comparison. The exception compares the effect of aspect ratio to strain rate. Further analysis can be done to determine the effects of parallel ends and aspect ratio in terms of other material properties determined through the SHPB testing (i.e. dynamic compressive strength or strain). Box plots for each ANOVA test can be found in Appendix B.

The first statistical analysis was used to determine the effect on DIF between specimens with parallel ends and specimens that did not meet the parallel end tolerance recommendations. Table 5.8 shows the P-values for each concrete group. Based on these P-values it can be concluded that, at a 95\% confidence level, parallel ends are indeed significant for UHPC specimens in terms of affecting DIF. However, parallel ends are not significant for NSC.

Table 5.8: P-values from ANOVA test for parallel end significance

\begin{tabular}{|c|c|}
\hline ID & P-Value \\
\hline NSC & 0.243 \\
\hline UHPC - Ambient & 0.001 \\
\hline UHPC - TT & 0.006 \\
\hline
\end{tabular}

The second set of analysis is used to measure the significance aspect ratio has on the DIF of concretes. ANOVA tests were done for each concrete type, comparing the difference between the DIFs for each aspect ratio. Table 5.9 shows the P-values for each concrete group. Based on these P-values it can be concluded, within 95\% confidence, that aspect ratio is not a significant factor regarding DIF for each type of concrete. This applies to $0.5: 1,1: 1$, and 2:1 aspect ratios. 
Table 5.9: $\mathbf{P}$-values from ANOVA test for aspect ratio significance

\begin{tabular}{|c|c|}
\hline ID & P-Value \\
\hline NSC & 0.127 \\
\hline UHPC - Ambient & 0.138 \\
\hline UHPC - T'T & 0.125 \\
\hline
\end{tabular}

The third statistical test is used to determine the effect of aspect ratio on strain rate. An ANOVA test for each concrete type compares the strain rates within each aspect ratio. The calculated P-values are shown in Table 5.10. Based on these P-values it is evident that, at a $95 \%$ confidence level, aspect ratio has a significant effect on strain rate for each type of concrete.

Table 5.10: P-values from ANOVA test for aspect ratio significance on strain rate

\begin{tabular}{|c|c|}
\hline ID & P-Value \\
\hline NSC & 0.000 \\
\hline UHPC - Ambient & 0.000 \\
\hline UHPC - TT & 0.010 \\
\hline
\end{tabular}

The final statistical analysis performed was an ANOVA test to determine the significance between concrete type and DIF. This sample included all DIFs from specimens meeting parallel tolerance recommendations. The resulting P-value was 0.000. Based on this P-value it can be concluded that, at a 95\% confidence level, the difference between DIFs for each concrete type is definitively significant. 


\section{Chapter 6 Conclusions and Future Work}

The purpose of this thesis is to document the state of practice for SHPB testing on concrete in Michigan Technological University's Cement and Concrete Research Lab, and to perform a preliminary study on the behavior of UHPC loaded at high strain rates, specifically strain rates exceeding $10^{2} \mathrm{~s}^{-1}$. By reviewing previous research on SHPB concrete testing, it was possible to confirm the equipment response of the SHPB equipment through comparison of normal strength concrete test results. Furthermore, the dynamic compressive behavior of UHPC was investigated. This was achieved through testing ambient cured and thermally treated UHPC specimens at high strain rates using the SHPB and comparing the results to those of NSC. Through experimental design, several variables regarding SHPB concrete testing were also explored, including specimen aspect ratio, pulse shaping techniques, and the effect of parallelness. These variables were explored further through statistical analysis,

specifically ANOVA tests. Ultimately, the information provided in this thesis demonstrates the influence of strain rate, particularly high strain rates, on the compressive strength of concrete.

\subsection{Conclusions}

Several conclusions were reached from the research conducted herein:

- Normal strength concrete experiences an increase in compressive strength as strain rate increases. These increases range between 3 to 4 times the static compressive strength at strain rates between $10^{2}$ and $10^{3} \mathrm{~s}^{-1}$.

- Ultra-high performance concrete also experiences an increase in compressive strength as strain rate increases. These increases range between 1.73 and 2.95 for ambient cured UHPC and 1.21 and 2.45 for thermally treated concrete. 
- As a result of the lower DIFs for UHPC compared to NSC, UHPC demonstrates less rate sensitivity. Statistical analysis affirms this conclusion, showing a significant difference in DIFs between NSC and UHPC.

- Based on the results of the three aspect ratios used in this research for each concrete mix, it is evident that a shorter specimen achieves higher strain rates during SHPB testing for the same testing set-up. Statistical data confirms this conclusion, showing significant difference in strain rate between aspect ratios for each concrete type.

- Parallel specimen ends are an important factor that influences the results of SHPB testing. Based on statistical analysis parallel ends have a significant effect on DIF for UHPC, but are insignificant for NSC. Due to this influence, a minimum tolerance specification needs to be developed for SHPB testing, replacing the existing recommendations.

\subsection{Future Work}

Several areas surrounding this research should be considered for further investigation. With limitations on the data in this research, such as the influence of parallel specimen ends and fiber edge effects, results should be considered as preliminary. The following areas are valid issues to explore further, but were not within the scope of this research. With many variables throughout the SHPB testing process, these variables could be isolated to determine their level of influence on the test results. One of these variables is the pulse shaper size. This research selected a pulse shaper size from preliminary testing and used a single size. However, if the effect of size, along with various pulse shaping materials, could be determined, it could lead to a standard specification regarding the use of pulse shapers to better standardize the body of data. Another variable is the specimen design, specifically the specimen aspect ratio. While results for this research seem fairly consistent across each aspect ratio, further investigation into the effects of aspect ratio could lead to a standard specimen size or range of aspect ratios that are acceptable for SHPB concrete testing, similar to the standardization of static compressive testing. Lastly, the specimen preparation for 
SHPB testing was shown to be very important and influential on the results. This preparation includes further determining the effect of parallel ends and specifying a minimum parallel end tolerance. Specimen preparation also includes investigating the effects of fiber edge effects in UHPC. Further research is needed in each of these aforementioned areas. 


\section{Chapter 7 References}

Abotula, S. and V. Chalivendra (2010). Effect of Aspect Ratio of Cylindrical Pulse shapers on Force Equilibrium in Hopkinson Pressure Bar Experiments. SEM Annual Conference, Indianapolis, Indiana, USA, Society for Experimental Mechanics, Inc.

Ahlborn, T. M., E. P. Steinberg, J.L. Hartman, B.A. Graybeal, J. L. Potter, and J. Volygi. (2003). Ultra-High Performance Concrete - Study Tour 2002. 3rd International Symposium on High Performance Concrete. Orlando, FL: 1-15.

American Society for Testing and Materials. Annual Book of ASTM Standards. (2013)

ASTM C39, Standard Test Method for Compressive Strength of Cylindrical Concrete Specimens. 2005.

ASTM C192, Making and Curing Concrete Test Specimens in the Laboratory. 2007.

Batoz, J.-F. and M. Behloul (2009). UHPFRC Development on the Last Two Decades: An Overview. UHPFRC 2009 - FIB - AFGC. Marseille, France: 1-13.

Bischoff, P. H. and S. H. Perry (1991). "Compressive beaviour of concrete at high strain rates." Materials and Structures 24(6): 425-450.

Blais, P. Y. and M. Couture. (1999). "Precast, Prestressed Pedestrian Bridge — World's First Reactive Powder Concrete Structure." PCI Journal 44(5): 60-71.

Cavill, B., M. Rebentrost, and V. Perry. (2006). Ductal - An Ultra-High Performance Material for Resistance to Blasts and Impacts. 1st Specialty Conference on Disaster Mitigation, Calgary, Alberta, Canada. 
Chen, R., H. Liu, and R. Zeng. (2013). "SHPB Dynamic Experiment on Silica Fume Concrete." Advanced Materials Research 631-632: 771-775.

Davies, E. D. H. and S. C. Hunter (1963). "The Dynamic Compression Testing of Solids by the Method of the Split Hopkinson Pressure Bar." Journal of the Mechanics and Physics of Solids 11(3): 155-179.

Ductal ${ }^{\circledR}$ Reference T 009. Operating Procedure Cylinder End Preparation. LaFarge North America, Calgary, Canada.

Endicott, W. A. (2006). "Iowa Bridge Gives Glimpse into the Future." Ascent(Summer): 4146.

Forrestal, M. J., T. W. Wright, and W. Chen. (2006). "The effect of radial inertia on brittle samples during the split Hopkinson pressure bar test." International Journal of Impact Engineering 34: 405-411.

Frew, D. J., S. A. Akers, W. Chen, and M.L. Green. (2010). "Development of a dynamic triaxial Kolsky bar." Measurement Science and Technology 21: 1-10.

Frew, D. J., M. J. Forrestal, and W. Chen. (2001). "A Split-Hopkinson Pressure Bar Technique to Determine Compressive Stress-strain Data for Rock Materials." Experimental Mechanics 41(1): 40-46.

Frew, D. J., M. J. Forrestal, W. Chen. (2002). "Pulse Shaping Techniques for Testing Brittle Materials with a Split Hopkinson Pressure Bar." Experimental Mechanics 42(1): 9310

Gama, B.A., S.L. Lopatnikov, and J.W.J Gillespie. 2004. Hopkinson Bar Experimental Technique: A Critical Review. Applied Mechanics Reviews 57(4):223-251. 
Gilbertson, C.G. (2011). Dynamic Properties of Wood Using the Split-Hopkinson Pressure Bar. Houghton, MI: PhD Dissertation. Michigan Technological University.

Gong, J. C. and L. E. Malvern (1990). "Passively Confined Tests of Axial Dynamic Compressive Strength of Concrete." Experimental Mechanics: 55-59.

Gray III, George T. (2000). "Classic Split-Hopkinson Pressure Bar Testing." ASM Handbook 8: 462-476.

Graybeal, B. A. (2006). "Material Property Characterization of Ultra-High Performance Concrete”. FHWA, U.S. Department of Transportation, Report No. FHWA-HRT06-103, McLean, VA.

Huang, C. and G. Subhash (2003). "Influence of lateral confinement on dynamic evolution during uniaxial compressive response of brittle solids." Journal of the Mechanics and Physics of Solids 51: 1089-1105.

Jerome, E.L. (1991). Analysis of a Proposed Six Inch Diameter Split Hopkinson Pressure Bar. Gainesville, FL: PhD Dissertation. University of Florida.

Li, Q. M. and H. Meng (2003). "About the dynamic strength enhancement of concrete-like materials in a split Hopkinson pressure bar test." International Journal of Solids and Structures 40: 343-360.

Lok, T. S., X. B. Li, D. Liu, and P.J. Zhao. (2002). "Testing and Response of Large Diameter Brittle Materials Subjected to High Strain Rate." Journal of Materials in Civil Engineering 14(3): 262-269.

Lok, T. S. and P. J. Zhao (2004). "Impact Response of Steel Fiber-Reinforced Concrete Using a Split Hopkinson Pressure Bar." Journal of Materials in Civil Engineering 16: 54-59. 
Lu, Y. B., Q. M. Li, G.W. Ma. (2010). "Numerical investigation of the dynamic compressive strength of rocks based on the split Hopkinson pressure bar tests." International Journal of Rock Mechanics \& Mining Sciences 47: 829-838.

Malvern, L. and C. A. Ross (1984). Dynamic Response of Concrete and Concrete Structures. Gaineville, University of Florida: 50.

Mather, B. (2004). "Concrete Durability." Cement and Concrete Composites 26: 3-4.

Mehta, P. K. and P. J. M. Monteiro (2006). Concrete: Microstructure, Properties, and Materials. New York, NY, McGraw-Hill.

Meyers, J. J. and M. Tinsley (2013). "Impact Resistance of Blast Mitigation Material Using Modified ACI Drop-Weight Impact Test." ACI Materials Journal 110(3): 339-348.

Millon, O., W. Riedel, C. Mayrhofer, and K. Thoma. (2012). "Failure Mechanisms of UHPC Components Under Explosive Loading."

Peuse, E.J. (2008). Impact of Age at Thermal Treatment on the Mechanical Properties of an Ultra-High Performance Concrete. Houghton, MI: MS Thesis. Michigan Technological University.

Ramesh, K. T. (2008). High Strain Rate and Impact Experiments, Springer.

Ross, C. A. (1989). Split-Hopkinson Pressure Bar Tests. Tyndall Air Force Base, Air Force Engineering \& Services Center.

Ross, C. A., J. W. Tedesco, and S.T. Kuennen. (1995). "Effects of Strain Rate on Concrete Strength." ACI Structural Journal 92(1): 1-11. 
Ross, C. A., P. Y. Thompson, and J.W. Tedesco. (1989). "Split-hopkinson Pressure-Bar Tests on Concrete and Mortar in Tension and Compression." ACI Materials Journal 86(5): 475-481.

Shan, R., Y. Jiang, and B. Li. (2000). "Obtaining dynamic complete stress-strain curves for rock using the Split Hopkinson Pressure Bar technique." International Journal of Rock Mechanics and Mining Sciences 37: 983-992.

Tanaka, Y., K. Maekawa, A. Ootake, Y. Shimoyama, and O. Kaneko. (2009). Innovation and Application of UFC Bridges in Japan. UHPFRC 2009 - FIB - AFGC. Marseille, France: 1-17.

Tang, T., L. E. Malvern, and D. A. Jenkins. (1992). "Rate Effects in Uniaxial Dynamic Compression of Concrete." Journal of Engineering Mechanics 118(1): 108-124.

Vecchio, K. S. and F. Jiang (2007). "Improved Pulse Shaping to Achieve Constant Strain Rate and Stress Equilibrium in Split-Hopkinson Pressure Bar Testing." Metallurgical and Materials Transactions A 38A: 2656-2665.

Vitton, S. J., G. Subhash, and G. Dewey. (2002). Evaluation of the Dynamic Fracture Characterisitcs of Aggregate in PCC Pavements. Houghton, MI, Michigan Technological University.

Wang, S., M.-H. Zhang, and S.T. Quek. (2011). "Mechanical Behavior of fiber-reinforced high-strength concrete subjected to high strain-rate compressive loading." Construction and Building Materials 31: 1-11.

Wang, Z.-L., Y.-S. Liu, and R.F. Shen. (2008). "Stress-strain relationship of steel fiberreinforced concrete under dynamic compression." Construction and Building Materials 22: 811-819. 
Zhang, M., H. J. Wu, Q.M. Li, and F.L. Huang. (2009). "Further investigation on the dynamic compressive strength enhancement of concrete-like materials based on split Hopkinson pressure bar tests. Part I: Experiments." International Journal of Impact Engineering 36: 1327-1334.

Zhigang, R., C. Meng, L. Zhe'an, and X. Weiguo. (2012). "Dynamic Mechanical Property of Hybrid Fiber Reinforced Concrete (HFRC)." Journal of Wuhan University of Technology - Mater. Sci. Ed. : 783-788. 


\section{Appendix A: Parallelness Measurements}

The following tables consist of the data used to measure the parallelness of each specimen and compare them to the recommended tolerances. For each sample a relative height was measured at five different locations using a micrometer. The micrometer ranged from 0-100, where 1 unit $=1 / 1000$ inch. Total heights were not measured. Instead the height is relative to the micrometer reading for each specimen. From these values, a mean was calculated. The specimen mean was subtracted from the height for each location of measurement. Using geometry and an approximate distance between the center of the specimen to any other point of measurement of 1.25 inches, the degree difference between any measurement location and the mean was calculated and reported. Samples with measurements that did not meet the recommended tolerance of $0.5^{\circ}$ are shaded.

Table A.1: Parallel measurements for 2:1 NSC samples

\begin{tabular}{|c|c|c|c|c|c|c|c|}
\hline \multirow{2}{*}{ Sample ID } & & \multicolumn{5}{|c|}{ Measurements } & \multirow{2}{*}{ Mean } \\
\hline & & 1 & 2 & 3 & 4 & 5 & \\
\hline \multirow{3}{*}{ N-C1 } & Height & 75 & 82 & 72 & 69 & 80.5 & \multirow{3}{*}{75.7} \\
\hline & Height - Mean & -0.7 & 6.3 & -3.7 & -6.7 & 4.8 & \\
\hline & Degree Diff. & 0.03210 & 0.28891 & 0.16968 & 0.30726 & 0.22013 & \\
\hline \multirow{3}{*}{$\mathrm{N}-\mathrm{C} 2$} & Height & 58 & 48 & 74.5 & 71.5 & 52.5 & \multirow{3}{*}{60.9} \\
\hline & Height - Mean & -2.9 & -12.9 & 13.6 & 10.6 & -8.4 & \\
\hline & Degree Diff. & 0.13299 & 0.59157 & 0.62367 & 0.48610 & 0.38522 & \\
\hline \multirow{3}{*}{ N-C3 } & Height & 75 & 77 & 75.5 & 68.5 & 77 & \multirow{3}{*}{74.6} \\
\hline & Height - Mean & 0.4 & 2.4 & 0.9 & -6.1 & 2.4 & \\
\hline & Degree Diff. & 0.01834 & 0.11006 & 0.04127 & 0.27974 & 0.11006 & \\
\hline
\end{tabular}

$1=1 / 1000$ inch 
Table A.2: Parallel measurements for 1:1 NSC samples

\begin{tabular}{|c|c|c|c|c|c|c|c|}
\hline \multirow{2}{*}{ Sample ID } & & \multicolumn{5}{|c|}{ Measurements } & \multirow{2}{*}{ Mean } \\
\hline & & 1 & 2 & 3 & 4 & 5 & \\
\hline \multirow{3}{*}{ N-B1 } & Height & 71.5 & 53.5 & 85 & 84.5 & 65 & \multirow{3}{*}{71.9} \\
\hline & Height - Mean & -0.4 & -18.4 & 13.1 & 12.6 & -6.9 & \\
\hline & Degree Diff. & 0.01834 & 0.84376 & 0.60074 & 0.57781 & 0.31643 & \\
\hline \multirow{3}{*}{ N-B2 } & Height & 46 & 37 & 39 & 54.5 & 53 & \multirow{3}{*}{45.9} \\
\hline & Height - Mean & 0.1 & -8.9 & -6.9 & 8.6 & 7.1 & \\
\hline & Degree Diff. & 0.00459 & 0.40815 & 0.31643 & 0.39439 & 0.32560 & \\
\hline \multirow{3}{*}{ N-B3 } & Height & 95 & 105 & 108 & 92 & 85 & \multirow{3}{*}{97} \\
\hline & Height - Mean & -2 & 8 & 11 & -5 & -12 & \\
\hline & Degree Diff. & 0.09172 & 0.36687 & 0.50445 & 0.22930 & 0.55030 & \\
\hline \multirow{3}{*}{ N-B4 } & Height & 19 & 20 & 24 & 18.5 & 11.5 & \multirow{3}{*}{18.6} \\
\hline & Height - Mean & 0.4 & 1.4 & 5.4 & -0.1 & -7.1 & \\
\hline & Degree Diff. & 0.01834 & 0.06420 & 0.24764 & 0.00459 & 0.32560 & \\
\hline \multirow{3}{*}{ N-B5 } & Height & 61 & 50 & 67.5 & 67.5 & 58 & \multirow{3}{*}{60.8} \\
\hline & Height - Mean & 0.2 & -10.8 & 6.7 & 6.7 & -2.8 & \\
\hline & Degree Diff. & 0.00917 & 0.49527 & 0.30726 & 0.30726 & 0.12841 & \\
\hline \multirow{3}{*}{ N-B6 } & Height & 89 & 96 & 79 & 83 & 103 & \multirow{3}{*}{90} \\
\hline & Height - Mean & -1 & 6 & -11 & -7 & 13 & \\
\hline & Degree Diff. & 0.04586 & 0.27516 & 0.50445 & 0.32102 & 0.59616 & \\
\hline
\end{tabular}

$1=1 / 1000$ inch 
Table A.3: Parallel measurements for 0.5:1 NSC samples

\begin{tabular}{|c|c|c|c|c|c|c|c|}
\hline \multirow{2}{*}{ Sample ID } & & \multicolumn{5}{|c|}{ Measurements } & \multirow{2}{*}{ Mear } \\
\hline & & 1 & 2 & 3 & 4 & 5 & \\
\hline \multirow{3}{*}{ N-A1 } & Height & 69.5 & 66.5 & 86 & 70 & 57 & \multirow{3}{*}{69.8} \\
\hline & Height - Mean & -0.3 & -3.3 & 16.2 & 0.2 & -12.8 & \\
\hline & Degree Diff. & 0.01376 & 0.15134 & 0.74289 & 0.00917 & 0.58699 & \\
\hline \multirow{3}{*}{ N-A2 } & Height & 58.5 & 65.5 & 55 & 60 & 62 & \multirow{3}{*}{60.2} \\
\hline & Height - Mean & -1.7 & 5.3 & -5.2 & -0.2 & 1.8 & \\
\hline & Degree Diff. & 0.07796 & 0.24306 & 0.23847 & 0.00917 & 0.08255 & \\
\hline \multirow{3}{*}{ N-A3 } & Height & 48 & 39 & 43 & 53 & 54 & \multirow{3}{*}{47.4} \\
\hline & Height - Mean & 0.6 & -8.4 & -4.4 & 5.6 & 6.6 & \\
\hline & Degree Diff. & 0.02752 & 0.38522 & 0.20178 & 0.25681 & 0.30267 & \\
\hline \multirow{3}{*}{ N-A4 } & Height & 68.5 & 80 & 74.5 & 59 & 75 & \multirow{3}{*}{71.4} \\
\hline & Height - Mean & -2.9 & 8.6 & 3.1 & -12.4 & 3.6 & \\
\hline & Degree Diff. & 0.13299 & 0.39439 & 0.14217 & 0.56864 & 0.16510 & \\
\hline \multirow{3}{*}{ N-A5 } & Height & 90 & 78 & 89.5 & 101 & 98.5 & \multirow{3}{*}{91.4} \\
\hline & Height - Mean & -1.4 & -13.4 & -1.9 & 9.6 & 7.1 & \\
\hline & Degree Diff. & 0.06420 & 0.61450 & 0.08713 & 0.44025 & 0.32560 & \\
\hline \multirow{3}{*}{ N-A6 } & Height & $\mathrm{x}$ & $\mathrm{x}$ & $\mathrm{x}$ & $\mathrm{x}$ & $\mathrm{x}$ & \multirow{3}{*}{$\mathrm{x}$} \\
\hline & Height - Mean & $\mathrm{x}$ & $\mathrm{x}$ & $\mathrm{x}$ & $\mathrm{x}$ & $\mathrm{x}$ & \\
\hline & Degree Diff. & $\mathrm{x}$ & $\mathrm{x}$ & $\mathrm{x}$ & $\mathrm{x}$ & $\mathrm{x}$ & \\
\hline \multirow{3}{*}{ N-A7 } & Height & 82 & 86.5 & 99 & 80 & 95 & \multirow{3}{*}{88.5} \\
\hline & Height - Mean & -6.5 & -2 & 10.5 & -8.5 & 6.5 & \\
\hline & Degree Diff. & 0.29809 & 0.09172 & 0.48152 & 0.38980 & 0.29809 & \\
\hline \multirow{3}{*}{ N-A8 } & Height & 19 & 27.5 & 26.5 & 7 & 12 & \multirow{3}{*}{18.4} \\
\hline & Height - Mean & 0.6 & 9.1 & 8.1 & -11.4 & -6.4 & \\
\hline & Degree Diff. & 0.02752 & 0.00728 & 0.00648 & 0.00912 & 0.00512 & \\
\hline
\end{tabular}

$1=1 / 1000$ inch 
Table A.4: Parallel measurements for 2:1 ambient UHPC samples

\begin{tabular}{|c|c|c|c|c|c|c|c|}
\hline \multirow{2}{*}{ Sample ID } & & \multicolumn{5}{|c|}{ Measurements } & \multirow{2}{*}{ Mean } \\
\hline & & 1 & 2 & 3 & 4 & 5 & \\
\hline \multirow{3}{*}{ U-C1-Amb } & Height & 15 & 12 & 2 & 10 & 21 & \multirow{3}{*}{12} \\
\hline & Height - Mean & 3 & 0 & -10 & -2 & 9 & \\
\hline & Degree Diff. & 0.13758 & 0.00000 & 0.45859 & 0.09172 & 0.41273 & \\
\hline \multirow{3}{*}{ U-C2-Amb } & Height & 2 & 8 & 11 & 1.5 & -8 & \multirow{3}{*}{2.9} \\
\hline & Height - Mean & -0.9 & 5.1 & 8.1 & -1.4 & -10.9 & \\
\hline & Degree Diff. & 0.04127 & 0.23388 & 0.37146 & 0.06420 & 0.49986 & \\
\hline \multirow{3}{*}{ U-C3-Amb } & Height & 87 & 80 & 76 & 93 & 95 & \multirow{3}{*}{86.2} \\
\hline & Height - Mean & 0.8 & -6.2 & -10.2 & 6.8 & 8.8 & \\
\hline & Degree Diff. & 0.03669 & 0.28433 & 0.46776 & 0.31184 & 0.40356 & \\
\hline
\end{tabular}

$1=1 / 1000$ inch

Table A.5: Parallel measurements for 1:1 ambient UHPC samples

\begin{tabular}{|c|c|c|c|c|c|c|c|}
\hline \multirow{2}{*}{ Sample ID } & & \multicolumn{5}{|c|}{ Measurements } & \multirow{2}{*}{ Mean } \\
\hline & & 1 & 2 & 3 & 4 & 5 & \\
\hline \multirow{3}{*}{ U-B1-Amb } & Height & 82 & 78.5 & 78 & 81 & 75 & \multirow{3}{*}{78.9} \\
\hline & Height - Mean & 3.1 & -0.4 & -0.9 & 2.1 & -3.9 & \\
\hline & Degree Diff. & 0.14217 & 0.01834 & 0.04127 & 0.09631 & 0.17885 & \\
\hline \multirow{3}{*}{ U-B2-Amb } & Height & 15 & 16 & 5 & 14 & 25 & \multirow{3}{*}{15} \\
\hline & Height - Mean & 0 & 1 & -10 & -1 & 10 & \\
\hline & Degree Diff. & 0.00000 & 0.04586 & 0.45859 & 0.04586 & 0.45859 & \\
\hline \multirow{3}{*}{ U-B3-Amb } & Height & 81 & 84 & 103 & 79 & 64 & \multirow{3}{*}{82.2} \\
\hline & Height - Mean & -1.2 & 1.8 & 20.8 & -3.2 & -18.2 & \\
\hline & Degree Diff. & 0.05503 & 0.08255 & 0.95380 & 0.14675 & 0.83459 & \\
\hline \multirow{3}{*}{ U-B4-Amb } & Height & 73 & 66.5 & 82 & 70 & 57 & \multirow{3}{*}{69.7} \\
\hline & Height - Mean & 3.3 & -3.2 & 12.3 & 0.3 & -12.7 & \\
\hline & Degree Diff. & 0.15134 & 0.14675 & 0.56406 & 0.01376 & 0.58240 & \\
\hline \multirow{3}{*}{ U-B5-Amb } & Height & 103 & 102.5 & 92 & 101 & 107 & \multirow{3}{*}{101.1} \\
\hline & Height - Mean & 1.9 & 1.4 & -9.1 & -0.1 & 5.9 & \\
\hline & Degree Diff. & 0.08713 & 0.06420 & 0.41732 & 0.00459 & 0.27057 & \\
\hline \multirow{3}{*}{ U-B6-Amb } & Height & 8 & 9 & 4 & 7.5 & 10.5 & \multirow{3}{*}{7.8} \\
\hline & Height - Mean & 0.2 & 1.2 & -3.8 & -0.3 & 2.7 & \\
\hline & Degree Diff. & 0.00917 & 0.05503 & 0.17427 & 0.01376 & 0.12382 & \\
\hline \multirow{3}{*}{ U-B7-Amb } & Height & 52 & 43 & 52.5 & 52 & 43 & \multirow{3}{*}{48.5} \\
\hline & Height - Mean & 3.5 & -5.5 & 4 & 3.5 & -5.5 & \\
\hline & Degree Diff. & 0.16051 & 0.25223 & 0.18344 & 0.16051 & 0.25223 & \\
\hline
\end{tabular}

$1=1 / 1000$ inch 
Table A.6: Parallel measurements of 0.5:1 ambient UHPC samples

\begin{tabular}{|c|c|c|c|c|c|c|c|}
\hline \multirow{2}{*}{ Sample ID } & & \multicolumn{5}{|c|}{ Measurements } & \multirow{2}{*}{ Mean } \\
\hline & & 1 & 2 & 3 & 4 & 5 & \\
\hline \multirow{3}{*}{ U-A1-Amb } & Height & 96.5 & 92.5 & 90 & 103.5 & 99.5 & \multirow{3}{*}{96.4} \\
\hline & Height - Mean & 0.1 & -3.9 & -6.4 & 7.1 & 3.1 & \\
\hline & Degree Diff. & 0.00459 & 0.17885 & 0.29350 & 0.32560 & 0.14217 & \\
\hline \multirow{3}{*}{ U-A2-Amb } & Height & $\mathrm{x}$ & $\mathrm{x}$ & $\mathrm{x}$ & $\mathrm{x}$ & $\mathrm{x}$ & \multirow{3}{*}{$\mathrm{x}$} \\
\hline & Height - Mean & $\mathrm{x}$ & $\mathrm{x}$ & $\mathrm{x}$ & $\mathrm{x}$ & $\mathrm{x}$ & \\
\hline & Degree Diff. & $\mathrm{x}$ & $\mathrm{x}$ & $\mathrm{x}$ & $\mathrm{x}$ & $\mathrm{x}$ & \\
\hline \multirow{3}{*}{ U-A3-Amb } & Height & 106 & 110 & 91 & 96.5 & 114 & \multirow{3}{*}{103.5} \\
\hline & Height - Mean & 2.5 & 6.5 & -12.5 & -7 & 10.5 & \\
\hline & Degree Diff. & 0.11465 & 0.29809 & 0.57323 & 0.32102 & 0.48152 & \\
\hline \multirow{3}{*}{ U-A4-Amb } & Ieight & 69 & 66 & 60 & 67 & 69 & \multirow{3}{*}{66.2} \\
\hline & Height - Mean & 2.8 & -0.2 & -6.2 & 0.8 & 2.8 & \\
\hline & Degree Diff. & 0.12841 & 0.00917 & 0.28433 & 0.03669 & 0.12841 & \\
\hline \multirow{3}{*}{ U-A5-Amb } & Height & 100 & 89 & 96 & 109 & 103 & \multirow{3}{*}{99.4} \\
\hline & Height - Mean & 0.6 & -10.4 & -3.4 & 9.6 & 3.6 & \\
\hline & Degree Diff. & 0.02752 & 0.47693 & 0.15592 & 0.44025 & 0.16510 & \\
\hline \multirow{3}{*}{ U-A6-Amb } & Height & 51.5 & 60 & 53 & 36 & 45 & \multirow{3}{*}{49.1} \\
\hline & Height - Mean & 2.4 & 10.9 & 3.9 & -13.1 & -4.1 & \\
\hline & Degree Diff. & 0.11006 & 0.49986 & 0.17885 & 0.60074 & 0.18802 & \\
\hline \multirow{3}{*}{ U-A7-Amb } & Height & 74 & 81 & 72 & 69 & 70.5 & \multirow{3}{*}{73.3} \\
\hline & Height - Mean & 0.7 & 7.7 & -1.3 & -4.3 & -2.8 & \\
\hline & Degree Diff. & 0.03210 & 0.00616 & 0.00104 & 0.00344 & 0.00224 & \\
\hline \multirow{3}{*}{ U-A8-Amb } & Height & 62 & 64.5 & 56 & 58 & 73 & \multirow{3}{*}{62.7} \\
\hline & Height - Mean & -0.7 & -8.8 & -17.3 & -15.3 & -0.3 & \\
\hline & Degree Diff. & 0.03210 & 0.00704 & 0.01384 & 0.01224 & 0.00024 & \\
\hline
\end{tabular}

$1=1 / 1000$ inch 
Table A.7: Parallel measurements for 2:1 thermally treated UHPC samples

\begin{tabular}{|c|c|c|c|c|c|c|c|}
\hline \multirow{2}{*}{ Sample ID } & & \multicolumn{5}{|c|}{ Measurements } & \multirow{2}{*}{ Mean } \\
\hline & & 1 & 2 & 3 & 4 & 5 & \\
\hline \multirow{3}{*}{ U-C1-TT } & Height & 105.5 & 89 & 106 & 106 & 95 & \multirow{3}{*}{100.3} \\
\hline & Height - Mean & 5.2 & -11.3 & 5.7 & 5.7 & -5.3 & \\
\hline & Degree Diff. & 0.23847 & 0.51820 & 0.26140 & 0.26140 & 0.24306 & \\
\hline \multirow{3}{*}{ U-C2-TT } & Height & 60 & 75 & 64 & 48 & 59.5 & \multirow{3}{*}{61.3} \\
\hline & Height - Mean & -1.3 & 13.7 & 2.7 & -13.3 & -1.8 & \\
\hline & Degree Diff. & 0.05962 & 0.62826 & 0.12382 & 0.60991 & 0.08255 & \\
\hline \multirow{3}{*}{ U-C3-TT } & Height & 87 & 79 & 81 & 96 & 91 & \multirow{3}{*}{86.8} \\
\hline & Height - Mean & 0.2 & -7.8 & -5.8 & 9.2 & 4.2 & \\
\hline & Degree Diff. & 0.00917 & 0.35770 & 0.26599 & 0.42190 & 0.19261 & \\
\hline
\end{tabular}

$1=1 / 1000$ inch

Table A.8: Parallel measurements for 1:1 thermally treated UHPC samples

\begin{tabular}{|c|c|c|c|c|c|c|c|}
\hline \multirow{2}{*}{ Sample ID } & & \multicolumn{5}{|c|}{ Measurements } & \multirow{2}{*}{ Mean } \\
\hline & & 1 & 2 & 3 & 4 & 5 & \\
\hline \multirow{3}{*}{ U-B1-TT } & Height & 79.5 & 86 & 75 & 68.5 & 79.5 & \multirow{3}{*}{77.7} \\
\hline & Height - Mean & 1.8 & 8.3 & -2.7 & -9.2 & 1.8 & \\
\hline & Degree Diff. & 0.08255 & 0.38063 & 0.12382 & 0.42190 & 0.08255 & \\
\hline \multirow{3}{*}{ U-B2-TT } & Height & 68 & 75 & 57 & 60 & 75 & \multirow{3}{*}{67} \\
\hline & Height - Mean & 1 & 8 & -10 & -7 & 8 & \\
\hline & Degree Diff. & 0.04586 & 0.36687 & 0.45859 & 0.32102 & 0.36687 & \\
\hline \multirow{3}{*}{ U-B3-TT } & Height & 78 & 96 & 81 & 69 & 81 & \multirow{3}{*}{81} \\
\hline & Height - Mean & -3 & 15 & 0 & -12 & 0 & \\
\hline & Degree Diff. & 0.13758 & 0.68787 & 0.00000 & 0.55030 & 0.00000 & \\
\hline \multirow{3}{*}{ U-B4-TT } & Height & 72 & 67 & 70 & 75.5 & 67 & \multirow{3}{*}{70.3} \\
\hline & Height - Mean & 1.7 & -3.3 & -0.3 & 5.2 & -3.3 & \\
\hline & Degree Diff. & 0.07796 & 0.15134 & 0.01376 & 0.23847 & 0.15134 & \\
\hline \multirow{3}{*}{ U-B5-TT } & Height & 52 & 61 & 44 & 53 & 32 & \multirow{3}{*}{48.4} \\
\hline & Height - Mean & 3.6 & 12.6 & -4.4 & 4.6 & -16.4 & \\
\hline & Degree Diff. & 0.16510 & 0.57781 & 0.20178 & 0.21095 & 0.75206 & \\
\hline \multirow{3}{*}{ U-B6-TT } & Height & 61.5 & 64 & 46 & 55 & 75 & \multirow{3}{*}{60.3} \\
\hline & Height - Mean & 1.2 & 3.7 & -14.3 & -5.3 & 14.7 & \\
\hline & Degree Diff. & 0.05503 & 0.16968 & 0.65577 & 0.24306 & 0.67411 & \\
\hline \multirow{3}{*}{ U-B7-TT } & Height & 65 & 57 & 48 & 70 & 73 & \multirow{3}{*}{62.6} \\
\hline & Height - Mean & 2.4 & -5.6 & -14.6 & 7.4 & 10.4 & \\
\hline & Degree Diff. & 0.11006 & 0.25681 & 0.66952 & 0.33936 & 0.47693 & \\
\hline
\end{tabular}

$1=1 / 1000$ inch 
Table A.9: Parallel measurements for 0.5:1 thermally treated UHPC samples

\begin{tabular}{|c|c|c|c|c|c|c|c|}
\hline \multirow{2}{*}{ Sample ID } & & \multicolumn{5}{|c|}{ Measurements } & \multirow{2}{*}{ Mean } \\
\hline & & 1 & 2 & 3 & 4 & 5 & \\
\hline \multirow{3}{*}{ U-A1-T'T } & Height & 94.5 & 108 & 102.5 & 82 & 91 & \multirow{3}{*}{95.6} \\
\hline & Height - Mean & -1.1 & 12.4 & 6.9 & -13.6 & -4.6 & \\
\hline & Degree Diff. & 0.05045 & 0.56864 & 0.31643 & 0.62367 & 0.21095 & \\
\hline \multirow{3}{*}{ U-A2-TT } & Height & 100 & 110 & 99 & 98 & 97 & \multirow{3}{*}{100.8} \\
\hline & Height - Mean & -0.8 & 9.2 & -1.8 & -2.8 & -3.8 & \\
\hline & \begin{tabular}{|l|} 
Degree Diff. \\
\end{tabular} & 0.03669 & 0.42190 & 0.08255 & 0.12841 & 0.17427 & \\
\hline \multirow{3}{*}{ U-A3-TT } & Height & 11.5 & 17 & 29 & 12 & -1 & \multirow{3}{*}{13.7} \\
\hline & Height - Mean & -2.2 & 3.3 & 15.3 & -1.7 & -14.7 & \\
\hline & Degree Diff. & 0.10089 & 0.15134 & 0.70162 & 0.07796 & 0.67411 & \\
\hline \multirow{3}{*}{ U-A4-TT } & Height & 92 & 79 & 108 & 95 & 75 & \multirow{3}{*}{89.8} \\
\hline & Height - Mean & 2.2 & -10.8 & 18.2 & 5.2 & -14.8 & \\
\hline & Degree Diff. & 0.10089 & 0.49527 & 0.83459 & 0.23847 & 0.67869 & \\
\hline \multirow{3}{*}{ U-A5-TT } & Height & 60 & 58 & 66 & 59 & 53 & \multirow{3}{*}{59.2} \\
\hline & Height - Mean & 0.8 & -1.2 & 6.8 & -0.2 & -6.2 & \\
\hline & Degree Diff. & 0.03669 & 0.05503 & 0.31184 & 0.00917 & 0.28433 & \\
\hline \multirow{3}{*}{ U-A6-TT } & Height & 93 & 90 & 103 & 98 & 89 & \multirow{3}{*}{94.6} \\
\hline & Height - Mean & -1.6 & -4.6 & 8.4 & 3.4 & -5.6 & \\
\hline & Degree Diff. & 0.07338 & 0.21095 & 0.38522 & 0.15592 & 0.25681 & \\
\hline \multirow{3}{*}{ U-A7-TT } & Height & 18 & 27 & 10.5 & 6 & 19.5 & \multirow{3}{*}{16.2} \\
\hline & Height - Mean & 1.8 & 10.8 & -5.7 & -10.2 & 3.3 & \\
\hline & Degree Diff. & 0.08255 & 0.00864 & 0.00456 & 0.00816 & 0.00264 & \\
\hline
\end{tabular}

$1=1 / 1000$ inch 


\section{Appendix B: Statistical Analysis - Box Plots}

The following box plots were developed using an ANOVA statistical analysis through MiniTab software, as outlined in Section 5.6.

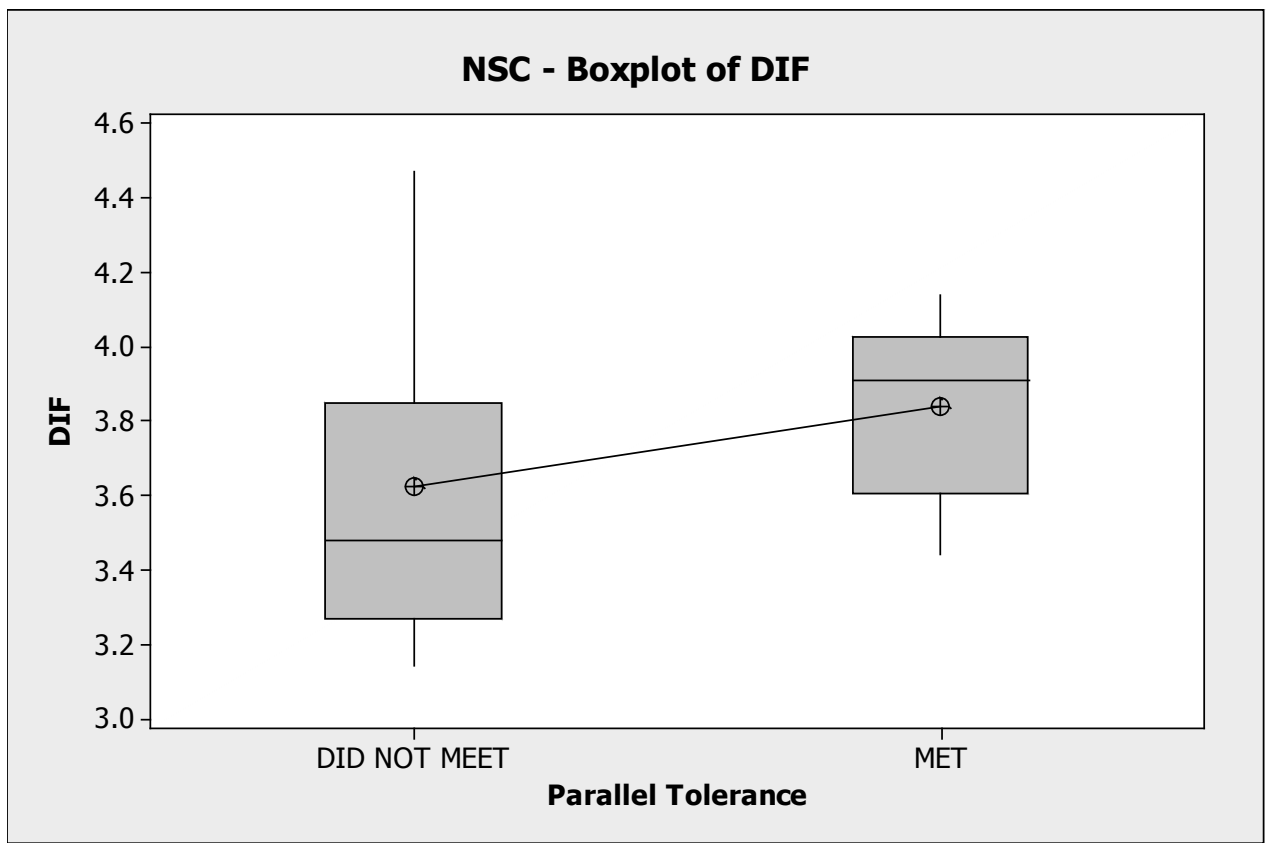

Figure B.1: Boxplot from ANOVA test for NSC specimens that either met or did not meet parallel tolerance 


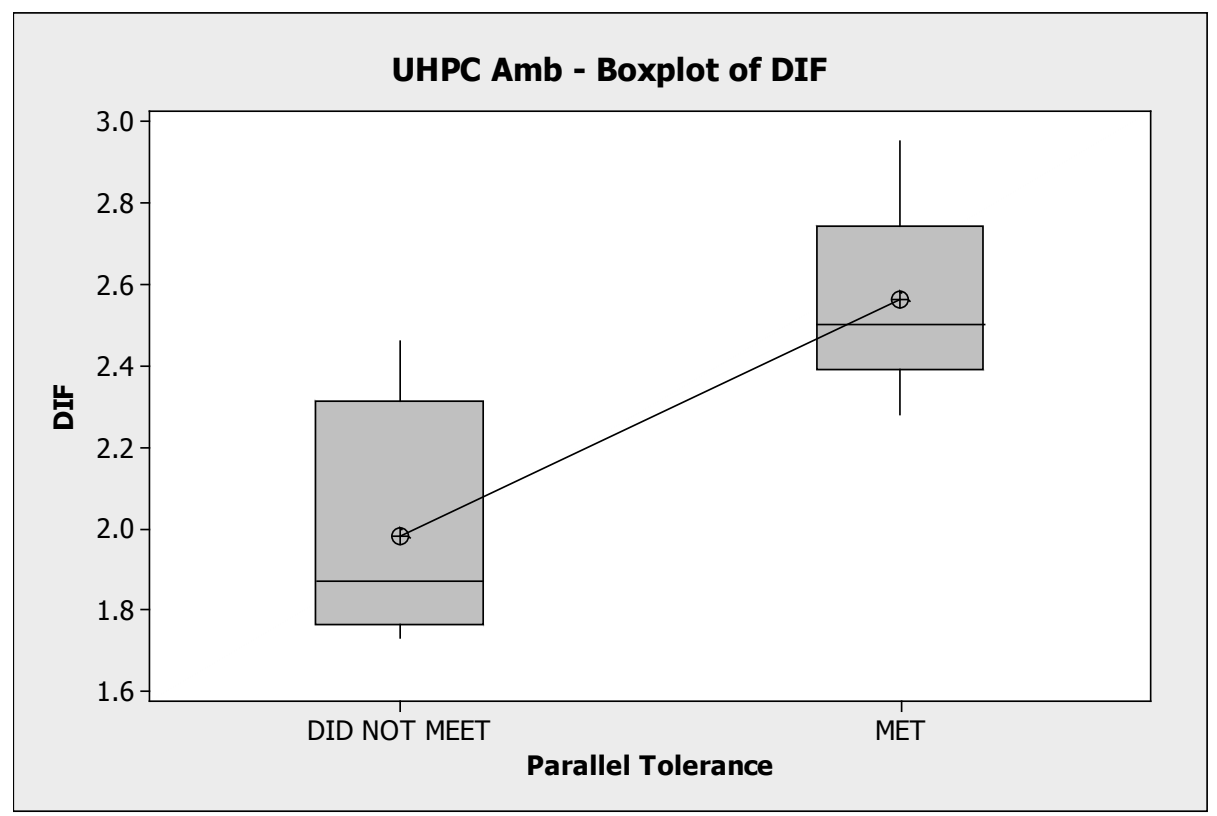

Figure B.2: Boxplot from ANOVA test for ambient cured UHPC specimens that either met or did not meet parallel tolerance

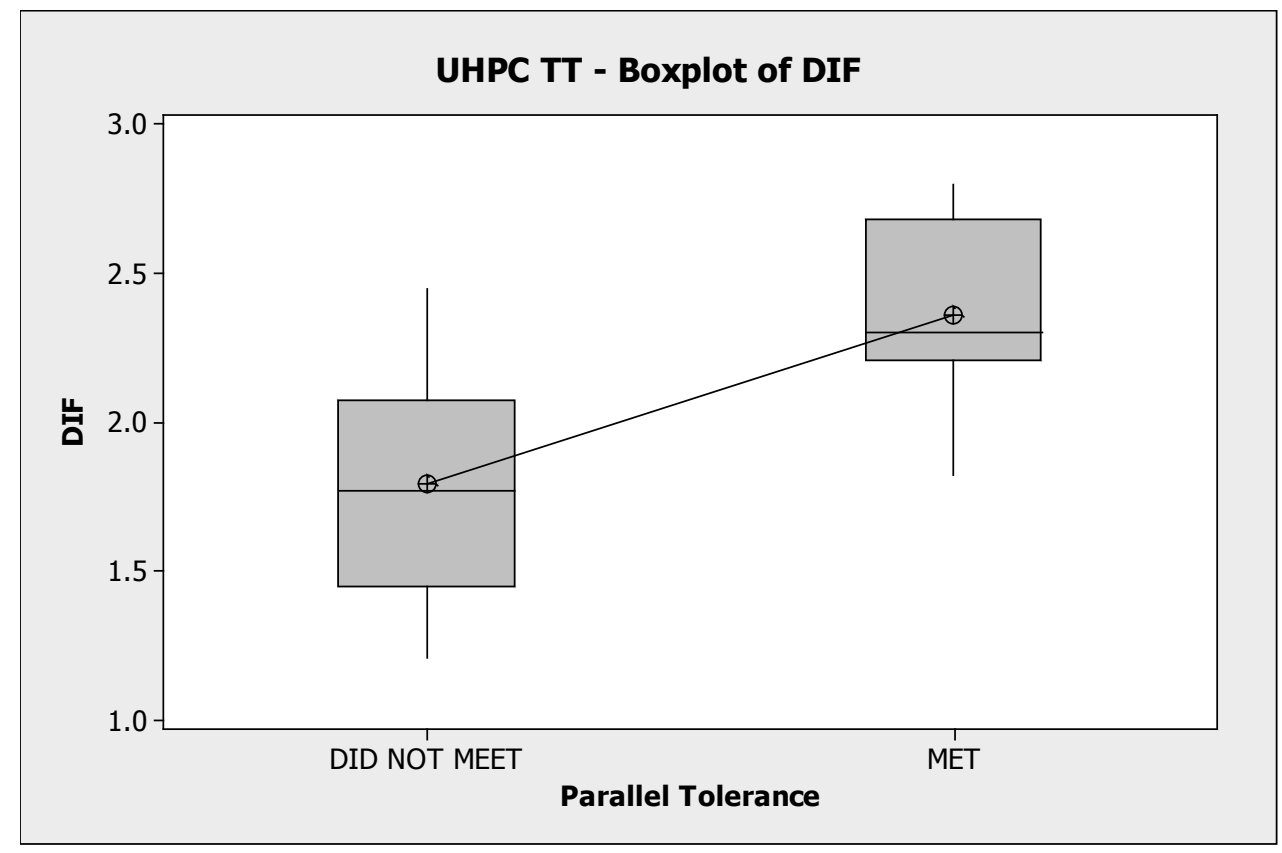

Figure B.3: Boxplot from ANOVA test for thermally treated UHPC specimens that either met or did not meet parallel tolerance 


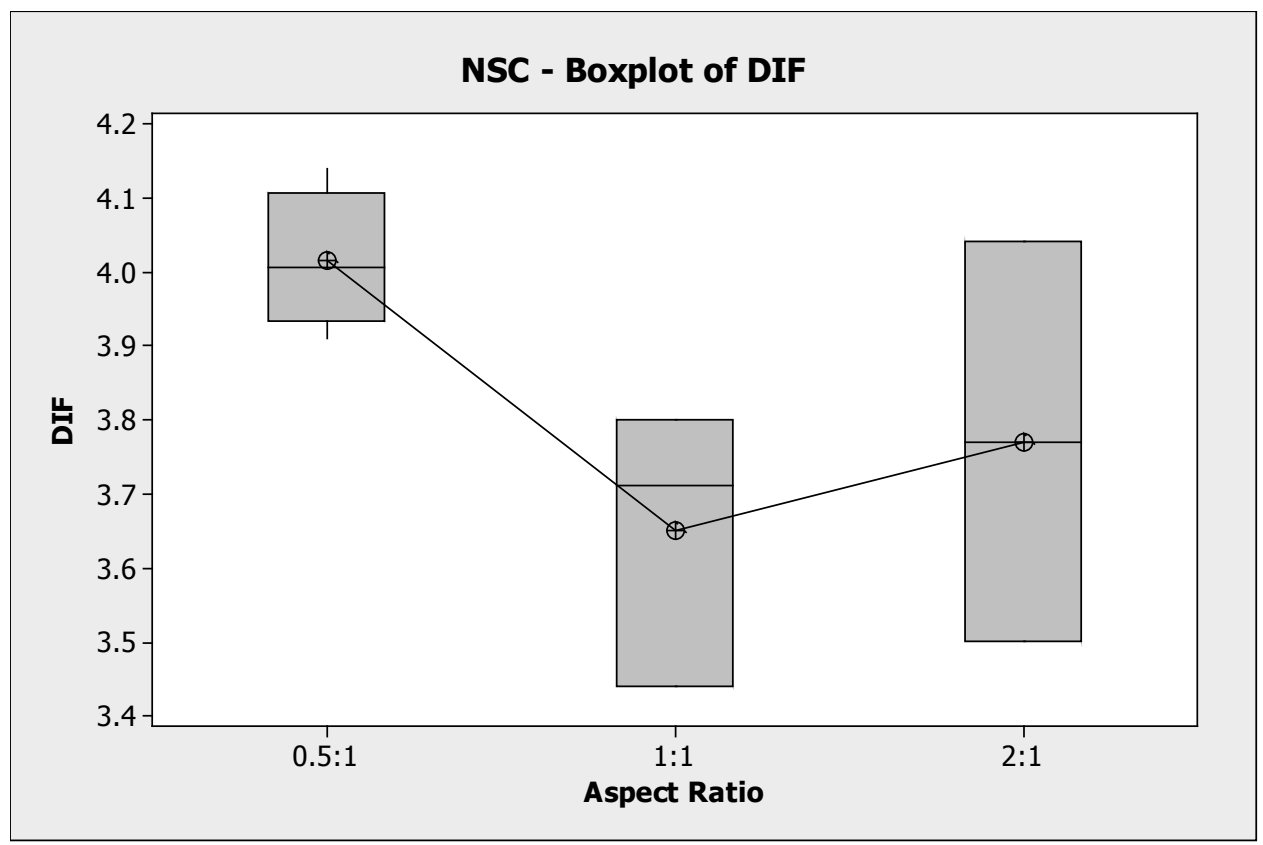

Figure B.4: Boxplot from ANOVA test for NSC comparing DIF for each aspect ratio

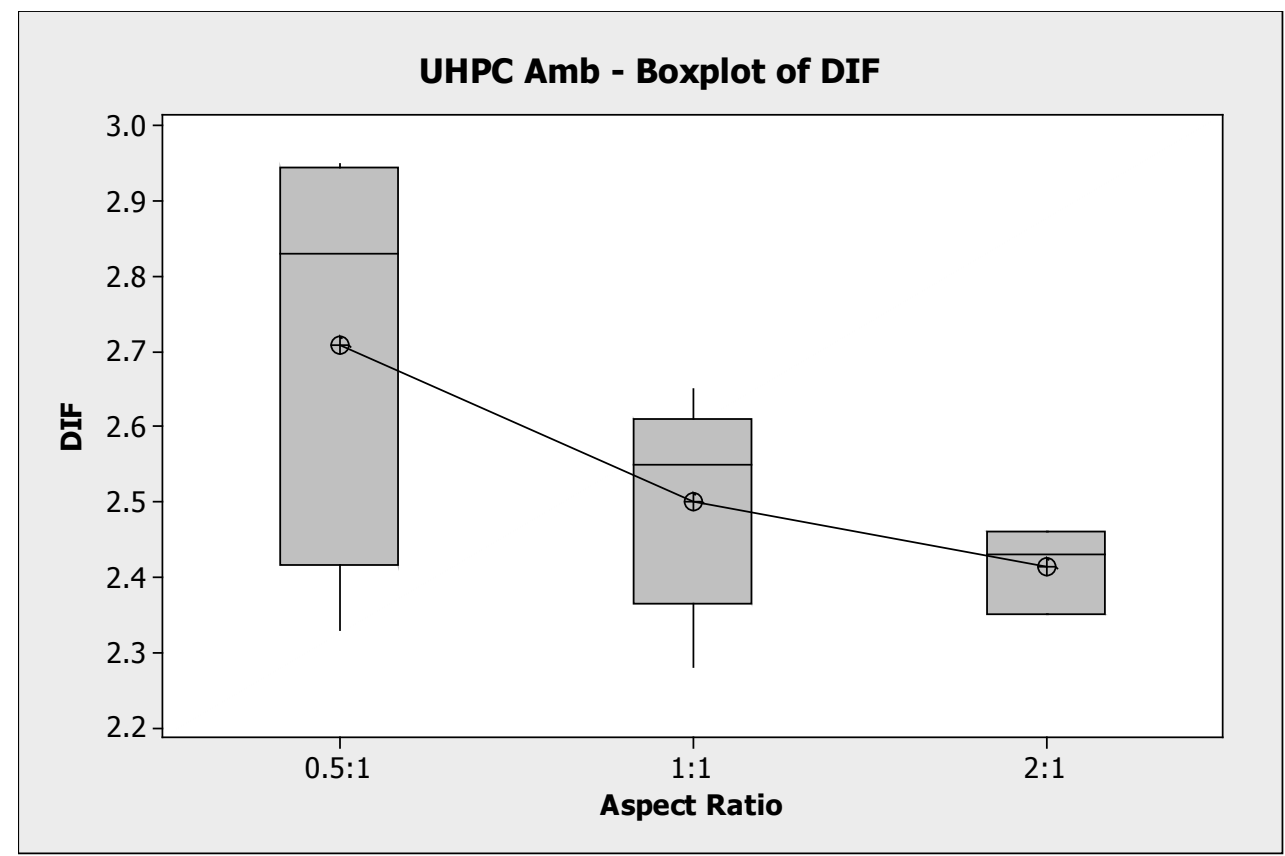

Figure B.5: Boxplot from ANOVA test for ambient cured UHPC comparing DIF for each aspect ratio 


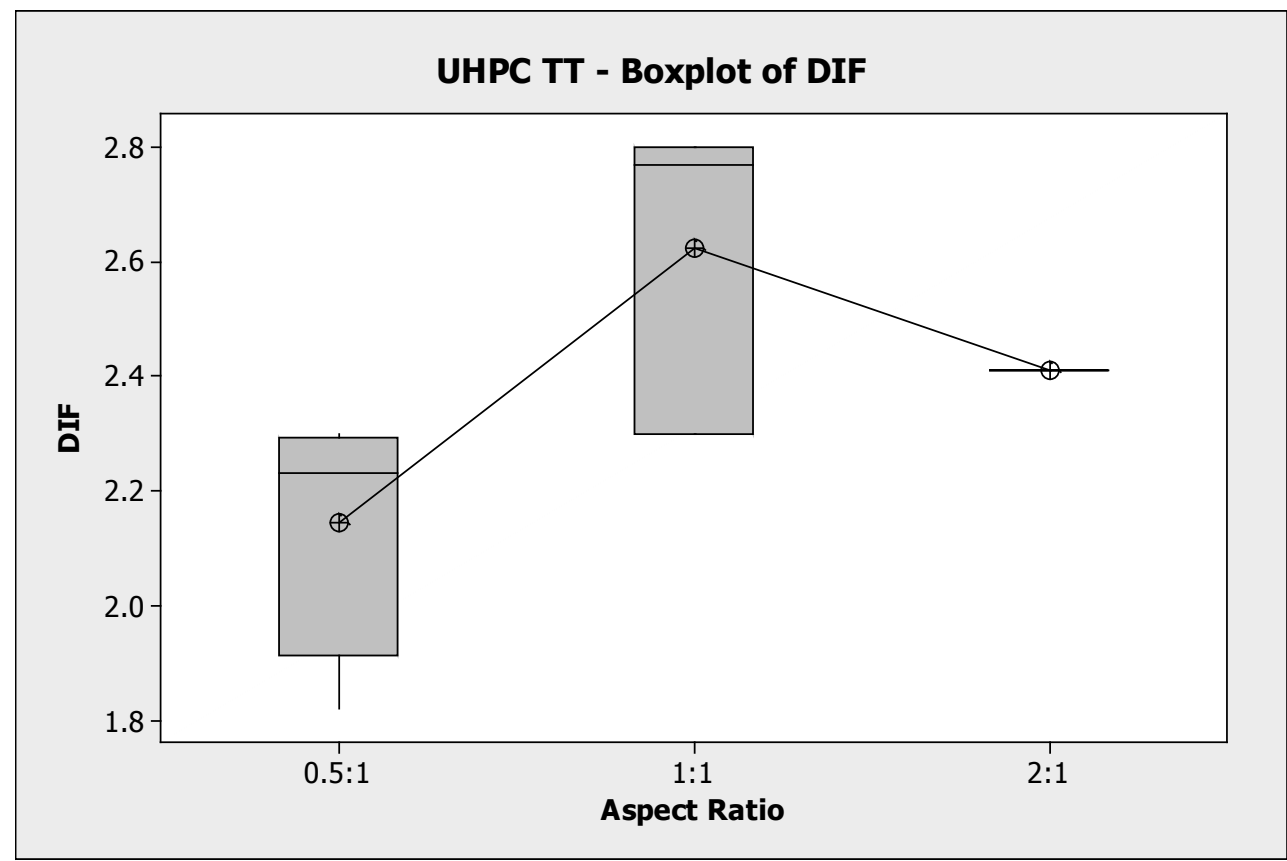

Figure B.6: Boxplot from ANOVA test for ambient cured UHPC comparing DIF for each aspect ratio

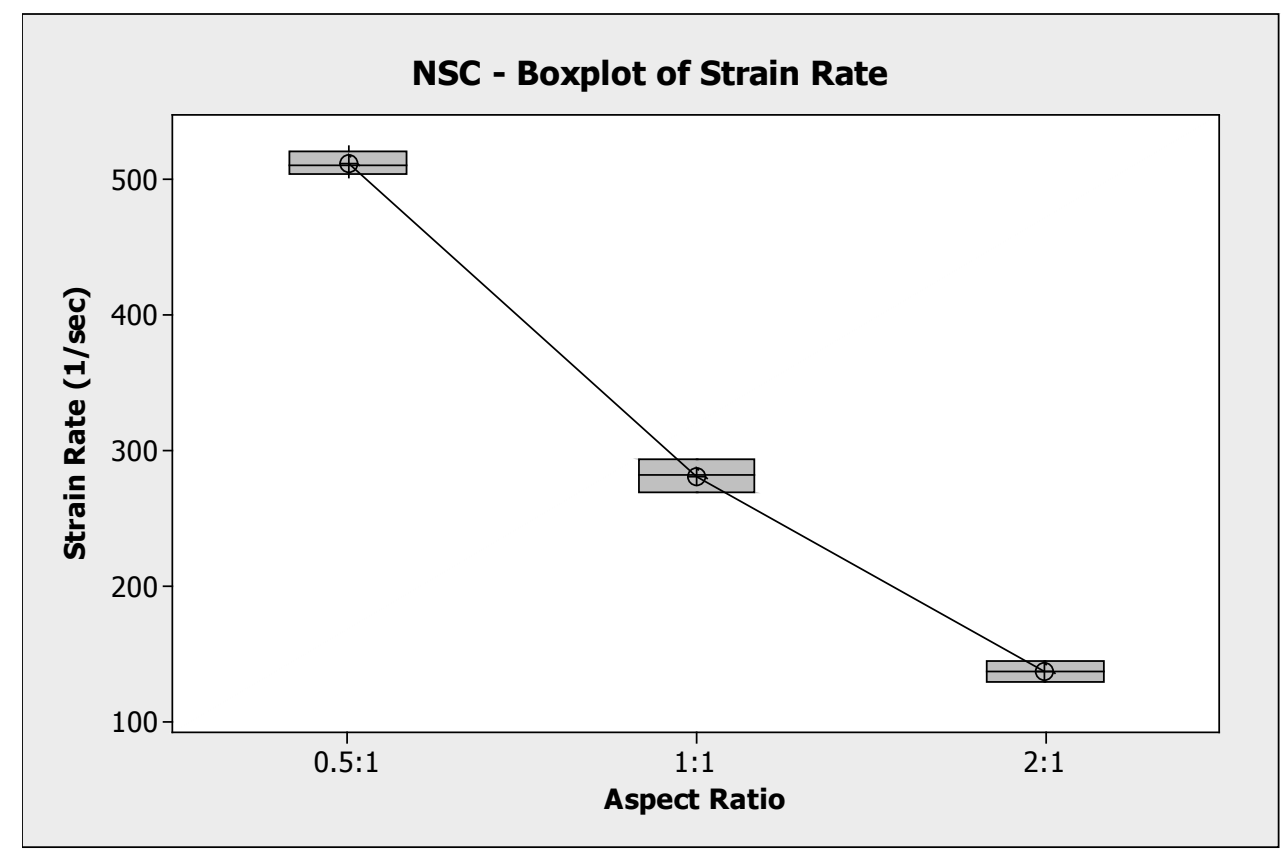

Figure B.7: Boxplot from ANOVA test for NSC comparing strain rate for each aspect ratio 


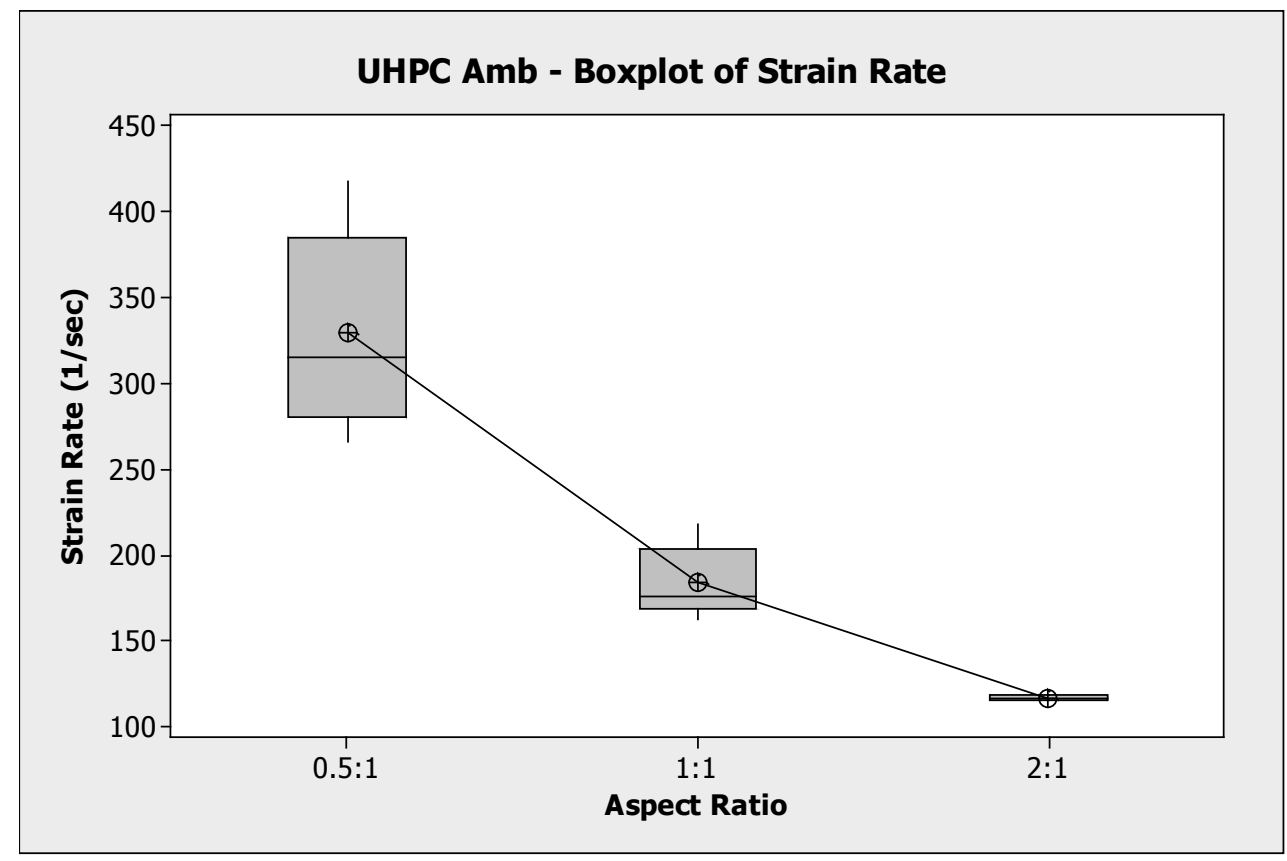

Figure B.8: Boxplot from ANOVA test for ambient cured UHPC comparing strain rate for each aspect ratio

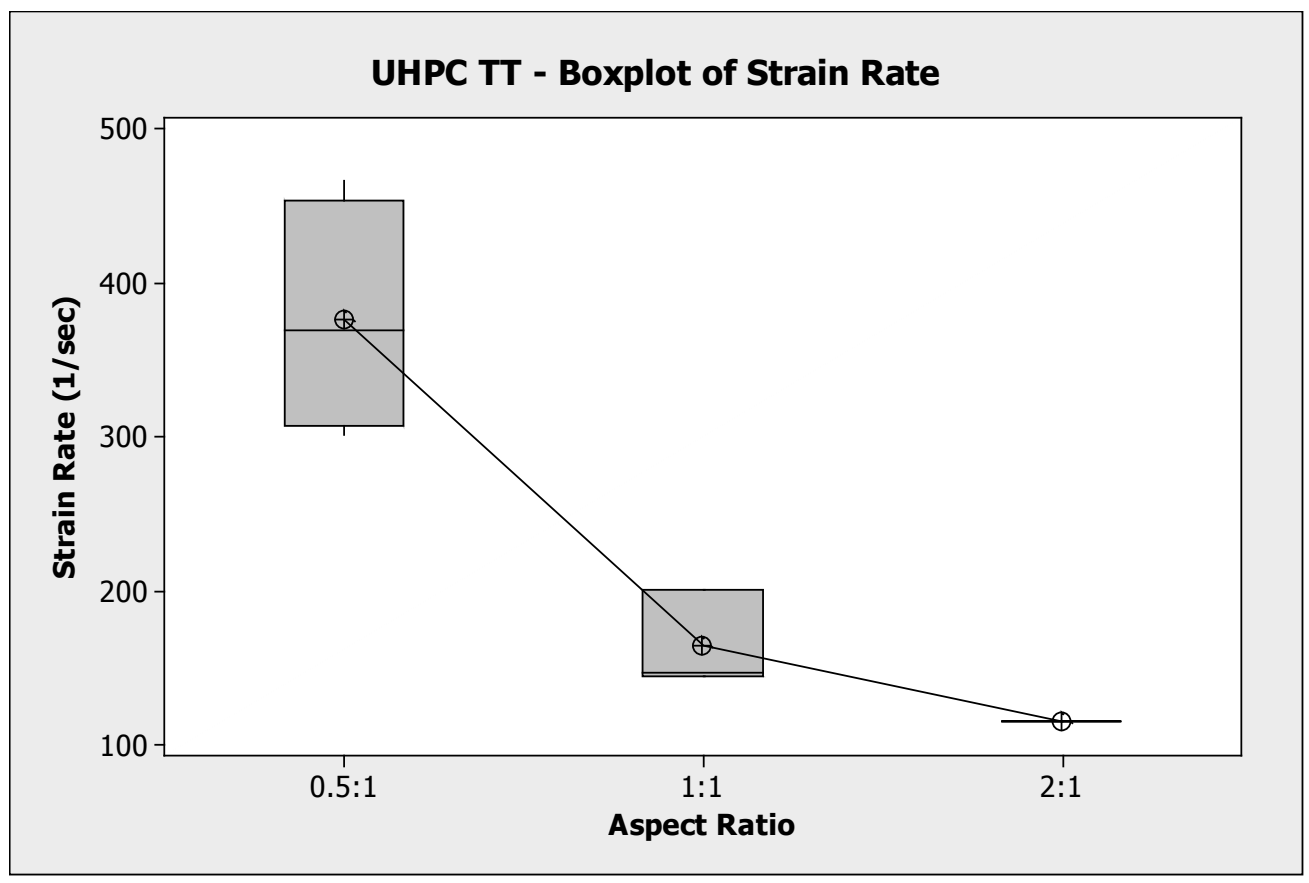

Figure B.9: Boxplot from ANOVA test for thermally treated UHPC comparing strain rate for each aspect ratio 


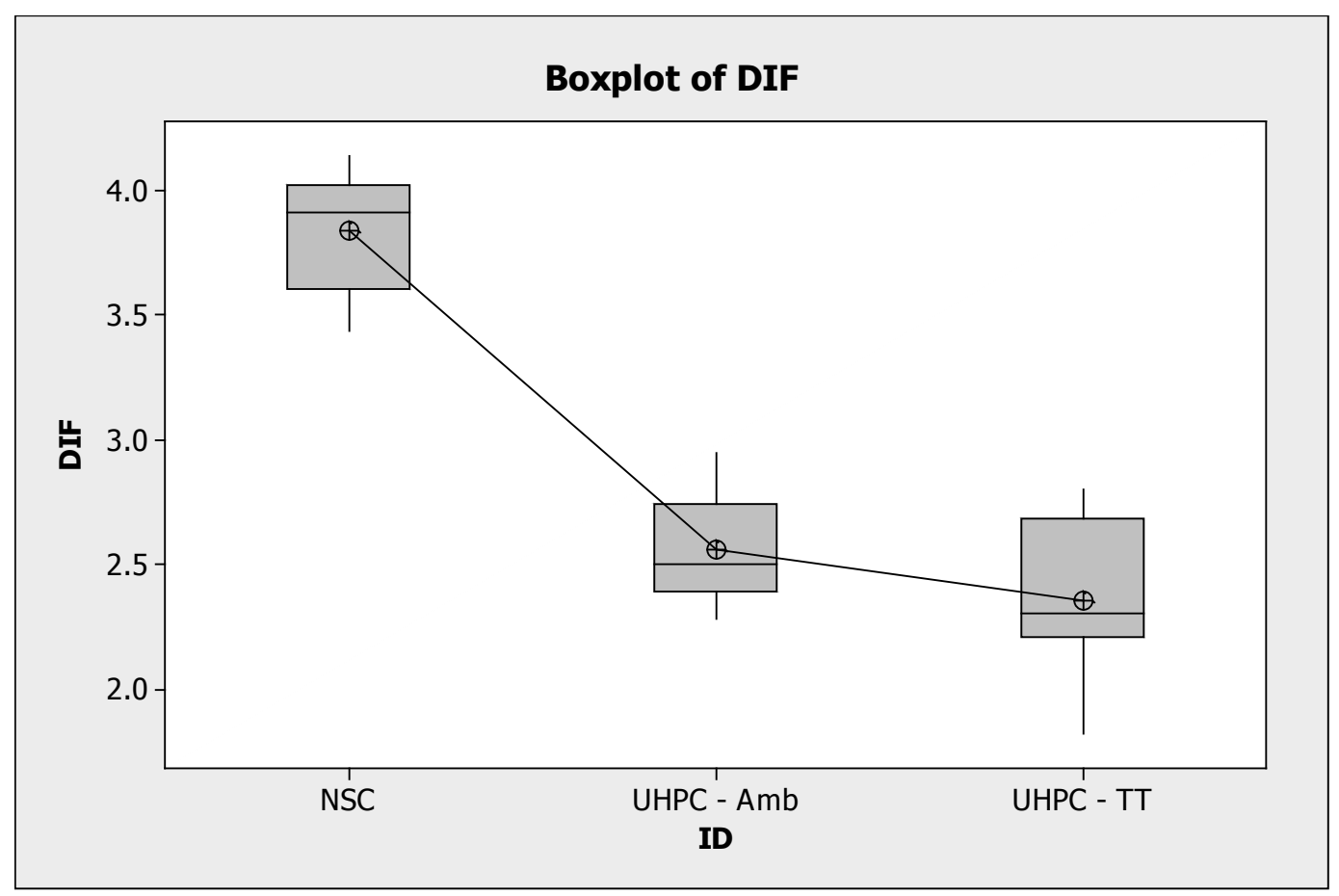

Figure B.10: Boxplot from ANOVA test for each concrete type, comparing DIF 


\title{
Appendix C: Permission for Use of Copyrighted Material
}

The email below corresponds to Figure 2.4.

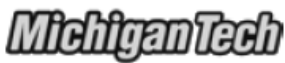

\section{Re: Copyright Permission - Rilem}

\author{
1 message
}

Julie Lozachmeur <j.lozachmeur@rilem.org>

Thu, Nov 14, 2013 at 7:38 AM

To: Jake Clark <jfclark@mtu.edu>

Dear Jacob

We give you the permission to use the Figure 5 (Strain-rate influence on compressive strength) from the 1991 P.H. Bischoff and S. H. Perry article titled "Compressive behaviour of concrete at high strain rates" from the Volume 24, issue 6, of the joumal Materials and Structures.

Our request is that the full acknowledgement will be given to the source

Best regards,

Julie Lozachmeur for the RILEM General Secretariat

A $17: 42$ 13/11/2013 +0100, vous avez écrit :

Hello,

I am inquiring about getting a permission to use copyrighted material from an article in your Materials and Structures joumal for my report as part of my requirements for a Master of Science in Civil Engineering degree at Michigan Technological University in Houghton, Michigan, USA.

The material I would like to use is Figure 5 (Strain-rate influence on compressive strength) from the 1991 P.H. Bischoff and S. H. Perry article titiled "Compressive behaviour of concrete at high strain rates". This article is found in the Materials and Structures Journal, Volume 24, Issue 6. The figure is on page 435 of the article

Thank you

Jacob

Jacob Clark

Michigan Technological University

Dept. of Civil and Environmental Engineering

jfclark@mtu.edu

(517) 242-6256 